University of South Florida

DIGITAL COMMONS

Digital Commons @ University of

@ UNIVERSITY OF SOUTH FLORIDA

South Florida

Integrative Biology Books

Integrative Biology

1909

\title{
Asteroids of the Deep-sea Collected by the Investigator in the \\ Indian Ocean: A Translation of Astéries Recueillies par \\ I'Investigator dans l'Océan Indien. I. Les Astéries de Mer Profonde
}

René Koehler

John M. Lawrence

University of South Florida, lawr@usf.edu

Follow this and additional works at: https://digitalcommons.usf.edu/bin_books

\section{Recommended Citation}

Koehler, R. (2020). Asteroids of the Deep-sea Collected by the Investigator in the Indian Ocean: A Translation of Astéries Recueillies par I'Investigator dans l'Océan Indien. I. Les Astéries de Mer Profonde (J. M. Lawrence, Trans.). Herizos Press, Tampa.

This Book is brought to you for free and open access by the Integrative Biology at Digital Commons @ University of South Florida. It has been accepted for inclusion in Integrative Biology Books by an authorized administrator of Digital Commons @ University of South Florida. For more information, please contact digitalcommons@usf.edu. 


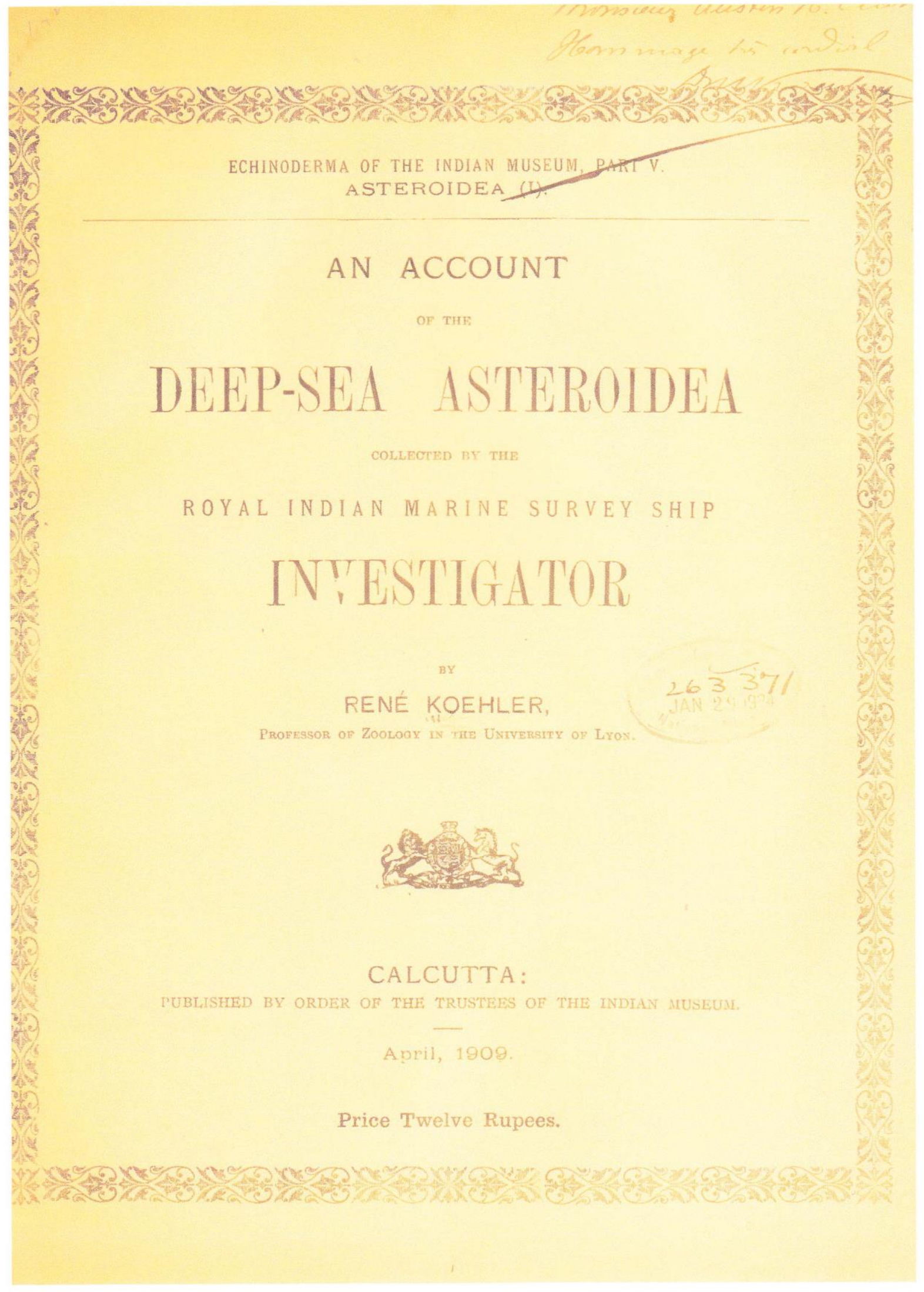


Kœhler, R. 1909. Asteroids of the deep-sea collected by the Investigator in the Indian Ocean. Translated by John M. Lawrence.

(C) Herizos Press, Tampa, Florida. 


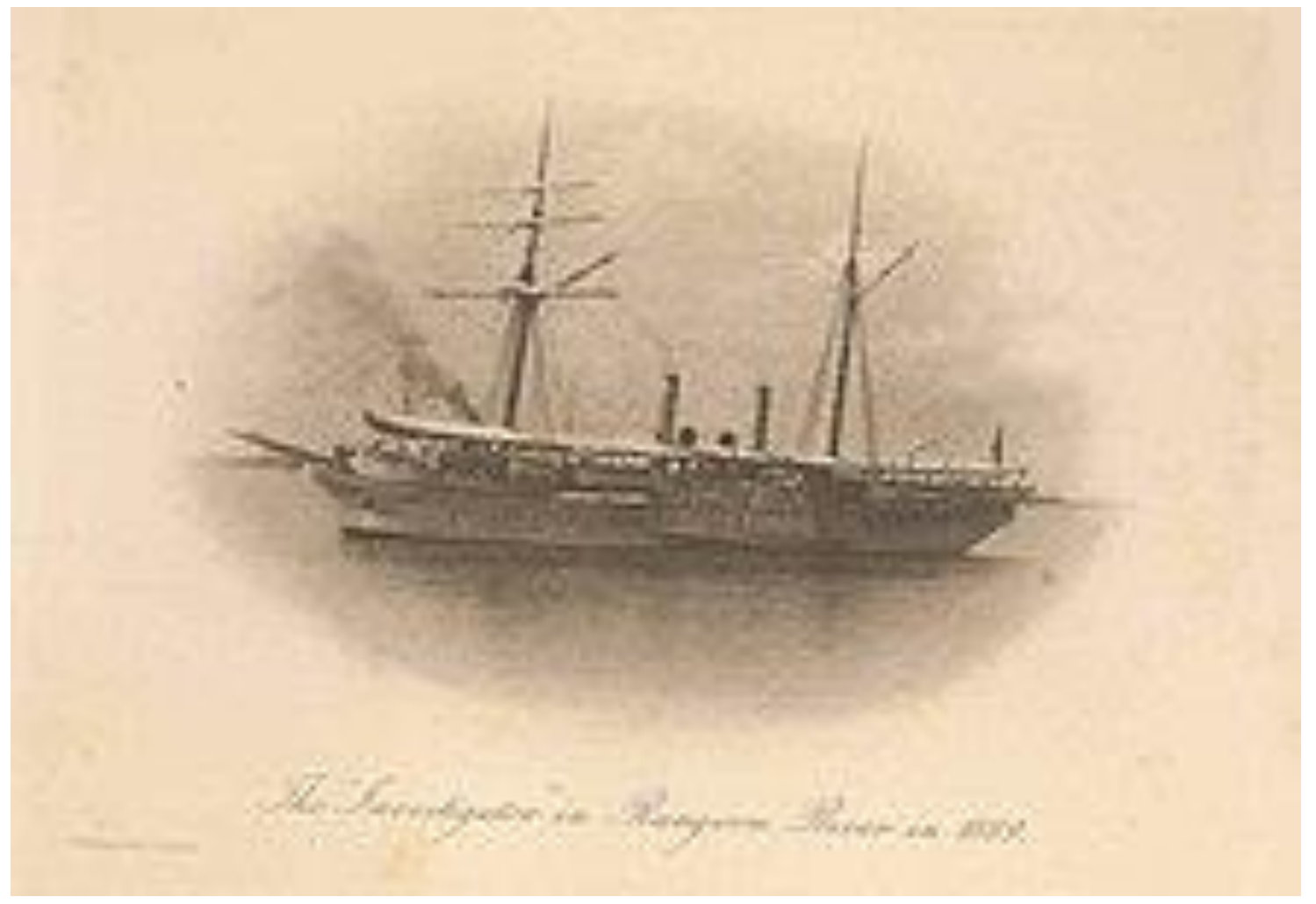

\section{Investigator in Burma}

The Royal Indian Marine Survey Ship Investigator made collections in the 1890's in an area of the Indian Ocean that had not been studied. An account of the voyages of the Investigator was published by Alred William Alcock in 1902: A Naturalist in Indian Seas, or, Four Years with the Royal Indian Marine Survey Ship Investigator.

The collections of the Investigator are in the Indian Museum in Kolkata, West Bengal, India. The Museum was founded by the Asiatic Society of Bengal in Kolkata (Calcutta), India, in 1814.

The Indian Museum originated from the Asiatic Society of Bengal. When the Indian Museum of Calcutta was established in 1814 , the Society handed over most of its valuable collections to it. 


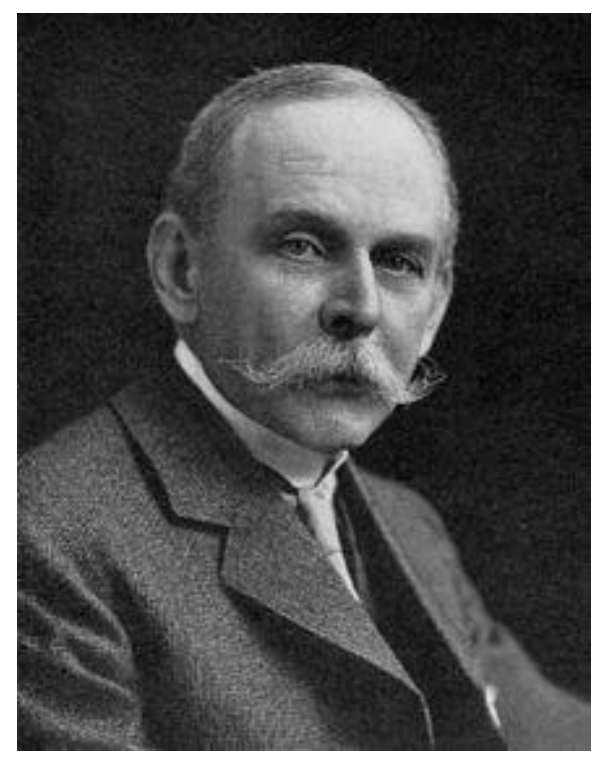

Alfred William Alcock (23 June 1859-4 March 1933) CIE, FRS was a British physician, naturalist, and carcinologist. In 1885 he graduated M.B., C.M., "with honourable distinction" from Aberdeen University and joined the Indian Medical Service. In 1888 he became SurgeonNaturalist to the Indian Marine Survey on the survey ship Investigator. Here he studied marine zoology and published many papers. Among these papers were accounts of many of the asteroids collected by the Investigator. Those not studied by Alcock were later sent to Koehler. Many of these asteroids studied by Koehler have Alcock as the author of the species.

I corrected a few obvious errors in Koehler's memoir:

Gulf of Mannar instead of Gulf of Manaar.

Station 126. $8^{\circ} 49^{\prime}$ Lat. N. $73^{\circ} 18^{\prime} 45^{\prime \prime}$ Long. E. Depth 1370 fathoms. One specimen.

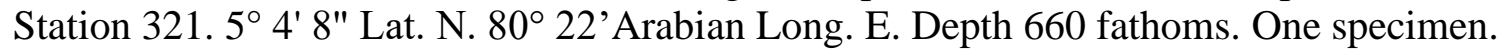
Station 330. 12॰49' 30" Lat. N. 96'24' 30”' Long. E.

instead of

Station 126. $8^{\circ} 49^{\prime}$ Lat. N. $73^{\circ} 18^{\prime} 45^{\prime \prime}$ Long. N. Depth 1370 fathoms. One specimen. Station $321.5^{\circ} 4^{\prime} 8^{\prime \prime}$ Lat. N. $80^{\circ} 22^{\prime}$ 'Long. N. Depth 660 fathoms. One specimen. Station 330. $12^{\circ} 49^{\prime} 30^{\prime}$ 'Lat. N. 96'24' 30” Long. N.

Freyella benthophila Sladen instead of Freyella bentophila Sladen.

In the depths reported for some stations, the greater depth is given first. E.g., "Depth 811-666 fathoms." I have not changed these.

I refer to the Bay of Bengal instead of Gulf of Bengal. I have retained Sea of Oman. 


\section{ASTEROIDS}

\section{OF THE DEEP-SEA}

COLLECTED BY

\section{THE INVESTIGATOR}

IN

THE INDIAN OCEAN

This work follows the memoires that have been published, first by J. Wood-Mason and A. Alcock in $1891(\mathbf{9 1})^{1}$, then by A. Alcock in 1893 (93 $a$ and $b$ ) on the asteroids of the deep-sea by the INVESTIGATOR in the Indian Ocean. These memoirs contained the description of some very interesting new species that for the most part were represented by Alcock either in 1893 (93a) or in 1894 (94) as well as in the Illustrations of the Zoology,,,, of the INVESTIGATOR (94-95)

Dr. N. Annandale, Superintendent of the Museum of Calcutta, has kindly asked me to determine the asteroids that had not been studied by Alcock and I thank him very much for the confidence he has shown.

The collection of the asteroids of the deep sea that he sent me in 1908 contains numerous new species. The total is not less than thirty, among which are five new genera. The forms already known are relatively not very numerous. I have recognized some species already described by Alcock and that come from the same places as those where this naturalist had reported them or nearby locations, but I have also found in the collection some species reported by W. K. Fisher at Hawaii and collected during the campaign of the ALBATROSS in 1902. I add that two of the new species that I recognize belong to new genera created by Fisher, the genera Astroceramus and Evoplosoma that are still each only represented by a single species. These facts are important to note from the zoogeographical point of view.

I shall return to this in a special chapter on a study of all the abyssal asteroids collected by the INVESTIGATOR, so that it can be studied following the investigations of Alcock and me. This new chapter if at the end of this work.

I shall especially study in the pages that follow the new species that are descried in detail. I also shall compare and with the greatest care, the types of Fisher, the species that the investigator has found and that have been discovered by the ALBATROSS at the Hawaiian Islands. As to the forms already studied by Alcock and that I have found in the collection that has been sent me, I have not returned and I shall mention only some species about which I have some remarks to make.

\footnotetext{
${ }^{1}$ The bold numbers in parenthesis refer to the Bibliographic Index at the end of this memoir.
} 



\title{
DESCRIPTIVE PART
}

\author{
JOHANNASTER, nov. gen. ${ }^{2}$
}

The disk is large and the arms, rather thin, are very elongated. The dorsal and ventral marginal plates are very numerous. The dorsal surface of the disk and arms is covered with small plates simply filled with fine granules that do not form paxillae. The plates are arranged without regular order. Between them are very numerous and very developed papulae. The dorsal and ventral marginal plates are only covered with granules and it hardly matters if the ventral marginal plates have, in the interradial arcs, some rudimentary spines on their external border. The ventral interradial areas are large and extend onto a large part of the length of the arm. The plates are arranged in rows going from the adambulacrals to the ventral marginals and subject to splitting. They are covered with granules and each usually has a very small spine. The teeth are little developed and do not project onto the ventral surface. The tube feet end in a disk whose diameter is less than that of the tube but that is however conspicuous. The anus is very small. The madreporite is very small with divergent furrows. There are small alveolar pedicellariae on the marginal and latero-ventral plates.

The genus Johannaster is attached by most of its characters to the plutonasterids. The specimens of very large size that I have studied have characteristics similar to those of Plutonaster subinermis, when seen by the dorsal surface, because the constitution of the ventral surface is very different. The characters of the dorsal plates covered with granules and irregularly arranged, the latero-ventral plates forming series that are often split like the Goniopecten and going from the adambulacrals to the marginals, the presence of an anus, etc., are very like the genus Johannaster of the putonasterids. On the other hand, the rudimentary state of the marginal spines, the little developed teeth, the tube feet with disks and the pedicellariae separate it from this group. Nevertheless, and with the benefit of the reservations I just made, I think that it is not a great inconvenience to relate this interesting genus to the Plutonasteridæ

Johannaster superbus, nov. sp.

(Pl. I, fig. 1 and 2; Pl. II, fig. 1)

${ }^{2}$ Dedicated to Jeanne Kœhler. 
Station $192.15^{\circ} 11^{\prime}$ Lat. N. $72^{\circ} 28^{\prime} 15^{\prime}$ ' Long. E. Depth 912-931 fathoms. Four specimens.

The specimens are all of large size. In the largest, that is shown in Pl. I, fig. $1, R=230 \mathrm{~mm}$ and $r=43 \mathrm{~mm}$. In another individual, $R=180 \mathrm{~mm}$ and $r=36 \mathrm{~mm}$.

The disk is large, flat, a little thin at the borders, with it dorsal and ventral surfaces nearly flat. It is continued insensibly with the arms that are wide at the base but narrow very rapidly. They become thus very narrow and their width decreases then very progressively to the end that is pointed. In the largest individual, I measure about $60 \mathrm{~mm}$ between the bases of the two consecutive interbrachial arcs. At the eighth dorsal marginal plate, the width of the arm is $32 \mathrm{~mm}$ and falls to 21.5 at the twentieth. At the fortieth plate, this width is no more than $13 \mathrm{~mm}$. The marginal plates form a moderately developed border. The ensemble is not very robust and the animal is far from being robust. The very supple arms are coiled and twisted in various ways and we can easily deform them.

The dorsal surface of the disk and arms is covered with very small plates, irregularly polygonal or rounded, whose diameter is scarcely $2 \mathrm{~mm}$ in the largest, those in the central region of the disk. Their size decreases rapidly toward the dorsal marginal plates. At the same time, the plates have a tendency to be arranged in oblique rows. But on most of the disk, they are irregularly arranged. On the medial line of the disk, we see the plates are a little larger than the adjacent ones. They continue the larger plates of the central region of the disk. They usually form three rows a little larger transversally. The median one is the most important. The other plates are smaller and they are arranged in indistinct transverse rows, extending to the dorsal margins. At the eighth dorsal marginal, I count about twenty plates on the width of the arm.

All these plates on both the disc and the arms, are covered with fine granules, dense, rounded and inconspicuous, close to each other and dispersed irregularly without showing a difference between the marginal granules and the others on the surface of the plate (Pl. I, fig. 2). Between the plates are extremely abundant papulae, wide and elongated. Each plate can be surrounded by four, five and even six papulae. These are soft and they can be 2 or $3 \mathrm{~mm}$ in length. They continue the entire length of the arm, but they do not occur in the five interradial areas of the disk. They have the form of triangles whose bases correspond to the five or six dorsal marginal plates on each side and that are covered with smaller plates. Thanks to the number the development of these papulae, the plates of the dorsal surface are more or less hidden and this surface thus takes a peculiar aspect.

The anus is central, very small, very straight slit.

The madreporite is located a little than a third of the distance that separates the center of the disk and the dorsal marginal plates. It is round, bare and rather small. Its diameter is only $4 \mathrm{~mm}$. It is more or less hidden under adjacent papulae. It has fine, divergent furrows.

The dorsal marginal plates are very numerous. There are seventy in the specimen I show. The first four or five of each series measure $5 \mathrm{~mm}$ in width and $2.5 \mathrm{~mm}$ in length. They are rectangular, two times wider than long, a little narrower outside than inside. In the following plates, the width decreases slowly as the length increases a little. They then become nearly square and measure on average $3.5 \times 3.5 \mathrm{~mm}$. They do not decrease much in size along most of the arm and they become really small only a fairly short distance from the end. At the end of the interradial area, they are a little more elevated than the dorsal plates of the disk. Their upper surface is slightly oblique so that the borders of the body are a little thinner. All the surface of the dorsal marginal plates is uniformly covered with very fine granules, dense, having the same dimensions as those of the adjacent dorsal plates. These granules are arranged irregularly except along the border adjacent to the plates where they form a regular row. The lines separating the plates are very thin. 
There is not the least trace of spines on the surface of the dorsal marginal plate, but we generally find on each of them a very small alveolar pedicellariae, formed by two slightly elongated granules, one against the other the other. These pedicellariae detach easily and it is rare to find them. But we can clearly recognize their scars that form small elongated pits. It is rare to find two on the same plate. The location of these pedicellariae is not regular, but usually they are found towards the middle of the plate.

The apical plate is very small, the arms being very small at the end. It is a little longer than wide, lozenge shaped, with a round distal corner. I see no indication of spines on the free border.

The ventral surface of the disk is slightly convex, a little thicker at the teeth than toward the borders that are thin. The ventral triangular areas are filled with plates whose lines of separation are very fine. They are arranged in transverse rows, going from the adambulcrals to the ventral marginals. Immediately outside the adambulacrals, we see a regular row of rectangular plates. The first correspond very exactly to the adambulcrals. But they then become narrower and it is not rare to find two plates opposite only one adambulcral. These plates extend to the twentieth marginal. After this first row follows another row, usually quite distinct, and shorter than the previous, because it stops around the fourteenth or fifteenth marginal. These plates correspond, except for some irregularities, to the plates of the first row. The other plates no longer form longitudinal rows but are arranged in oblique lines that start from the previous plates and reach the ventral marginals. These plates are narrow, irregularly polygonal. Their dimensions decease rapidly. Sometimes these lines contain only one series of plates, sometimes they are split into two series having reached the marginals. All are covered with very fine granules, rounded and very dense, often forming small radiating rows, especially at the level of the lines of longitudinal separation of the plates. Moreover, each plate usually has a small conical spine, erect, with a round end. The plates that border the adambulacrals sometimes have two of these spines, but in contrast they become much rarer on the small peripheral plates. Finally, the plates of the first row parallel to the adambulacrals, and often those of the second row, usually have a small pedicellaria, less developed than those of the dorsal marginals. These pedicellariae are formed of two elongated granules or of two very short spines. They detach very easily, but we can recognize their scars very clearly.

The ventral marginal spines are arranged like the dorsal marginals, but the border they form is a little narrower than the latter. They do not always correspond to the dorsal plates and, at some places, they can even alternate with them. These alternating plates are more frequent in some individuals than in others. The first ventral marginals are a little wider than long. They then become nearly square. Some of them, especially the first eight or ten, can have, near their external border, a small conical spine analogous to those of the latero-ventral plates, but are usually shorter. These spines appear to detach easily. Moreover, they are very inconstant. It is in the individual that I have shown in Pl. II, fig. 2 that they are more numerous. There are no more than five to ten in each interradial area. In the three other specimens, they are still rarer. The ventral marginal plates are covered with granules identical to those of the dorsal marginals. They have also some pedicellariae that are even more abundant than in the latter. It is not rare to find two or three on each plate.

The ambulacral grooves are usually very narrow, but they can open fairly widely, as can be seen in the individual represented in Pl. II, fig. 1, showing a double row of fairly large tube feet that end in a very clear disk although its diameter is less than that of the tube. These disks do not contain any trace of calcareous deposits.

The adambulacral plates are not very developed. They are as long as wide, or a little longer than wide. They have on their internal border a comb of seven to eight small spines, elongated, thin, flat and with the end rounded. These spines are unequal. The two end ones are a little smaller. 
Their length equals nearly the width of the plate. On the ventral surface of the plate, and toward the oral border, one usually finds a developed pedicellaria, formed of two or three upright and back to back spines. But the location of the pedicellaria is not very constant and it can be found in the middle of the plate. Moreover, it is not rare to find, especially in the proximal plates, two pedicellariae of which one can be bivalve and the other trivalve. Independent of this pedicellaria, one can see, at the same place, a spine similar to those of the adjacent ventral plates. This spine and the pedicellariae that accompany it occupies the internal half of the ventral surface of the plate. The rest of this half is bare. In the external half, the plate is covered with more or less numerous granules, not contiguous and identical to those of the latero-ventral plates.

The teeth, rather small, two and half times longer than wide, are flat. They do not project onto the ventral surface of the body. They have on their free border, a row of short and very thick spines that continue the spines of the ambulacral furrows. They develop more strongly at the proximal end of the tooth. The ventral surface has some conical granules, some of which form a more or less regular row along the sutural border. The other are disposed without apparent order.

In specimens in alcohol, the dorsal surface of the disk and arms has a brownish color on which the whitish papulae stand out. The ventral surface of the body is yellowish.

\section{Pectinaster hispidus (Alcock and Wood-Mason).}

Pontaster hispidus, Alcock and Wood-Mason (91), p. 428.

Station $108.7^{\circ} 04^{\prime \prime L a t . ~ N . ~ 70 ~ 34 ' 15 " L o n g . ~ E . ~ D e p t h ~ 1,043 ~ f a t h o m s . ~ A ~ v e r y ~ s m a l l ~ s p e c i m e n . ~}$ Station 249. $7^{\circ} 0^{\prime} 0^{\prime \prime L a t . ~ N . ~} 76^{\circ} 36^{\prime} 15^{\prime \prime}$ Long. E. Depth 1,022 fathoms. A large specimen.

Station 250. $6^{\circ} 54^{\prime} 30^{\prime \prime}$ Lat. N. 79 $34^{\prime} 30^{\prime \prime}$ Long. E. Depth 480 fathoms. A very small specimen.

Station 264. $10^{\circ} 50^{\prime} 30^{\prime}$ 'Lat. N. 80 41' 30"Long. E. Depth 981-900 fathoms. A large and a small specimen.

Station 300. $24^{\circ} 16^{\prime}$ Lat N. $60^{\circ} 26^{\prime}$ Long. E. Depth 1,375-1,165 fathoms. A very small specimen.

Station $317.7^{\circ} 04^{\prime}$ Lat. N. $79^{\circ} 32^{\prime \prime}$ Long. E. Depth 590 fathoms. A large specimen.

Station $320.7^{\circ} 23^{\prime}$ Lat. N. $75^{\circ} 44^{\prime}$ Long. E. Depth 1,053 fathoms. Two very small specimens.

The large specimens alone are well characterized. The young have not yet acquired all their characters.

Alcock and Wood-Mason classified this asteroid in the genus Pontaster, to which they gave its greatest extension. They brought together the genera Pectinaster and Cheiraster. I prefer to leave to these three the value assigned to them by Perrier. Because the Pontaster hispidus of Alcock and Wood-Mason have fasciculate pedicellaria, it finds its place in the genus Pectinaster. Alcock and Wood-Mason noted that $P$. hispidus was close to $P$. mimicus Sladen, and especially the variety echinata of $P$. forcipatus Sladen. I admit I was very uncomforable to apply a specific name to the specimens of the INVESTIGATOR: I have kept the name hispidus because they match exactly the description of Alcock and Wood-Mason, but I believe P. forcipatus, mimicus and hispidus instead belong to a single polymorphic species.

Sladen distinguished $P$. forcipatus from $P$. mimicus because the first has no secondary spines on the ventral marginal plates and it has pedicellariae on the dorsal side, as well as on the ventral side the along the ventral marginal plates. The latter have more spines than in P. mimicus, where the pedicellariae are few and are found only in the ventral interradial areas. The ventral marginal plates are almost bare and have a secondary spine. As for the variety echinata of $P$. forcipatus, it has stronger marginal spines than the type. The ventral marginal plates often, but not always, have 
a secondary spine. The pedicellariae are few on the dorsal side and they are rare or absent on the ventral side. Finally, the dorsal paxilles have a very developed central spine.

$P$. hispidus always has (at least in adults) a double spine on the ventral marginal plates and pedicellariae in the interbrachial angles between the dorsal and ventral marginal plates. The latter are partly naked and have pedicellariae in the first half of the arms at least. Pedicellariae are rare on the dorsal surface of the disc and arms.

It seems to me thus that there are transitions between these different forms and that their distinction is very subtle. However, as I could not examine the types of $P$. mimicus and forcipatus and the specimens I have in front of me conform well to the description of Alcock and WoodMason, I have kept the name given by these authors, pending a revision which will establish the value of the present species.

\section{Pontaster pilosus, Alcock.}

Pontaster pilosus, Alcock (93a), p. 79.

Station $150.7^{\circ} 05^{\prime} 45$ "Lat. N. $75^{\circ} 04^{\prime}$ Long. E. Depth 710 fathoms. A small specimen. Station $317.7^{\circ} 04^{\prime}$ Lat. N. $79^{\circ} 32^{\prime}$ Long. E. Depth 590 fathoms. One specimen.

In the specimen from Station $150, R=34 \mathrm{~mm}$. In the other, it ia $37 \mathrm{~mm}, r=6 \mathrm{~mm}$ in both individuals. In the type of Alcock, that I examined, it is $70 \mathrm{~mm}$.

This species belongs to the genus Pontaster and not to the genus Pectinaster. The dorsal marginal plates encroach onto the dorsal side, and, as Alcock indicated, the spines are on the outer and lower part of these plates. P. pilosus is therefore very different from Pectiinaster minicus, to which Alcock refers it. It is especially with the Pontasler venustus that it shows great affinities. It is certain that $P$. pilosus represents, in the Indian Ocean, $P$. venustus from the Atlantic. Perhaps it is only a variety of the latter species.

I recently had the opportunity to study a very beautiful series of $P$. venustus from the campaigns of the PRINCESSE-ALICE and I was able to compare the P. pilosus from the INVESTIGATOR. The latter species is more robust, and, for a corresponding size, the arms are longer. Also, the number of dorsal marginal plates is greater. Alcock has indicated from thirty to thirty five for his type individual. In this individual $R=70 \mathrm{~mm}$ while in P.venusus it does not exceed $50 \mathrm{~mm}$. In addition, the adambulacral spines are stronger and the marginal spines are also more developed. The dorsal and ventral marginal plates have more numerous and slightly longer small spines in $P$. pilosus. Finally, the paxillae are stronger, the peripheral spines are more elongated, but especially the central spine is notably longer and stronger in the Pontaster from the Indian Ocean than in $P$. venustus.

These differences, as we can see, are not very great and the two species are extremely similar. Sladen described a variety of $P$. venustus, collected by the CHALLENGER in the Cape Verde Islands $(89$, p. 55$)$, and which, in addition to some other secondary characters, is made notable for the width of the dorsal marginal plates and their encroachment on the paxillary area. In this variety, $R$ $=50 \mathrm{~mm}$. The largest specimens of the PRINCESSE-ALICE that I had in hand, did not exceed these dimensions. As I had the opportunity to say, they did not have the characters of var. robusta (09, p. 15). Perrier (94, p. 287) also described P. venustus from dredging of the Talisman. It differed from the type by the presence of three secondary spines instead of only one on the ventral marginal plates. 
$P$. venustus can thus have variations in the different stations from the Atlantic Ocean where it was collected. There would thus be nothing surprising in its penetrating into the Indian Ocean. It is a distinct variety there. In any case, whatever the value attributed to $P$. pilosus, it is important to note its very close affinities with $P$. venustus.

\section{Cheiraster Snyderi, Fisher.}

Cheiraster Snyderi, W. K. Fisher (06), p. 1040.

Station 255. 9²6' 30" Lat. N. 91 $51^{\circ} 56^{\prime} 30^{\prime \prime}$ Long. E. Depth 860-913 fathoms. One specimen.

$R=57 \mathrm{~mm} ; r=9 \mathrm{~mm}$. The specimen is near in size to the type of Fisher, in which $R$ measured $51 \mathrm{~mm}$. There can be no doubt about the identification. All the characters are correct. There are usually four pectinate pedicellariae in the ventral interradial area. There are six in one of these areas.

The species type was dredged by the ALBATROSS in the Hawaiian Islands at depths varying between 223 and 676 fathoms.

\section{Cheiraster inops, Fisher.}

Cheiraster inops, W. K. Fisher (06), p. 1043.

Station 333. $6^{\circ} 31^{\prime \prime}$ Lat. N. $79^{\circ} 38^{3 / 4}$ ' Long. E. Depth 401 fathoms. Four specimens.

Only one specimen is in very good condition. It is large: $R=130 \mathrm{~mm} ; r=19 \mathrm{~mm}$. The others are more or less badly preserved. Respective values of $R$ are 75, 65 and $37 \mathrm{~mm}$. The largest individual is therefore larger than the Fisher type, in which $R$ was only $50 \mathrm{~mm}$. It conforms well to the description of this author and it looks exactly like the enlarged photograph in his memoir (PI. XVII, fig. 2), taking into account, of course, the differences that result from the difference in size.

In my large specimen, there are fifty-five marginal plates. The papular areas are elongated and the two median series each contain about fifteen pores. The large ventral spine of the adambulacral plates is very developed. Sometimes I can see, next to it, a second, at the base of the arms.

The type of Ch. inops was collected by the ALBATROSS in the Hawaiian Islands, at depths varying from 250 to 684 fathoms.

W. K. Fisher gives the genus Ch. inops a broader meaning than Perrier and he considers it synonymous with the genus Pontaster s. lat. Although Ch. inops does not have pectinate pedicellariae, it can nevertheless remain in the genus Cheiraster s. strict., because its papularium, which is identical to that of Ch. Snyderi, has the structure attributed by Perrier to the genus Cheiraster.

Pararchaster indicus, nov. sp. 
Station $267.7^{\circ} 06^{\prime} 30^{\prime}$ La t. N. $79^{\circ} 36^{\prime}$ Long. E. Depth 457-589 fathoms. One specimen.

The single specimen collected is abnormal because it has only four arms. But this anomaly has a special quality and I shall study it after having described the specimen. It is moreover in very bad condition of preservation. No arm is entire and many of the spines are gone or broken.

Judging from the fragments that are preserved, the length of $R$ should be about $120 \mathrm{~mm}, r 13$ $\mathrm{mm}$. The disk is rather small. The arms are wide at the base and they decrease in width gradually. They are thick and strong. The entire animal appears very robust.

The dorsal surface of the disk is covered with small plates, round and close together. Some have an elongated, thin spine, although fairly broad at the base. It is up to $4 \mathrm{~mm}$ in length. This single spine is not surrounded by spinules. The other plates have six to ten extremely short erect spinules. They are rather rare in the middle of the disc. We encounter them only in interradial areas. There are two kinds of plates on the arms. Plates armed only with spinules are found on the sides while the median part of the arm has plates with large spines and some spinules. They become more numerous as the central spine becomes smaller toward the end of the arm. The armature of the plate prevents recognition of their regular arrangement. But on the denuded parts, we can state that they form very regular longitudinal and transverse rows.

Papulae are found in the middle of the plates of the disk and the arms, except in the immediate area of the center, in a circle whose radius is $5 \mathrm{~mm}$ at most. On the arms, these papulae extend the entire width of the paxillar area up to the area of the dorsal marginal plates, over a length of about $3 \mathrm{~cm}$, that is to say, up to the twelfth marginal plate. These papulae are numerous and close together. In this region, the skeleton forms rather a kind of network whose thick, round and protruding nodes represent the plates. When the papulae no longer exist, the plates are simply round and juxtaposed.

Some pectinate pedicellariae are found on the dorsal surface of the disk and arms. They are not numerous and seem not to be regularly arranged. I counted six on the disk. On the arms, these pedicellariae do not extend past the papular region. There are three or four on each arm. Their distribution appears to be completely irregular. These pedicellariae are very large. Their length is $2 \mathrm{~mm}$. They are each made up of seven or eight spines, slightly curved on each side.

The madreporite is rather small. Its outline is rectangular, elongated in the interradial direction. The furrows are very fine and divergent. It is located nearer the marginal plates than the center.

The dorsal marginal plates are thin, elongated and projecting inside. They do not encroach strongly on the dorsal side of the arm, so that the paxillar area remains wide. Each of them has a large elongated and strong spine, thick at the base, pointed and directed outside on the first plates. This spine can be $1 \mathrm{~cm}$ in length. It is generally followed by two or three other secondary spines. The first is as developed as it is. At its base are some small, very short spines. On the following plates, there is generally only one large spine surround at it base by some small spines. The rest of the surface of the marginal plates is bare. The unpaired plate makes, in each arc, a strong projection in the form of a large tubercle that has a very developed spine whose length is $15 \mathrm{~mm}$.

The ventral interradial areas are very little developed. They consist of a single row of three or four plates. In each of them, we find pectinate pedicellariae, but these have irregularities in number and arrangement. They are not symmetrical. Interradius 5 has three, interradius 1 has two, interradius 1 has only one, and finally, interradii 2 and 3 are confused. They have only two and a half. I.e., between two normal and entire pedicellariae is found a pedicellaria reduced to one half, as Perrier (94, p. 258) has already reported. 
These pedicellaria all have nearly the same size. They are a little larger than those of the dorsal surface. Their width can reach $3 \mathrm{~m}$. They usually have seven to eight spines on each side but sometimes some of these are missing.

The ventral marginal plates alternate with the dorsals. The first have in their middle a wide ridge that has a variable number, generally five or six, or large spines, with some smaller spines. The principal spines never reach the length of large spines of the dorsal marginals. The rest of the surface of the plates is bare. On the following plates, the ridge enlarges and has two more or less distinct rows of less strong spines. Each row has three or four spines, with some small spine. There is no trace of pedicellariae between the dorsal marginal plates and the ventral plate or between the successive plates of each row.

The ambulacral grooves are very wide. The elongated tube feet end in a very apparent disk. The large, wide adambulacral plates have in the groove, a small comb of three cylindrical spines, upright and contiguous. On their ventral surface, we note two large spines, placed back to back. These spines are very developed and as strong as those of the corresponding ventral marginal plates.

The teeth, which are not very large, are very prominent. They are separated by a wide membranous suture. Most of their spines are abraded so that it is not possible to indicate their exact arrangement. Their free border has spines that continue those of the ambulacral groove. On their ventral surface, I recognize traces of a row of large spines parallel to the suture. Outside these should be still more spines.

SIMILARITIES AND DIFFERENCES. - $P$. indicus does not have pectinate pedicellariae between the ventral marginal plates. It is distinguished by this character from P. Huddlestoni and violaceus described by Alcock as well as from P. pectinifer, cognatus and spinuliger from the Pacific, described by Ludwig. From the point of view of the distribution of the pedicellariae, it recalls more $P$. armatus Sladen, but it is separated by the more developed armature of the adambulcral plate and ventral marginals. It is easily recognized by its pedicellariae located exclusively on the dorsal surface of the disk and arms and on the ventral interradial areas, by the adambulacral plate with two large spines and by the numerous papulae on the entire width of the basal part of the arms.

I have said above, the only specimen collected by the INVESTIGATOR has only four arms. At first, it seemed that the fifth arm, that is the right anterior, was broken at the level of insertion on the disk. In fact, the anterior arm and the right posterior arm are greatly separated from each other and together form a very obtuse angle, as if there had originally been an arm between them that had accidentally disappeared. I do not believe things happened that way and it seem to me there was a kind of atrophy of the right anterior arm. Here, in fact, is what I observe:

In examining the specimen by its dorsal surface, we can see, at the base of the anterior and to the right, an unpaired marginal plate that ends the series of corresponding dorsal marginal plates. This plate is a little smaller than the other four unpaired plates. It is followed by two marginal plates are the first two dorsal marginal plates of the missing arm and is placed obliquely following each other on the lateral surface of the body. At the base of the right posterior arm, we find an analogous arrangement, with the difference that the unpaired marginal plate has a normal development. Between these two pairs of marginal plates, we see the plates of the dorsal surface of the disk are continued for two or three millimeters, following the general curve of the body and stopping near the border of the ventral marginal plates. 
On the ventral surface, the arrangements are more curious. In fact, in the single interradius that extends between the anterior arm and the right posterior arm, we note first an abnormal structure of the teeth. We distinguish, in fact, a pair of teeth that do not completely occupy the middle of interradius 3 and that is turned a little towards the anterior arm. This pair is normal, except that it is a little smaller and the suture narrower than in the other pairs. Between this pair and the right posterior arm, we note another pair of teeth, shorter and narrower, immediately applied against the preceding. The first tooth, squeezed between the preceding pair and the other tooth is extremely narrow and not very apparent. The second tooth is only a little smaller than the others.

These two pairs of teeth represent those of interradius 2 and 3. Those of interradius 3 are nearly normal while those of interradius 2 are formed of one reduced and one nearly completely atrophied tooth. The ventral area that result from the fusion of interradii 2 and 3 is wider than the other and contains all six latero-ventral plates with two pectinate pedicellariae and a half pedicellaria.

In fact, outside and a little above the row of ventral marginal plates that appear normal, we find two supernumerary marginal plates, one on each side, that go to meet the two smaller rows of two dorsal marginal plate reported above.

In summary, it seems that the right anterior arm has only by a rudiment on each side. On the dorsal surface, two dorsal marginal plates with some lateral plates and on the ventral surface, one ventral marginal plate. The interradial areas of interadii 2 and 3 are fused.

\section{Persephonaster Roulei nov. sp.}

\section{(Pl. VII, fig. 3; Pl. IX, fig. 4)}

I unite under this designation two asteroids without any indication of provenance that, at first glance, seem very different from each other because of the armature of the dorsal marginal plates. In one specimen, these plates have very developed spines, while in the other, they are nearly completely lacking. This latter specimen greatly resembles Psilasteropsis cingulata Fisher from the Hawaiian Islands (06, p. 1023). But, as I shall show later, these two individuals are distinct from the latter. On the other hand, as they are different from each other only by the armature of the dorsal marginal plates, I have believed it necessary to unite them into only one species that I place in the genus Persephonaster, and not in the genus Psilasteropsis for the reasons I indicate in the discussion that follows the description.

Both specimens are large. Here are their comparative dimensions:

Individual with armed dorsal marginal plates: $R=120 \mathrm{~mm} ; r=25$ to $27 \mathrm{~mm}$.

Individual with unarmed dorsal marginal plate. $R=120 ; r=25 \mathrm{~mm}$.

I shall particularly consider the first individual in my description and compare it to the second when necessary.

The disc is not very large. The arms are robust, very wide at the base and diminishing progressively toward the end that is very pointed. The marginal plates form a flat border and the dorsals encroach very greatly onto the dorsal surface so that the paxillar area is narrow. The ventral plates slightly overlap the dorsals below. The dorsal surface and the ventral surface are nearly flat. The entire animal is robust.

The dorsal surface of the disk is covered with small paxillae irregularly arranged in the immediate center. On the rest of the disk, they are more granular but they are aligned in distinct rows only at the base of the arms and in the area of the marginal plates. They become smaller and 
smaller towards the end. These paxillae are constituted of thin spines, cylindrical, elongated and generally lying flat, a little stronger on the specimen with unarmed dorsal marginal plates. Each of them has a number of central spines, varying from one to five, surrounded by about twenty peripheral spines of the same length. On the arms, the paxillae are arranged in very regular transverse rows and nearly exactly perpendicular to the line of marginal plates. As the base of the arms, the transverse rows of each side have about twenty paxillae. Often these rows are directly continuous with each other without interposing intermediate papillae. Elsewhere, there are two or three middle paxillae that are not part of the alignment of the lateral paxillae. The paxillae diminish progressively in size towards the end of the arms.

Because of the development of the dorsal plates, the paxillar area rapidly decreases. Its width is $16 \mathrm{~mm}$ at the fourth plate, $9 \mathrm{~mm}$ at the tenth and only $4 \mathrm{~mm}$ at the twentieth.

Between the paxillae are numerous small papulae on both the disk and on the arms.

The madreporite is round and small. Its diameter is not greater than $3 \mathrm{~mm}$. It is, however, very distinct because it is prominent and not at all hidden by the adjacent paxillae. It has fine furrows that are divergent from a point nearer the internal border than the eternal border. It is located nearer the dorsal marginal plates than to the center. I have not found the anus in the two specimens. It should certainly exist, but it is hidden in the midst of the paxillae.

There are forty seven to forty eight dorsal marginal plates. They are large, wide and thick. They form a very developed border that is higher than the dorsal surface of the disk and arms. They are strongly furrowed in the middle that rises up to form a transverse and prominent keel and the gullies that separate them are also very wide and deep as in Psilasteropsis cingulata. They are a little wider than long and keep a nearly constant width up to the twenty fifth or thirtieth. Beyond that, they rapidly become smaller at the same time that their surface becomes less and less convex to finally become completely flat. On the raised transverse keel are two upright spines. The internal one is small, in the form of a cone with a blunt end. The large, strong external one is conical, enlarged at the base and with a pointed end. Some plates of the interbrachial arch have in addition to the usual two spines, a supernumerary spine located between the two preceding ones and as large as the external one. Moreover, in attentively observing the portion of the plate that separates the two spines, we see a row of round granules, very different from the fine spinules that cover the rest of the surface and that some show a very clear tendency to form a spine. This disposition recalls that which I reported in Astropecten irregularis var. serrata (09, p. 47).

On the rest of their surface, the dorsal marginal plates have excessively fine and short spines, very dense, very erect in the area of the edge of the keel. They are inclined obliquely as they approach the adjacent border of the plates and are directed to meet the corresponding spinules of the adjacent plate to form a rudimentary fasciolar pedicellaria.

In the second specimen, the marginal plates have a structure that recalls that which Fisher indicated in Psilasteropsis cingulata. The covering of the plates is much more uniform than in the first individual. It is little more than very short spinules. The transverse keel has round granules. We usually see one of these granules and sometimes two form a small pointed tubercle forming a spine less developed that in the first specimen but recognizable. I observe this arrangement on nearly all the plates. However, there are some on which I never saw the least trace of this structure. Many dorsal marginal plates are abraded, which removed their covering, especially in the external area. But on none of them could I recognize an external spine nor even the least scar or indication of the spines. I am persuaded that they are totally lacking. 
Definitely, in the armature of the dorsal marginal plates of these two specimens, variations similar to those I have reported in Platonaster rigidus and Astropecten irregularis, etc. (09, p. 19 and 42) and that in no way could be invoked to establish specific separation.

The apical plate is narrow, elongated and two times longer than wide, with a proximal side a little hollowed, two lateral borders very slightly concave in the middle and a distal convex side on which I see no indication of a spine.

The ventral triangular areas are not very elevated, but they are very elongated. They have first a row of plates parallel to the adambulacrals and corresponding exactly to them, that continues up to the fourteenth plate, i.e., to the eighteenth or nineteenth ventral marginal plate. The other plates form small transverse series going from this row to the marginals. The three first series of each side of the median interradial line, each composed of two or three plates, border the first ventral marginal. The two following series, containing two plates each, border the second marginal plate. Beyond, there is only the row following the adambulacrals. These plates are uniformly covered with small cylindrical spines with a rounded end, very dense and longer on the first individual, shorter and more spaced on the second. In the latter, we even distinguish sometimes a central spine a little longer than the others.

The ventral marginal plates are separated from the dorsals, to which they correspond exactly, by a conspicuous groove. Their ventral surface is convex. They are widely separated from each other, especially outside. They are nearly two times wider than long, at least in the first half of the arm. Their ventral surface has small conical spines, flat and very short that, near the adjacent borders, suddenly give way to very fine spinules, directed obliquely toward their congeners as on the dorsal plates, thus forming a rudiment of fasiculate pedicelleriae. Among these flat spines, we distinguish two or three more elongated ones that, on the first plates, leave from the middle, but that, in the following, are inserted on the distal border of the plate. Finally, the ventral marginal plates have on their lateral surface, each two or three large elongated spines, fine and pointed, lying on the plate. They reach or even exceed the length, except the first ventral one that is a little shorter. There are usually three of these spines per plate on the first half of the arms. Sometimes the first marginal plates have four. Moreover, the lateral spines merge with the ventral spines that I reported above, so that the number of either is not always easy to define. We can say that the plates have, on their distal border, six to seven spines, the first ventral being the shortest.

The more or less open ambulacral grooves allows recognition of a double row of large pointed tube feet. The square adambulacral plates have in the groove a comb of seven to eight parallel spines, very elongated, very fine and pointed. The first and the last are a little shorter than the others. Their ventral surface is covered with erect spines, forming at least three very regular rows. They are a little longer in the unarmed individual.

The teeth, prominent and of medium dimensions, have on their free border a dozen spines that are continuous with those of the groove, but a little stronger and a little curved. At the end of the tooth is a large flat spine, characteristic of the genus Persephonaster, that goes horizontally towards the center of the mouth parallel to its congener. On the ventral surface of the teeth is first, along the suture, a row of short, erect spines. The last, directed obliquely, is stronger than the others and is located under the large terminal tooth spine. Inside are two or three regular rows of small conical, erect spines.

There is no doubt that the asteroid that I just described should be placed in the genus Persephonaster. We know that this genus was created by Alcock and Wood-Mason in 1891 for three new asteroids collected by the INVESTIGATOR, P. croceus, coelochiles and chodopeplus. I 
have been able to study the first two of these species. On the other hand, W. K. Fisher, in studying the asteroids of the Hawaiian Islands has been led to create a new genus that he named Psilasteropsis, in which he placed not only a new species, $P$. cingulata, but also an asteroid of the CHALLENGER placed by Sladen in the genus Psilaster, P. patagiatus (06, p. 1023). On my side, I had the occasion to study recently some $P$. patagiatus collected by the PRINCESSE-ALICE. I described a new species of Psilasteropsis, P. humilis, dredged by this ship (09, p, 61 and 62). I have also placed in this genus Psilasteropsis an antarctic species collected by the Scottish National Expedition, $P$. facetus (08, p, 538). In describing this latter species, I had already noted that the genera Psilasteropsis and Persephonaster are extremely close, but after having been able to compare specimens of the two genera Persephonaster and Psilasteropsis, I have been struck more by the similarities they have. If we recall the diagnoses given respectively by Alcock and Fisher of Persephonaster and of Psilasteropsis, we see finally that the second differs from the first only by the absence of spines on the dorsal marginal plates and by a lesser development of the ventral triangular areas. Now, these characters do not appear to me sufficient to justify a generic separation because they are far from being absolute. Thus the new species that I just described is represented by two individuals. In one of them, each dorsal marginal plate has two spines while the other lacks the stronger spine and the other is a more or less apparent tubercle. These variations are of the same order as those I reported in different other species and we cannot think of placing in two different genera two asteroids that differ only in one character.

The development and the length of the ventral interradial areas depend naturally on the length of the arms. As $P$. coelochiles, in which the arms remain wide for most of their length, the lateroventral plates extend very far. I have been able to verify this character in the specimens I have in my hands. But it is not the same in P. croceus. Alcock said that the latero-ventral plates extend up to the thirteenth or fourteenth ventral marginal, and in the type that he described, $R=95$. I have not had the opportunity to study this type but I have received from the Museum of Calcutta some Persephonaster that, by all their characters, conform to the description and to the figures that Alcock gave of $P$. croceus. In the largest specimen, $R=85$ to $88 \mathrm{~mm}$. This specimen has thus a size near that of the type. Now, the latero-ventral plates scarcely reach the sixth ventral marginal plate. In two other smaller individuals in which $R$ is respectively 10 and $36 \mathrm{~mm}$, the plates do not pass the fifth or even the fourth marginal plate. Moreover, in the figures of Alcock, we see clearly that the width of the arms decreases much more rapidly in P. croceus than in P. coelochiles and I cannot understand how this scholar said that the latero-ventral plates reach the thirteenth and fourteenth marginal.

The second character thus does not have generic value. I shall add again a remark. In Persephonaster armiger coming from the dredging of the ALBATROSS (05, p, 36), a species described by Ludwig and whose dorsal marginal plates have a spine. The latero-ventral plates stop toward the ninth or tenth ventral marginal plate in a specimen in which $R=82 \mathrm{~mm}$. In Psilasteropsis cingulata, the latero-ventral plates stop according to Fisher at the seventh marginal and in Persephonaser Roulei that I am going to describe, they reach the ninth. These differences, we see, are not very great and it is very difficult to indicate the boundary between the genera Persephonaster and Psilasteropsis according to such a character. I thus have the opinion to unite the genera Persephonaster and Psilasteropsis and to place in the first the species attributed to the second, which should naturally disappear. I propose, as a consequence, to modify the diagnosis of the genus Persephonaster given by Alcock and Wood-Mason in saying that the latero-ventral plates extend more of less far and, especially, adding that each tooth ends at its proximal extremity by a large flat spine, that leans on the adjacent one to be directed parallel to it and horizontally 
toward the center of the mouth. This arrangement seems eminently characteristic. The genus Persephonaster naturally takes its place in the Plutonasteridæ

Thus comprised, the genus Persephonaster must contain the following species:

Persephonaster croceus Alcock and Wood-Mason, Indian Ocean;

Persephonaster colochiles Alcock and Wood-Mason, Indian Ocean;

Persephonaster rhodopeplus Alcock, Indian Ocean;

Persephonaster Roulei Kœhler, Indian Ocean;

Persephonaster armiger Ludwig, Pacific Ocean;

Persephonaster penicillatus Fisher, Pacific Ocean;

Persephonaster cingulatus (Fisher) [Psilasteropsis], Pacific Ocean;

Persephonaster palagiatus (Sladen) [Psilaster], Atlantic Ocean;

Persephonaster humilis (Kœhler) [Psilasteropsis], Atlantic Ocean;

Persephonaster facetus (Kœhler) [Psilasteropsis], Atlantic Ocean.

As for the position of the last species in the genus Persephonaster, I must make the same reservations that I have made in attributing it to the genus Psilasteropsis, the state of the teeth do not permit recognition of the characteristic spine (08, p. 539).

Among the species that I just enumerated, Persephonaster Roulei is especially near $P$. cingulatus (Fisher) and armiger Ludwig. I have already spoken of its affinities with the first species and these affinities are so narrow that we could, at first glance, confuse the unarmed individual collected by the INVESTIGATOR with $P$. cingulatus. The two species are however quite distinct. There is, naturally, some doubt in regard to the first individual whose dorsal marginal plates each have two spines. Regarding the second, we have seen that the internal spine is, in general, more or less apparent. In addition, we note in the two specimens of the INVESTIGATOR that the marginal plates are covered with very fine and erect spines and not squamous granules. The ventral marginal plates have also, on the distal border, small spines and their covering is very different from that which W. K. Fisher has represented (06, Pl. III, fig. 2 a). Finally, the papillae have longer spines than in $P$. cingulatus and the prominent madreporite is very distinct.

$P$. Roulei is separated by various character from $P$. armiger that, according to the description of Ludwig, recalls by its characteristics, Plutonaster abyssicola. This is not the case of my species. $P$. armiger has only one spine on the dorsal marginal plates and it has fasiculate pedicellariae that I have not found the least trace in the two specimens collected by the INVESTIGATOR.

I dedicate this species to my excellent friend, Dr. Louis Roule, Professor at the University of Toulouse.

Astropecten Griegi, nov. sp.

(Pl. VII, fig 1; Pl. X, fig. 6)

Station 122. Depth 200-400 fathoms. One small specimen.

Station 248. $8^{\circ} 37^{\prime}$ Lat. N. $75^{\circ} 37^{\prime} 30^{\prime \prime}$ Long. E. Depth 224-281 fathoms. One specimen.

Station $269.8^{\circ} 09^{\prime}$ Lat. N. $76^{\circ} 30^{\prime}$ Long. E. Depth 464 fathoms. Two small specimens.

Station 323. $16^{\circ} 25^{\prime}$ Lat. N. $93^{\circ} 13^{\prime} 30^{\prime \prime}$ Long. E. Depth 163 fathoms. Two specimen.

Station $327.17^{\circ} 7^{\prime} 30^{\prime}$ Lat. N. $91^{\circ} 5^{\prime}$ ' 30'Long. E. Depth 410 fathoms. One specimen.

Andaman Islands. 130-259 fathoms. Four small specimens.

West coast of Andaman Islands. 230-290 fathoms. One small specimen. 
In the largest specimen, $R=85$ to $90 \mathrm{~mm}$ and $r=8 \mathrm{~mm}$. The individual from Station 248 is largest but all the arms are broken; $r=11$.

The length of the arms, compared to the extreme reduction of the disk, gives this Astropecten a very peculiar appearance and the fact is it looks much more like a Luidia than an Astropecten.

I think that A. Griegi is really the Astropecten reported by Alcock $(\mathbf{9 3}, a$, p. 87) in the area of Andaman, near 250 fathoms, and that he considered new. Alcock simply mentioned this asteroid without describing it.

The disk is very small. The arms are very narrow and very long. In the specimen shown in $\mathrm{Pl}$. $\mathrm{X}$, fig. 6, the arms are scarcely $10 \mathrm{~mm}$ in width at the base. In that o Pl. VII, fig 4, the arms are wider and are $11.5 \mathrm{~mm}$, but they are all incomplete. I take as the type the example in Pl. X.

The dorsal surface of the disk is covered with very dense paxillae, constituted of a long, cylindrical pedicel, ended in a tuft of long, spines, thin and cylindrical having nearly the length of the pedicel, 2.5 to $3 \mathrm{~mm}$ in length. There are two to four central spines surrounded by a circle of peripheral spines. The paxillae are dispersed irregularly. They completely hide the madreporite although it is prominent and has the form of a cone with a rounded end. Furrows leave this end. This plate is nearer the center than the marginal plates.

The paxillae are continuous on the arms with the same characteristics. We see in the median line of each arm, a band containing two or three paxillae, irregularly arranged. From this leave transverse rows, each containing seven or eight papillae that become smaller and smaller.

The paxillar area is very narrow, eight millimeters at the second dorsal marginal plate and five at the twelfth in the example shown in Pl. X, fig. 6. The paxillae of the arms are smaller than those on the disk, while their pedicel is relatively elongated and exceeds the length of the bundle formed by the spines that end it.

There are forty eight dorsal marginal plates in the example of $\mathrm{Pl}$. X, in which $R=85 \mathrm{~mm}$. In another individual a little larger $(R=90 \mathrm{~mm})$, there are fifty six. These plates, very narrow, are largely engulfed below by the ventral marginal s that correspond exactly to them. They are nearly square or slightly wider than long. The dorsal surface is oblique and they are separated by very clear grooves. They have on their surface fine elongated granules or, if one prefers, cylindrical spines that are extremely short in the median region. Nearing the adjacent side, thee small spines elongate and are arranged obliquely, so that where the lines separate, they meet their congeners, thus recalling fasiculate pedicellariae. Towards the middle of the internal border is a spine, thin, conical, pointed, directed obliquely outside and having nearly the length of the plate.

The apical plate, very wide, has a slightly concave proximal border. It has, on its free border, two small dorsal spines and, below, four ventral spines.

The ventral marginal plates are wide. They are covered with cylindrical spines, short and erect with a rounded end. Outside and on their distal border, they have a row of generally four spines. The two internals are short, while the two externals are very developed in the form of a pointed saber blade. The second spine, longer than the first, is very developed in the first half of the arm. The third is much longer and the fourth is still a little longer than the preceding. Its length exceeds two articles. These two latter spines extend far beyond the lower body and are applied against the external edge of the dorsal marginal plates. By adding thus a spine that each of these latter has, they constitute a very developed armature.

The ambulacral grooves are very wide and have a double row of very regular pointed tube feet.

The adambulacral plates, small and square, have on their internal border, three large spines, the median one is cylindrical and pointed, a little larger than the other two, which are flat and obtuse. The spines are erect or slightly inclined inward. Outside, we find, on the ventral surface an 
oblique row of two spines. The distal spine is larger, flat and pointed. The shorter proximal is cylindrical and obtuse. Following are some small spines, short and merging gradually with those of the ventral marginal plates.

The teeth are small and a little prominent. The have on their free border a row of a dozen elongated and cylindrical spines that continue those of the groove. The proximal tooth spine, and especially the last, length more and are placed horizontally beside at the side of each other and beside their congeners so that each pair of teeth ends in four spines, the two median larger, directed towards the center of the mouth. On the ventral surface of the teeth are, along the suture, a row of large, short spines. Outside, are one or two rows of smaller and shorter spines.

SIMILARITIES AND DIFFERENCES. - A. Griegi is distinguished easily from other Astropecten by its very long and very thin arms, with a very small disk. I do not see a species with which it could be confused.

I ask Dr. James Grieg, the Norwegian naturalist scholar to whom science owes numerous studies on Arctic echinoderms, to accept the dedication of this species.

\section{PHIDIASTER, nov. gen.}

The genus Phidiaster is near the genus Psilaster and it shares with it several important characters. The teeth are very narrow and projecting. They have on their ventral surface a row of large, short spines and, on their free border, another external row, but it does not continue the adambulacral spines. The spines are arranged as in the genus Psilaster. But here the each tooth has at their oral extremity, two large, flat spines that are directed horizonally towards the mouth.

The first adambulacral plates are elongated, notably those of the first pair that are developed along the external half of the tooth. The ventral triangular areas are small. The dorsal surface of the disk and the arms is covered with paxillae arranged in transverse rows on the arms. There is a very apparent epiproctal cone. The anus is missing. The madreporite is very small.

The genus Phidiaster is distinguished especially from the genus Psilaster by the great development of the dorsal marginal plates. These plates, like the ventral marginals, have two large, very strong and erect spines, forming along the arms four longitudinal rows, one dorsal, one ventral and two laterals that recall much more what exists in some Astropecten than in Psilaser. The characters of the very developed armature, the thickness of the dorsal marginal plates and the presence of two large proximal tooth spines does not allow leaving our asteroid in the genus Psilaster. It appears necessary to place it in a new genus.

Phidiaster Agassizi. nov. sp.

(Pl. IX, fig. 1, 2 and 3)

Station 306. $9^{\circ} 20^{\prime}$ Lat. X. $95^{\circ} 24 "$ Long. E. Depth 930 fathoms. One specimen.

Station 307. Depth 888 fathoms. One specimen.

Without Station No. Three specimens.

Without Station No. Six specimens. 
The dimensions from thee specimens are the following:

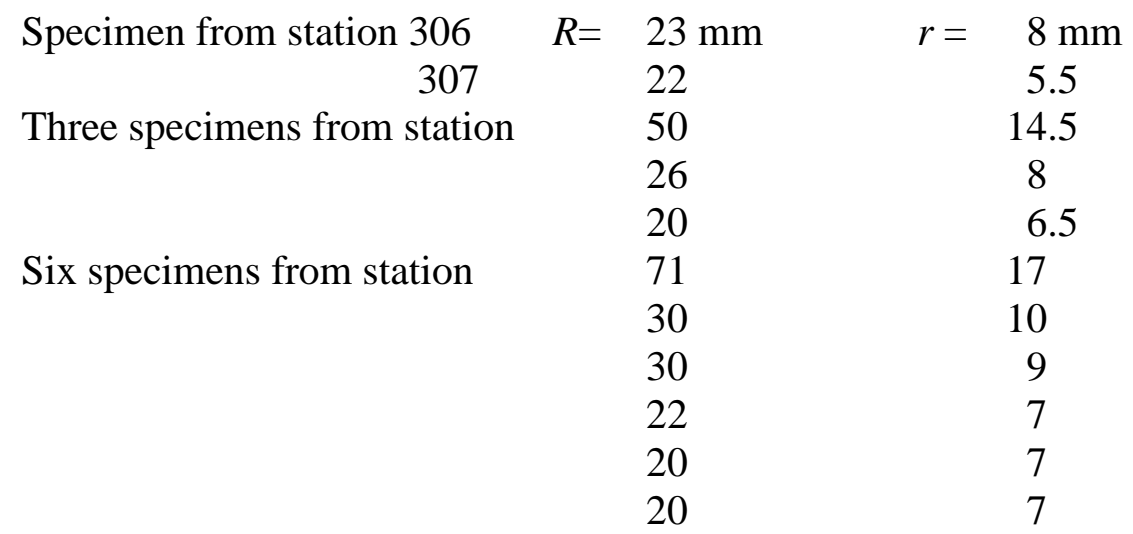

All these individuals are in general very well preserved. I shall take the largest as type.

The disk, of medium size, is thick and robust. The arms, wide at the base and strong, taper gradually up to the end that is pointed. Their lateral surface is nearly vertical. However, the ventral marginals extend slightly below the dorsal marginals. The height of the body is $8 \mathrm{~mm}$ in the interradial areas. The dorsal surface of the disk and arms is flat. The ventral surface is convex. In the middle of the dorsal surface is a round appendage. It is $3 \mathrm{~mm}$ in height in the type and can be the same height in smaller individuals. The dorsal surface of the disk and arms is covered with rather small paxillae, dense and elongated in the radial direction. They are $1 \mathrm{~mm}$ in length and about $0.7 \mathrm{~mm}$ in width. They are arranged regularly only at the base of the arms. They form then very slightly oblique and very regular transverse files, except at the base of the arms where we see a very narrow space where the paxillae are arranged without order, leaving exactly from the middle of the arms to reach the dorsal marginal plates. In the type, the width of the paxillar area at the base of the arms, between the first two dorsal marginal plates is $15 \mathrm{~mm}$, between the fifth pair of the plate, it is $10 \mathrm{~mm}$, and $7.5 \mathrm{~mm}$ between the plates of the tenth pair. Each row of the fifth pair of marginal plates has a dozen paxillae. Naturally, these paxillae become smaller and less numerous in each row going toward the end of the arms. The paxillae are very dense. It is difficult to see the papulae between them, especially the small ones between the transverse rows. Each paxilla has a central group of small round granules, flat and dense, a dozen on the largest, surrounded by a circle large ones, a little thinner and a little elongated. In the central region of the disk where the paxillae are confluent, the granules become smaller and smaller. They are continued on the epiproctal cone, at the end of which they are scarcely visible with a magnifying glass because of their great fineness.

I cannot distinguish the anus. The madreporite is very small, sunken in the midst of the adjacent paxillae. It is located nearer the marginal plates than the center of the disk.

There are twenty-one dorsal marginal plates. They are large, thick and very tall. Their height is little greater than their width. At the base of the interbrachial arcs, they are a little taller than the ventral marginals. They become shorter after the fourth. The dorsal marginal plates are separated by a very clear groove. Their dorsal region is slightly convex and their lateral sides are flat. They are relatively very wide and encroach onto the dorsal surface of the arms, forming a thick border. Their dorsal region is a little wider than long. They are covered with very large granules toward the middle of their dorsal surface where they are flat and even a little squamiform. Then these 
granules become rapidly finer towards the borders along which is a very regular row. In addition, each plate has toward the internal border, a pointed spine, conical and erect, which approaches the distal edge. Toward the external border is another spine, much stronger than the preceding, wide at the base, pointed and inclined outwards. The length of this spines is greater than two millimeters on the fourth and fifth plates. On the first three plates of each series (two only when the specimens are small), these external spines are missing, but in contrast, the internal spines are much stronger and longer and they equal the size of the adjacent exterior spines.

The apical plate is small and conical. When it is intact, it has three small spines, short and rounded, one dorsal and two lateral.

The ventral interradial areas are very small and have only a small number of small plates going from the adambulcrals to the marginals. The few plates found immediately outside the median interradial line are very irregular. Outside them, we can see a row of three plates going from the third adambulcral to the first ventral marginal, then two successive rows, each containing two plates, going from the fourth and fifth adambulacral plate to the second marginal. Beyond, the rows are reduced to only one plate. These continue very far. They pass the middle of the arm and reach the twelfth of fifteenth ventral marginal plate. But their form is not distinct because the granules that cover them merge on one hand with those of the adambulacral plates and on the other with those of the ventral marginals. All the latero-ventral plates are covered with large granules, flat and dense.

The ventral marginal plates correspond to the dorsals that they border below and are equally very developed. At first they are a little shorter than the dorsals, but are not slow to pass them. After the first fifth of the arm, they occupy two thirds of the height of the lateral surfaces. Their ventral surface is rectangular, at first wider than long, then as long as wide. They have in their internal region, large granules, rounded and flat, identical to those of the latero-ventrals. These granules scarcely form more than two rows. They continue on the lateral surfaces but are bare in the middle and stay localized toward the border where they form two or three rows of which the last is smaller, extended along the lines separating the plates (PL.IX, fig. 3). Independently of these granules, each plate has on its ventral surface and at a small distance from the internal border, a very strong spine, conical with an enlarged base and blunt end, directed obliquely outside. On the lateral surface and near the upper border, there is a second spine, much stronger and directed obliquely above.

The ambulacral grooves are very wide. The tube feet are very large with an obtuse end. The adambulacral plates correspond exactly with the adjacent latero-ventrals, but are however, a little smaller, six of the first have the same length as five of them. They are not very large and a little longer than wide. They have in the groove, a comb of six spines, not very long, cylindrical and very wide with a rounded end. The median spines are a little longer than the others. On their ventral surface the adambulacral plates have large spines, very short, wide, thick and obtuse, that merit very well the name flat granules. They form two or three irregular rows and merge gradually with granules of the latero-ventral plates. The first two or three adambulacral plates of each series are much more enlarged than the others. This characteristic is seen especially on the first which goes the length of the external face of the teeth, covering the surface of the tooth over half of its length.

This plate has only two spines in the groove, while on the ventral surface we see several series of flat granules arrange one behind the other in successive pairs. These granules become less numerous on the following plates, while the number of spines of the groove increases. We pass gradually to the normal arrangement indicated above. This structure recalls absolutely that which exists in Psilaser. 
The teeth are elongated, narrow. They are separated in each plate by an enlarged membranous suture along which are aligned fifteen large spines, very short, ending in a round, flat end that becomes small and approaches it congeners in the distal region of the tooth. Outside, and on the free surface of the tooth, is another row of smaller spines, thin, vertical and applied tightly against the tooth. These spines do not at all reach the ventral spines and they do not extend to the distal end of the tooth. On the oral border, we see appear suddenly two elongated spines, flat with a rounded end and translucent. These two spines are located in the same horizontal plane and are back to back. The internal one is longer and wider than the external. The internal spine is applied against its congener of the other tooth. These four spines that end each pair of teeth move together horizontally toward the center of the mouth.

Phidiaster Agassizi has an external similarity to Persephonaster croceus Alcock. The specimen from station 307 was even associated with an individual of the latter species with which it had been confused. But the resemblance is completely superficial. The two asteroids are very different from one another. However, it is curious that the proximal tooth spines are arranged in an similar manner in the two genera.

I ask Professor A. Agassiz to allow me to dedicate this interesting species to him.

\title{
Porcellanaster caulifer, Sladen.
}

\author{
(Pl. XI, fig. 5; Pl. XIII, fig. 1)
}

Parcellanaster cautifer, Sladen (89, p. 138).

Station $111.12^{\circ} 50^{\prime}$ Lat. N. $90^{\circ} 52^{\prime}$ Long. E. Depth 1,664 fathoms. A very small specimen. Station 299. $23^{\circ} 43^{\prime}$ Lat. N. $58^{\circ} 51^{\prime}$ 30" Long. E. Depth 1,299 fathoms. Three specimens. Station 300. $21^{\circ} 16^{\prime}$ Lat. N. 60 26" Long. E. Depth 1,375-1,165 fathoms. Several samples. Station 316. .5 43' 30" Lat. N. 80 $05^{\prime} 30^{\prime \prime}$ Long. E. Depth 1,500 fathoms. Three very small specimens.

In the largest specimen, $R=$ about $22 \mathrm{~mm}$. In the others, $R$ varies between 12 and $16 \mathrm{~mm}$, except in those from Statoon 316 that are very young.

This Porcellanaster approaches very exactly the description and figures of Sladen so that their determination appears to me without doubt. However, some individuals and especially the largest, have some spines on the latero-ventral plates. I have represented the largest specimen in which these spines are very numerous (Pl. XIII, fig. 1). In the smaller specimens, these spines are usually missing or are very rare. E.g., we find one or two in one ventral interradial area and none in the others.

We would not base a specific separation on this character. Moreover, Sladen has reported the presence of these spines in some specimens of $P$. caulifer. One species from the Arctic studied by Ludwig, $P$. pacificus, also has spines in the ventral imterradiul areas. So we cannot say that these areas are always unarmed in the genus Porcellanaster.

P. caulifer is the only species of Porcellanaster that I have encountered in the collection of the INVESTIGATOR that was given to me. I have not found the $P$. coerulens that Alcock has indicated in some stations. I have received, in all, three specimens labeled $P$. corulens. The first has a note "Arabian sea, 740 fathoms." It has reached me in very bad condition, However, I have recognized easily that it does not belong to the genus Porcellanaser, but to a new genus Sidonaster that I shall 
describe later. Its state of preservation does not allow me to specify the species. It appears to me, nevertheless, closer to $S$. Batheri than to $S$. Vaneyi. The second individual, very young, come from Station 117 , depth 1,748 fathoms. This certainly not $P$. corulens, I shall describe it below with the name Caulaster dubius. As for the third individual, it is also very young ( $R=$ about $5 \mathrm{~mm})$. The label has: Station 111, depth 1,644 fathoms. This is a Porcellanaster, but it is absolutely impossible to determine specifically because, not only it has not yet acquired all its characters, but most of the dorsal surface of the disk is missing.

\title{
Caulaster dubius, nov sp.
}

\author{
(Pl. I, fig. 5; Pl. V, fig. 8; Pl. XI, fig. 10
}

Station $117.11^{\circ} 58^{\prime}$ Lat. N. $88^{\circ} 52^{\prime} 17^{\prime \prime}$ Long. E. Depth 1,748 fathoms. One specimen.

The single individual is of very small size and it is evidently a young: $R=5 \mathrm{~mm}, r=2.5 \mathrm{~mm}$. It belongs to a series of small specimens that Alcock and Wood-Mason reported in 1891 (91, $\mathrm{p}$. 434) coming from Stations 111 (1,661 fathoms) and 117 and that they designated the name Porcellanster sp. prox. coerulens. They say only that the epiproctal appendage is very long, that the spines of the dorsal surface are localized in five very narrow interradial bands and that the dorsal marginal plates, unarmed, are very convex.

It would appear surprising that I use the generic term Caulaster that seems to have disappeared from zoological nomenclature, according to the observations of Sladen and Ludwig. These two scholars have, in fact, established that the species attached by Perrier to the genus Caulaster were young Porcellanaster. It is possible that the very young individual from Station 117 also belongs to the genus Porcellanaster, but I am not certain of it because, as we shall see later, the number of adambulacral spines is greater than that we find usually in this latter genus. In any case, it is completely different from the three young Porcellanaster that the INVESTIGATOR has dredged at Station 316 and that I consider to be $P$. caulifer. One of these three individuals is smaller than the asteroid from Station 117. The second is nearly the same size, and the last is a little larger. None of them has yet acquired spines on the dorsal marginal plates. Just as one can be convinced by examining the comparative figures I have given of the specimen of Station 117 (Pl. XI, fig. 4) and one of $P$. caulifer from Station 316 (Pl. XI, fig. 5), there is not the least similarity between the two forms. The dorsal marginal plates have already, in the specimens from this latter Station, the principal characters that they have in the adult, and they form a regular border in which the dimensions decrease gradually from the first up to the last, while in the specimen from Station 117, these plates are arranged as Perrier indicated in his genus Caulaster. On the other hand, the armature of the dorsal surface of the disk is very different and, instead of more or less numerous spines of young $P$. caulifera, I see here spines associated in groups of two, forming a kind of pedicellaria that Perrier has already reported besides and that, from my side, I have found in a porcellanasterid collected by the PRINCESSE-ALICE and that I had made a new species of the genus Albatrossaster (09, p. 25).

As my asteroid differs greatly from Porcellanaster known in the Indian Ocean and we cannot be certain that it belongs to this genus, and as, on the other hand, it could enter the genus Caulaster, I have not believed I make an error in placing it, at least provisionally, in the latter genus. I take it as a convenient label because the characters that Perrier attributed to it agree with those of my 
specimen and that I do not see any genus of Porcellanasteridæ to which I can attach it. Perhaps Caulaster represents the young forms of different genera that we cannot distinguish at this state.

Whatever it is, here are the characters of our specimen.

The disk is rounded with straight sides or a little hollowed, very distinct from the arms, a little swollen on the dorsal surface, while this surface is flat on the arms. These are not very wide at the base and they do not taper much to their end. The dorsal surface of the disk is covered with a thin membrane, transparent and on nearly all the surface. It has only some small spines on the five interradial bands. These spines are moreover very few and they appear in the neighborhood of the cribriform organ. Some are small, very fine, conical, pointed and isolated. The others, larger, are united in twos, with a bundle of fibers close to the base. They thus form pedicellariae measuring 0.2 to $0.3 \mathrm{~mm}$ in length that are articulated on a rounded tubercle ( $\mathrm{Pl}$. V, fig. 8).. We find from three to six of these pedicellariae in each interradial area.

Toward the middle of the dorsal surface is an epiproctal appendage whose length nearly equals two thirds of the ray from the disk. It is covered with extremely small, dense plates, each having a very short and very fine spine.

There are four dorsal marginal plates. Their width increases from the first to the third or fourth. The first two are rectangular, longer than wide. The third is also longer than it is wide, but it is very enlarged and its edges are more or less rounded, so that it often has an oval shape. The fourth, shorter than the previous one, is less developed than it is, but it is still relatively large. Like it, it is often located more inward than the previous one. It encroaches even more on the dorsal side of the arms: so it is very close to its fellow without touching it. This fourth plate is missing on two sides. These plates are thick and their dorsal side is convex, especially on the last two that are swollen.

The apical plate is large and thick, with the proximal edge strongly concave. It has three terminal spines. Generally these are only scars.

The ventral triangular areas are small and bare. There are only three marginal plates on each side: they correspond for about the first three dorsals. The fourth is missing. These plates are extremely thin, but however they are not rudimentary as in the genus Albatrossaster.

The cribriform organs, only one in each area, are narrow. Each has three or four lamellae framed on each side by a row of flattened papillae.

The ambulacral grooves are wide. Each has nine pairs of tube feet.

There are eight adambulacral plates. They have a proximal apophysis protruding into the goove. The first six each has three spines flattened, enlarged, with an obtuse point, and directed obliquely towards the groove. The following only have two. The proximal spine is inserted on the apophysis. It is a little larger than the other two that occupy the rest of the border of the plate. Very often, the first spine is directed towards the mouth, while the other two face the end of the arm. But this arrangement is not constant.

I particularly call attention to the number of three adambulacral spines, which is constant on the first plates. We observe very rarely in the genus Porcellanaster.

The teeth are not very projecting. Each has two spines on its free border, flattened and prostrate. The end is obtuse. The odd terminal spine that existed presumably is missing and I cannot distinguish the trace of its insertion.

The odontophore is very small, triangular, longer than wide, with a sharp tip. 
The genus Sidonaster is close to the genus Porcellanaster. Like it, the membranous dorsal surface is armed with spines interspersed with papulae. The dorsal marginal plates are not contiguous on the median line toward the end of the arms that are more or less raised upwards. The ambulacral grooves are very wide. The tube feet are very large and less numerous than in the porcellanasters. The genus Sidonaster is mainly characterized by the structure of the cribriform organs, which are papilliform instead of being lamellar. Each organ, which is alone in the interbrachial space, is made up of numerous papillae in the shape of small spines, fine and dense, very regularly arranged in vertical and oblique lines so that their edges form small staggered rows that also show a vertical arrangement. Cribriform organs are still very developed. They are very wide and their middle is little depressed in the two species that currently represent the genus Sidonaster.

A similar structure of cribriform organ is found in other genera of Porcellanasteridae, such as Styracaster and Hyphalaster etc., but it is completely unknown in the genus Porcellanaster. It is therefore necessary to separate from the latter the forms with this arrangement.

The collections of the INVESTIGATOR contain two different species of the genus Sidonaster. The first is represented by a single specimen, the second by several specimens.

Sidonaster Vaneyi, nov. sp.

(Pl. III, fig. 6; ; Pl. VI, fig. 5; Pl. X, fig. 3)

Station $290.24^{\circ} 53^{\prime}$. Lat. N. $57^{\circ} 43^{\prime}$. Long. E. Depth 833-733 fathoms. One specimen in an excellent state of preservation.

$R=$ about $20 \mathrm{~mm} ; r=10 \mathrm{~mm}$.

The arms are very separated from the disc, they are very short and thinner toward their end, which is raised. The disc is pentagonal with the sides nearly vertical. These are almost entirely filled by the cribriform organ that is very large.

The dorsal surface of the disc is formed by thin integument, on which are spines and papulae. The spines are thin, elongated, cylindrical, slightly flattened at the end that is often truncated, and even vey slightly enlarged. Other spines have a pointed end but it is never sharp. When examined under the microscope, we see on their dorsal surface small granules, more or less numerous and more or less conspicuous, and separated from each other. The length of these spines varies between 1 and $1.5 \mathrm{~mm}$. They are not very dense and the papulae between them are noticeably more numerous, while remaining separated by intervals greater than their diameter that is about $0.3 \mathrm{~mm}$. These papulae have the shape of a very low cone. Like the spines, the latter do not go beyond the distal edge of each cribriform organ. The two stop quite abruptly at the base of the arms. Their dorsal surface is covered by a very linearly folded integument. This integument of the dorsal surface of the arms is in the form of an elongated, triangular space that continues to the bottom of the concavity of the apical plate, whose apex is rounded. The dorsal marginal plates are separated over the entire length of the arms.

Towards the center of the disc is a curved epiproctal appendage. Its surface is covered with small rounded papillae that are very thick.

The madreporite is small and rounded with fairly conspicuous radiating furrows. Its diameter barely reaches $2 \mathrm{~mm}$. It is contiguous to the cribriform organ. 
There are five dorsal marginal plates on each side. The first is extremely narrow due to the development of the cribriform organ. It is longer than wide. The second is longer. It is about as long as wide, or slightly wider than long. The third and the fourth are larger and much longer than wide. The last is smaller. Each plate has, toward the middle of its internal edge, a strong spine, very broad at the base and quickly tapering into an acute point. We sometimes find, next to each of the spines of the first three plates, a very small accessory spine. On one of the arms, the third plate has a small spine on each side of the main spine.

The apical plate is large but not very projecting. It is very strongly concave on its proximal edge. It has seven long pointed spines, wide at the base, sub-equal and one and a half times longer than those of the marginal plates. Three of these spines are on the distal edge, one dorsal and two ventral. The other spines are inserted on the sides of the plate. Almost all these spines are preserved in the specimen.

The ventral interradial areas each form a triangle. The base is bordered, over almost its entire length, by the corresponding cribriform organ. They reach the distal end of the third adambulacral plate. We see transverse folds on their surface and can distinguish, under the integument, a few polygonal or rounded granules, irregularly arranged. Each has a fine, elongated, cylindrical spine, shorter than those on the dorsal surface.

The ventral marginal plates usually have the same number as the dorsals, to which they correspond fairly exactly. Sometimes the fifth is missing.

The cribriform organs are extremely developed and very large. They are at least $6 \mathrm{~mm}$. in length. They have the form of large shields, the middle of which is marked by a very slightly depressed vertical line. The papillae or spines that constitute them are elongated, very fine and very dense. When observed under the microscope, we notice that their calcareous axis is made up of a very delicate network, similar to that of the spines of the back side of the disc. On the living animal, these papillae must have been arranged very regularly in oblique lines, because we still recognize, in some places of these organs, the staggered lines which correspond to their ends. But this arrangement is more or less obliterated as a result of the displacement of the papillae that are tilted in various directions. The border papillae form a regular row. They are a little wider but flattened. There are about twenty-five on each of the vertical edges of the organ. Those that border the two dorsal and ventral edges are slightly thinner and more spaced.

The ambulacral grooves are very wide. The twelve pairs of tube feet are very large. The first pair corresponds to the teeth and the following correspond to the adambulacral plates, eleven on each side. These plates are longer than wide. Their ambulacral border is strongly indented and forms a cavity bordered by two ridges, the proximal is more pronounced. Each plate has two spines near the proximal edge, conical, fairly strong and with a blunt point. This number of two is very constant on all five arms.

The teeth are not very strong. They have the usual form of the genus Porcellanaster. Each has two spines identical to the adambulacral spines.In addition each pair of teeth has, toward its proximal end, an unpaired spine that is not more developed than the other two. It is directed obliquely toward the base.

I dedicate this species to my excellent friend and colleague Vaney, Professor at the University of Lyon.

Sidonaster Batheri, nov. sp. 
Station 192. $15^{\circ} 11^{\prime}$ Lat. N. $72^{\circ} 28^{\prime} 45^{\prime \prime}$ Long. E. Depth 912-931 fathoms. Three specimens.

Station $194.13^{\circ} 17^{\prime}$ Lat. N. $72^{\circ} 3^{\prime} 45^{\prime \prime}$ Long. E. Depth 891 fathoms. One specimen.

Station 254. $11^{\circ} 16^{\prime} 30^{\prime \prime}$ Lat. N. $92^{\circ} 58^{\prime}$ Long. E. Depth 669 fathoms. One specimen.

Station 299. $23^{\circ} 43^{\prime}$ Lat. N. 58 51'30" Long. E. Depth 1,299 fathoms. One specimen.

Station 300. $24^{\circ} 16^{\prime}$ Lat. N. 60 $26^{\prime}$ Long. E. Depth 1,375-1,165 fathoms. One specimen.

Station 306. $9^{\circ} 20^{\prime \prime}$ Lat. N. $95^{\circ} 24^{\prime}$ Long. E. Depth 930 fathoms. One specimen.

Station $318.7^{\circ} 28^{\prime}$ Lat. N. $79^{\circ} 19^{\prime} 30^{\prime}$ Long. E. Depth 1,085 fathoms. Two specimens.

Without Station No. $14^{\circ} 22^{\prime}$ Lat. N. $74^{\circ} 21$ ' $23^{\prime \prime}$ Long. E. Depth 1,132 fathoms. One specimen.

Here are the values of $R$ and $r$ Ifor the different specimens, with the number of dorsal marginal plates of each of them:

$\begin{array}{lllll} & & R & r & \text { Number of dorsal marginal plates } \\ \text { Station } & 192 & 26 \mathrm{~mm} & 10 \mathrm{~mm} & 5 \\ & 192 & 13 & 6.5 & 6 \\ & 194 & 22 & 10.5 & 6 \\ 254 & 21 & 6.5 & 6 \\ & 299 & 15 & 6 & 6 \\ & 300 & 13 & 6.5 & 5 \\ & 306 & 15 & 6.5 & 6 \\ & 348 & 21 & 10 & 7 \\ \text { Without number } & 348 & 16 & 7 & 7 \\ & & 15 & 6 & 6\end{array}$

I shall describe this species, especially according to the specimens of Stations 192, 194 and 318 that are the largest and best preserved.

The disk is of medium dimensions. The arms, very large and very strong, are very distinct from the disk. It is not completely the same in the specimen from Station from 194 where the arms are a little shorter, triangular, widened at the base that continues gradually into the disk. I have carefully compared this specimen with the others and except for this difference in the form of the arms, I have not been able to find any character that permitted me to separate them. The sides of the disc are straight or slighted concave. Each of them is nearly exclusively bordered by the corresponding cribriform organ. The arms are raised in the specimen from Station 192. They are a little less in those of Stations 104 and 319, but they become more in the others.

The dorsal surface of the disk has, in the central region, rounded papulae, sometimes a little projecting, sometimes very flat. Between them are some spines, fine and delicate, that are less numerous than in $S$. vaneyi, but are a little shorter. The spines and papulae in the central part of the disk extend into the interradial region by five wide bands reaching the cribriform organs. But these bands correspond only to half the width of the cribriform organs.

As a result of this arrangement, it is not only the dorsal surface of the arms that has a bare integument but part of the dorsal surface of the disk in the radial area that also lacks spines and papulae. The integument is very thin, transparent and very finely folded.

Toward the middle of the dorsal surface of the disk there is an epiproctal appendage that is especially developed in the two specimens of Station 318. It is a little smaller in the large individual of Station 192 and still less developed in that of Station 194. 
The madreporite is of medium size, rounded or slightly oval. It has furrows that are divergent from its internal border. The spines that surround it are denser than on the rest of the disk. Its external border is exactly contiguous with the corresponding cribriform plate.

There are usually six or seven dorsal marginal plates. The first is in large part filled by the cribriform organ. Its smooth part is very narrow. The following plates are rectangular, longer than wide. They are completely the same dimensions except for the second that is a little smaller and the last that is smaller than the others. Their lateral borders are slightly rounded and they have a tendency to be imbricated toward the middle of the arms. The fourth slightly covers the third and the fifth, the fourth. Their surface is very finely granulose. Toward the internal border, each plate has a strong spine, conical and pointed, but, so it seems to me, a little less strong and less long, in general, than in S. Vaneyi. On the second and third marginal plates is sometimes a small accessory spine. The plates of each row remain widely separate from the corresponding row up to the end of the arm. The apical plate is large, slightly protruding and strongly concave on its proximal border. It has seven spines arranged as in the preceding species. The proximal lateral spine is generally a little shorter than the distal spine. On nearly all the large specimens, these spines are broken are completely abraded. They are in the best state of preservation on the small one and on the individual from Station 254,

The ventral marginal plates have the same form as the dorsals, but they do not always correspond exactly and, in some specimens, there is one more. The cribriform organs have the same arrangement as in $S$. Vaneyi and they are nearly as long. In the individual from Station 192 where $R=26 \mathrm{~mm}$, its length is7.5 mm. In that of Station $318(R=21)$, its length is $6 \mathrm{~mm}$.

The ventral triangular areas are covered with very distinct regular plates forming more or less regular rows going from the adambulacrals to the ventral marginals. I usually count five rows on each side of the median interradial line. The first plates next to the odontopohores are larger than the others and the plates immediately following the adambulacrals are larger than those of the row to which they belong. There are about seven plates in the first row and four in the second. Each plate has in it middle a spine similar to those of the dorsal surface but smaller.

The ambulacral grooves are very wide and the tube feet are very large. I count a dozen pairs in the specimen from Station 194 and thirty in that of Station 192. The adambulacral plates have the internal border strongly concave for the corresponding tube foot. They have a very pronounced proximal apophysis. Each of them has two conical and pointed spines near the proximal border. The proximal spine is a little larger than the other. Sometimes the third adambulacral plate has three spines.

The teeth are very strong and projecting. They have on their free border a row of teeth. The number is four at least and very often is five. There is, moreover, an unpaired spine for each pair of teeth.

SIMILARITIES AND DIFFERENCE. - S. Batheri is obviously very near $S$. Vaneyi, but it differs by very clear characters that appear to me to justify specific separation. First of all, the dorsal surface of the disk has spines and papulae in its central region and on the five interradial bands. Secondly, each tooth has four to five spines instead of two as in $S$. Vaneyi.

I am happy to dedicate this species to F. A. Bather of the British Museum, whose competency for all that concerns echinoderm is well known and who has edited for several years with rare talent the review of works on echinoderms in the Zoological Record. 


\title{
Styracaster Caroli, Ludwig.
}

\author{
(Pl. III, fig. 5; Pl. V, fig.
}

Styracaster horridus, Alcock and Wood-Mason (91), p. 434.

Styracaster horridus, Alcock (93 a), p. 86.

Styracaster Caroli, Ludwig (07), p. 315.

Three specimens of this species have been sent to me: they were labeled St. horridus and had the following indications:

Station 117. $11^{\circ} 58^{\prime}$ Lat. N. $88^{\circ} 52^{\prime} 17^{\prime \prime}$ Long E. Depth 1,748 fathoms. One specimen. Station 118. $12^{\circ} 20^{\prime}$ Lat. N. $85^{\circ} 8^{\prime}$ 'Long. E. Depth 1,803 fathoms. One specimen. Without Station No. $6^{\circ} 18^{\prime}$ Lat. N. $90^{\circ} 40^{\prime}$ Long. E. Depth 1,520 fathoms.

The two individuals from Stations 117 and 118 are evidently those that were studied by Alcock and Wood-Mason and reported as St. horridus. Ludwig, in describing briefly the characters of a new species collected by the VALDIVIA from east of Zanzibar at $6^{\circ}$ Lat. S. at a depth of 2,950 fathoms that he called St. Caroli, considered that the Styracaster from the Indian Ocean that Alcock and Wood-Mason called St. horridus belonged to this new species. The English authors had moreover noted that their specimens had only four adambulacral spines in the groove on some proximal plates, most of the plates having only three and this number decreasing to two at the end of the arms.

The study that I have made of the Styracaster of the INVESTIGATOR has led me to share completely Ludwig's point of view. But as this scholar still has published only a very short diagnosis of St. Caroli, it appears to me useful to describe one of the specimens of the INVESTIGATOR with greater detail. I chose the specimen from station 118 that is well preserved. I have represented the ventral surface in Pl. V, fig. 1.

The dimensions are the following: $R=53 \mathrm{~mm}, r=12.5 \mathrm{~mm}$. One of the arms is complete. Two others have more than half of their length. The last is broken near the base. The disk is of medium dimensions, with the side very concave. It is continued by its border with the five arms that taper rapidly and that are strongly keeled. A section has the form of a tringle whose base is nearly flat.

Their dorsal surface is covered with dense paxillae, each with four, rarely five, small contiguous globules (Pl. III, fig 5). These paxillae are a little less dense on the triangular areas that are continuous with the basal part of the arms up to the union of the fourth and fifth pairs of the dorsal marginal plates. Toward the center, we note an epiproctal cone, wide and conical, but little extended and ended by two blunt cones. The madreporite is very large. Its border encroaches on the two corresponding dorsal marginal plates. It is nearly semicircular, with the internal border nearly straight and the external border strongly convex. The very conspicuous furrows diverge from the internal border.

There are twenty dorsal marginal plates. The last two are located on the sides of the apical plate. The next to the last is narrow and rectangular. They are longer than wide, especially after the twentieth. It is at this point that they unite with their congeners to which they correspond very exactly except to the straight posterior arms. They meet after an acute angle. Toward the middle of their common border is a strong and pointed spine. I count twelve of these spines. They are continuous over the length of the arm. The first two are particularly developed and strong. Their 
length decreases rapidly. The arrangement indicated by Ludwig relative to these two spines that are inclined obliquely and are outside the extension of the others is not very clear. It is a little more apparent in the specimen from Station 117.

The apical plate is two times longer than wide, with a split dorsal surface and a proximal corner. Its end has three small spines, short and obtuse.

The ventral interradial areas have, outside the odontophore, some large plates, irregularly arranged, that continue up to the fourth or fifth adambulacral plate. Outside, the plates, smaller, form some rows that are irregular and not always distinct. We usually see, on each side of the medial interradial line, a first row of five or six rectangular plates, then a second with four plates, and finally one or two other rows of two plates each. These plates are covered by an integument absolutely smooth with not the least trace of spines or granules.

The ventral marginal plates correspond to the dorsals, except in the last portion of the arms where they alternate more or less regularly with them. But the number is always the same. They are rectangular and sensibly less tall than the dorsals.

There are seven cribriform organs on each side of the interbrachial arc. They are not very developed. The three medians have nearly the same width as the smooth part of the plate that separates them. They have about fifteen rows of papillae. The two extreme organs of each side are narrower than the others.

The ambulacral grooves are wide. There are thirty-two adambulacral plates on the entire arm. They are rectangular, longer than wide, with a rounded and prominent proximal corner. The first plate has four spines, short and pointed. The proximal one is longer than the other three. All the other plates regularly have three spines. The first two are located on the proximal corner and the third a little separated from the preceding. The first spine is a little stronger. Its length decreases in the two following. The ventral surface of the adambulacral plates is unarmed except in the first where there is a small spine very near the proximal border. In the specimen without a station number, I sometimes find a spine on the first plate and another on the second.

The elongated teeth are very projecting. The have the usual form of a plowshare that we see in the genus Styracaster, with a median enlarged suture in its middle while they touch toward the two ends. They have on their free border seven to eight spines that continue the spines of the groove. They are a little smaller than the larger spine of the first adambulacral plate. The proximal spine and the unpaired spine are more developed. The teeth usually have no spine on their surface. However, on the specimen without station number, I find a few spines, one to three, toward the sutural border.

It is evident that this Styracaaster is the St. Caroli described by Ludwig. The only differences that I see are related to the number of dental spines that is seven or eight instead of six and the granules of the paxillae that are often four and sometimes even five per paxilla.

The three specimens that I have in hand and that have nearly the same size, are a little smaller than those of Ludwig and the arms are comparatively a little shorter. In the specimen I have described, the number of spines of the dorsal median line of the arms is only twelve. In the individual of Station 117, there are six to seven per arm. These small differences have little importance.

Thoracaster Alberti, nov. sp.

(Pl. III, fig. 1, 2, 3 and 4; Pl. V, fig. 7)

Station $287.21^{\circ} 08^{\prime} 30^{\prime \prime}$ Lat. N. $65^{\circ} 17^{\prime}$ Long. E. Depth 1,506 fathoms. Seven specimens. 
The specimens in general are very well preserved, except some of the arms are incomplete. The size is nearly the same in six of them where $R$ varies between 60 and $62 \mathrm{~mm} ; r=20$ to $21 \mathrm{~mm}$. The seventh is smaller. $R=45 \mathrm{~mm}, r=18 \mathrm{~mm}$. In some individuals, the arms are extended and remain in the plane of the disk for their entire length. In others, they are curved toward the end. In one or two finally, while remaining nearly straight, are raised obliquely at the base and form with the plane of the disk an angle of about $45^{\circ}$.

The disk is large and thick, more or less concave in the interbrachial areas. It is continued by angles with the arms that are very wide at the base and that taper very rapidly. At the same time, these arms become cylindrical with a flat ventral surface. Their dorsal surface is rounded and without the least trace of a keel. The dorsal and ventral surfaces of the disk are a little convex. The border formed by the dorsal and ventral marginal plates is wide. The first encroaches on the dorsal surface of the disk, as in Th. cylindricus. The entire ensemble is robust and rigid. The arms are stiff and solid.

The dorsal surface of the disk has, in some specimens, a rudiment of an epiproctal cone in the form of a slightly projecting mamelon. In others, this rudiment is not even apparent. In the small individual, we note in the center of the disk a small clear and slightly projecting patch that does not reach even a millimeter in diameter. The dorsal surface of the disk is covered with small paxillae, sometime very dense and even polygonal according to the reciprocal pressure, while to the contrary, are separated by very conspicuous grooves as shown in fig. 4 of Pl. III. The diameter of the paxillae is from 0.5 to $0.6 \mathrm{~mm}$. Each has twenty to thirty very dense and slkightly projecting granules. These paxilae are smaller and finer and their contours become less apparent in the center of the marginal plate. At the base of the arms, the paxillae extend into a more or less elongated area, in which the summit corresponds to the point of union of the fifth or sixth pairs of dorsal marginal plates and that, in one specimen, extends even to the seventh pair.

The madreporite is oval or semi-circular. Its length is about $1 \mathrm{~mm}$. It is separated from the dorsal marginal plates by three or four rows of paxillae. The furrows diverge on the proximal border.

There are seventeen or eighteen dorsal marginal plates on each side of the unpaired plate. The plates of the first pairs are separated from each other. Sometimes, however, those of the fifth pair touch either by their distal corner. Elsewhere the contact is made at the sixth pair. In one specimen, the contact on the dorsal median line is only at the seventh pair of plates, as I have noted above. After this point where they unite, the plates of each row alternate more or less irregularly. On the disk, the plates are nearly as long as wide. On the arms they become a little longer than wide

The apical plate is small, oval or triangular and slightly projecting. Its distal border has very small spines whose insertions are very near each other. It covers the two last marginal plates that are small and not connected to their congeners on the dorsal surface of the arms.

The ventral triangular areas are uniformly covered with small pointed granules, without the least indication of groups. These granules are very dense but not contiguous. They become denser towards the periphery.

The ventral marginal plates are in the same number as the dorsals and correspond exactly to them. They are at first longer than wide, then they become as long as wide and finally a little longer than wide.

There are four cribriform organs in each interbrachial arc. They are not well preserved in some specimens that have been abraded. When they are intact, we note that those found at the base of the arms are extremely developed and enlarged. In the first marginal plate, they are even confluent 
and leave bare, on the dorsal and ventral marginal plates, only a very narrow median portion. This bare portion enlarges gradually as it is separated from the unpaired plate, thus separating the cribriform organs more and more clearly. But it is only the three last ones of each side that are really distinct and separated from each other by a more or less wide smooth part, extending without interruption from the dorsal marginal plate and the corresponding ventral plate. The part of the marginals that remains bare on the first plates, with the form of a double $\mathrm{V}$ whose rounded end points downward for the dorsal plates and upwards from the ventrals. The two summits are separated by the confluent part of the cribriform organs. On the following plates, the triangular areas are joined at the same time that they enlarge. Each area has some small, conical and pointed spines that form a small median row on the first plate. When we look at the asteroid full face, the spines project onto the sides of the disc whose borders thus appear spiny. These small spines are more numerous on the fifth, sixth and seventh marginal plates whose part is left free by the cribriform organs becoming wider. But they are less developed. They are continuous on the following plates and we even find them beyond the cribriform organs in the form of fine pointed granules, scarcely apparent and scattered in variable numbers, but can be raised at the surface of the marginal plates. These spines appear moreover to detach the arms easily. They are missing when they are subjected to abrasion. They leave as scars a small depression. But these are not visible on the disk. As a result this structure of the marginal plates of Th. Alberti is not absolutely smooth as in other porcellanasterids.

In the smaller individual, the cribriform organs are not confluent and the part that remains bare on the dorsal and ventral marginal plates has from the beginning the form of an elongated space, narrowed in its middle.

When we examine attentively with a magnifying glass the vertical suture that follows the last cribriform organ, we can note, as between the dorsal marginal plates as between the ventrals, one or two rows of extremely fine papillae and that constitute a rudimentary cribriform organ.

The structure of the cribriform organs shows nothing peculiar. It is formed as usual by very dense papillae arranged at the same time in oblique and vertical rows. There are twenty to twentyfive of the latter in the largest. Each organ is slightly depressed in the middle. The depression corresponds to the border of separation of the successive marginal plates.

The ambulacral grooves are very wide, at least in the proximal half of the arms. They enclose twenty nine to thirty paird of tube feet whose ends are very small.

The small adambulacral plates have on their free border four spines directed obliquely toward the groove, short and equal, arranged parallel to each other, flat, with a round or truncated end. On the ventral surface, and separated from the two spines of the groove by an empty space, is a slightly irregular row of elongated granules or even of spines, three or four per plate, stronger than those of the ventral triangular areas.

The teeth have the usual form (PL. V. fig. 7). They have on their free border, about a dozen spines continuous with those of the groove and becoming a little stronger toward the point of the tooth, especially the proximal spine that forms with its congener a pair going toward the center of the mouth. On the ventral surface, we note first an internal row, parallel to the suture, of conical spines whose proximal ones are long. Outside comes another row of spines external to the distal border of the tooth, then some other spines irregularly arranged.

The odontophore is small and triangular, a little wider than long and often covered with granules identical to those of the ventral areas. 
SIMILARITIES AND DIFFERENCES. - The genus Thoracaster is known until now only by two species, Th. cylindratus Sladen of the Atlantic and Th. magnus Ludwig of the Pacific. The new species of the Indian Ocean has fourteen cribriform organs as the preceding, but these organs are confluent. It also is distinguished by the dorsal and ventral marginal plates armed with small spines developed especially on the first plate of each series.

I dedicate this species to my brother, Albert.

\section{Astrogonium ${ }^{3}$ Jordani (Fisher)}

Pseudarchaster Jordani, W. K. Fisher (06, p. 1038)

Station $239.7^{\circ} 00^{\prime} 00^{\prime \prime}$ Lat. N. $76^{\circ} 36^{\prime} 15^{\prime \prime}$ Long. E. Depth 1,022 fathoms. One specimen. Station $280.11^{\circ} 29^{\prime} 45^{\prime \prime}$ Lat. N. $30^{\circ} 02^{\prime} 30^{\prime \prime}$ Long. E. Depth 446 fathoms. A small specimen. Station $318.7^{\circ} 28^{\prime} 00^{\prime \prime}$ Lat. N. $79^{\circ} 19^{\prime} 30^{\prime \prime}$ Long. E. Depth 1,085 fathoms. Six specimens.

In the largest specimens, $R$ is 64 to $70 \mathrm{~mm}, r=19 \mathrm{~mm}$. These individuals are thus a little larger than the type of Fisher in which $R=52 \mathrm{~mm}$ and $r=16.5 \mathrm{~mm}$.

The small individual of Station 280 was associated with two large Astrogonium mozaicum.

All these specimens conform well with the description and figures of Fisher, especially those whose dimensions are near the type. In the largest, the ventral marginal plates have stronger and more numerous spines that sometimes extend beyond the border of the plates. On the border of the dorsal marginal plates, the granules are elongated a little and sometimes form small pointed cones.

\section{Astrogonium roseum (Alcock)}

Mediaster roseus, Alcock (93), p. 98.

I have had the opportunity to examine the type of Alcock. I do not share the point of view of this scholar on the generic position of this asteroid. Although the specimen is not in an excellent state of preservation, its characters are very clear and I do not hesitate to place it in the genus Astrogonium. It is very near Astrogonium fallax Perrier of the Atlantic.

Having had the opportunity to study very recently Astergonium fallax coming from the dredges of the TALISMAN and the PRINCESSE-ALICE, I can confirm the close association. But the species of the Indian Ocean is a little different from that of the Atlantic. The ventral marginal plates are, in fact, exclusively covered with granulations. Those in the preceding have not the least trace of small flat spines. Nor do I see the least indication of the fasciculate pedicellariae that exist in $A$. fallax in the middle of the ventral interradial areas.

Verrill (99, p. 184) has noted also that Mediaster roseus of Alcock is not a true Mediaster. He thinks that it is a Pseudarchaster (Asterogonium) that resembles P. granuliferus. This latter has according to the description of Verrill, three to five fasciculate pedicellariae in each ventral interradial area. The species of the INVESIGATOR is easily distinguished.

\section{Astrogonium mozaicum (Alcock and Wood-Mason)}

\footnotetext{
${ }^{3}$ For the reasons I have already given $(\mathbf{0 9}$, p. 64) and conforming to the point of view of Perrier, I preserve the name Asrogonium to the genus called Pseudoarchaster by Sladen. I recall that these two terms are absolutely synonymous.
} 
Pseudarachaster mozaicum, Alcock and Wood-Mason (91), p. 432.

Pseudarachaster mozaicum, Alcock (93 a), p. 85.

Pseudarachaster mozaicum, Alcock (93 b), p. 3.

Pseudarachaster mozaicum, Alcock (94), Pl. III fig. 2 and 2a.

Station $280.11^{\circ} 29^{\prime} 45^{\prime \prime}$ Lat. N. $80^{\circ} 02^{\prime} 30^{\prime \prime}$ Long. E. Depth 446 fathoms. Two specimens, of which one is in a poor state.

Station $281.11^{\circ} 15^{\prime} 15^{\prime \prime}$ Lat. N. $80^{\circ} 07^{\prime}$ Long. E. Depth 300 fathoms. One specimen.

Station 289. $23^{\circ} 56^{\prime} 45^{\prime \prime}$ Lat. N. $58^{\circ} 34^{\prime}$ Long. E. Depth 811-666 fathoms. One specimen.

Station $297.25^{\circ} 11^{\prime} 30^{\prime \prime}$ Lat. N. $57^{\circ} 15^{\prime}$ Long. E. Depth 700-689 fathoms. Five specimen.

Station $333.6^{\circ} 31^{\prime}$ Lat. N. $79^{\circ} 38^{3 / 4^{\prime}}$ Long. E. Depth 401 fathoms. One small specimen.

Station 339. $22^{\circ} 53^{\prime \prime} 45^{\prime \prime}$ Lat. N. 59 $39^{\prime} 45^{\prime \prime}$ Long. E. Depth 604 fathoms. Three specimens.

Andaman Islands. Depth about 500 fathoms. One specimen.

Without indication of locality. One specimen.

Here are the values of $R$ and $r$ in the different specimens.

$\begin{array}{llll}\text { Station } & 280 & R=87 \mathrm{~mm} & r=25 \mathrm{~mm} \\ & 281 & 47 & 17 \\ & 289 & 33 & 11 \\ & 297 & 56 & 15 \\ & 297 & 53 & 15 \\ & 297 & 52 & 14 \\ & 297 & 50 & 17 \\ & 297 & 43 & 13 \\ & 333 & 35 & 15 \\ & 339 & 70 & 24.5 \\ & 330 & 70 & 24 \\ & 330 & 58 & 17.5 \\ \text { Andaman Islands } & & 80 & 20 \\ \text { Location unknown } & & 70 & 21\end{array}$

We see from the indications above that the relative values of $R$ and $r$ are susceptible to having some variations. The arms are long and the disk is smaller in the two specimens from Station 280 that are very large, in the small specimens from Station 297, in the small one from Station 289 and in the one that has no indication of locality. To the contrary, the disk is larger and the arms are smaller in the specimens from Station 339 and the Andaman Islands. As for the individual from Station 281, the arms are very short, but it has very apparent regeneration in three of them and I suppose that the other two also have had regeneration whose traces have disappeared.

The description that Alcock and Wood-Mason have given of this species is a little short. On the other hand, in the figure that has been published by Alcock (94, Pl. III fig 2 and $2 a$ ), the engraver has not emphasized the small marginal spines that are so remarkable and so characteristic of this species, so that we can confuse it with others, such as A. Jordani (Fisher) for example. I have been able to examine the type of Alcock. I can confirm that it completely conforms to the specimens that I have enumerated above. It is notably very close by its characters to the specimen 
in good condition from Station 280 that I have represented in Pl. I, fig. 3. Its marginal plates have on their external border spines identical to those of the latter.

It thus appears to me useful to give a sketch of this species and to add to the description of Alcock some remarks that I have been able to make.

In all the specimens that I have seen, the disk is always large and the arms very wide at the base. They then narrow rapidly and their end is pointed. The ensemble is not very robust.

The dorsal surface of the disk has paxillae dispersed very irregularly except in the central region in a circle about one centimeter in diameter. These paxillae form on the disk longitudinal and oblique rows. On the arms, we note a median row a little larger than the others that extends to the apical plate. On each side we recognize at least one row, likewise going to the end of the arm, then some other rows that stop at different points. The second toward the twelfth marginal plate, the third toward the tenth and the fourth toward the sixth. The other paxillae form oblique rows that are directed toward the dorsal marginal plates, like the preceding longitudinal rows. Those around these plates in the interbrachial arcs are very small. The paxillae of the median row of the arms are a little wider than long. The others are as long as wide. Then they become longer than wide. The largest paxillae are clearly hexagonal. The others are round or oval. These paxillae are not very large. In the individual from Station 280 that I have figured, the largest is scarcely 1.5 $\mathrm{mm}$ in width. In other specimens, as for example that of the Andaman Islands, they are a little larger.

Each paxilla has a central group of round granules, widely separated and not numerous. Each group contains five, six or sometimes seven granules on the largest paxillae. Twenty to twentyfive finer granules form a circle around the preceding. The ensemble is not compact. In the specimen from the Andaman Islands reported above and whose paxillae are large, the central group can contain about a dozen granules. The paxillae are always well separated from each other. In the intervals are numerous papulae. In the hexagonal paxillae, papulae are at each corner.

The paxillae of the arms, very wide at the base, rapidly become very narrow. In the specimen from Station 280, they are 7 to $8 \mathrm{~mm}$ in width at the seventh dorsal marginal plate and the total width of the arm is from 18 to $19 \mathrm{~mm}$. At the twelfth plate, the paxillar area is $5 \mathrm{~mm}$ and the arm $12 \mathrm{~mm}$. In another specimen, I note the following numbers. At the seventh marginal plate, the width of the paxillar area is $7 \mathrm{~mm}$ and the arm is $16.5 \mathrm{~mm}$. At the twelfth plate, the paxillar area is $3 \mathrm{~mm}$ and the arm, $9 \mathrm{~mm}$ in width. In the individual from the Andaman Islands, the numbers are respectively 10.5 and $18 \mathrm{~mm}$ at the seventh marginal, 6 and $12 \mathrm{~mm}$ at the twelfth.

The dorsal marginal plates are wide and short. They form a very apparent border. Their dorsal surface is usually oblique so that the edges of the body are more or less thin. This dorsal surface is always flat. The successive plates are separated by a narrow, shallow groove. I count thirty-eight dorsal marginal plates in the specimen from Station 280. In the individual from the Andaman Islands, there are only thirty-three, but the arms are regenerated. In the individual from Station 297, in which $\mathrm{R}=56 \mathrm{~mm}$, there are thirty-five plates. At the base of the interbrachial arcs, the dorsal marginal plates are two times wider than long. They always remain wider than long the entire length of the arm in the adult. Their surface is covered with round granules, very projecting but rather small. They are arranged in about five very apparent transverse rows with about five granules per plate. These granules are a little larger than those of the paxillae of the dorsal surface of the disk. On the two adjacent borders of the plates these granules become much finer and denser. They constitute a very regular marginal row. As we approach the external border of the marginal plates, we see elongated granules that become small conical spines at this border. Among them are 
one, two, or even three longer and larger spines. These small marginal spines are continuous to the end of the arms. They are on all the specimens.

The ventral interradial areas are large. The plates that cover them form transverse rows going from the adambulacrals to the ventral marginals. We always distinguish a longitudinal row of plates parallel to the adambulacrals. Outside them is a second more or less apparent row. The first row goes up to the eighth ventral marginal plate. The plates that constitute it, smaller than the adambulacrals, are rectangular and wider than long. Those of the second row are narrower. The others end by becoming as long as wide. There are about a dozen transverse rows on each side of the median interradial line. The first has eight to nine plates that become smaller and smaller as we approach the ventral marginals. Each plate has a large central spine, elongated, pointed and measuring 1 to $1.5 \mathrm{~mm}$. It is surrounded by some other much shorter spines, kinds of conical granules that generally make a peripheral border of the plates. On the adjacent borders of the plates of the row parallel to the adambulacrals, these small plates take a fasciculate arrangement, especially conspicuous on the first eighth or tenth. We sometimes find an indication of this structure on plate of the twelfth row. As we approach the marginal plates, we see peripheral spines lengthen a little without, however, reaching the length of the central spine.

The ventral marginal plates have the same number as the dorsals, to which they correspond exactly. They are always wider than long. In the interbrachial arcs, their width is two times their length. They are covered with flat spines, squamiform and pointed. Some are raised into small spines that are seen on the ventral surface of the plates, especially on their external border. These small marginal plates are joined to identical spines on the free edge of the dorsal marginal plates. They form a small armature that extends the entire length of the arms. On the adjacent border of the plates, the granules become very fine and elongated. They are directed obliquely outside and form a very regular row that constitute rudimentary fasciculate pedicellariae

The ambulacral grooves are more or less open, but generally very narrow. The adambulacral plates, rather small, are longer than wide. They have inside the grove a comb comprised on the first plates of six spines, elongated, cylindrical, pointed and divergent. The two external ones are shorter. The number falls to five in the following. The ventral surface of the adambulacral plates has two close, slightly irregular rows of spines. The number of spines varies from two to four in each row. These spines are conical and pointed. Generally, one of the spines of the first row, and sometimes two are much longer than the others. After the middle of the arm, we find only one elongated spine.

The teeth are small. They have on their free border a row of spines that continue those of the groove. They become much stronger and longer toward the oral end of the tooth. On their ventral surface, we find along the suture, a row of conical and pointed spines that are first very short, but that elongate rapidly toward the mouth. Outside is a second row of smaller spines.

The type of A. mozaicum was collected off the Andaman Islands at a depth of 188-220 fathoms. The species was found by the INVESTIGATOR at different localities of the Gulf of Oman Sea and the Bay of Bengal at depths varying from 300 to 811 fathoms.

\section{Dorigona ternalis ${ }^{4}$, Perrier.}

\footnotetext{
${ }^{4}$ I preserve the importance of the genus Corigona that given it by Ed. Perrier. It conforms absolutely to the genus Nymphaster that Sladen created after the learned Director of the Museum had set the limits of the first. I refer to the work of Perrier (94, pl. 335) for the discussion of priority of the two terms.
} 
(Pl. VIII, fig. 5 and 6)

See Perrier for the bibliography: Perrier (94), p. 371.

Station $126.8^{\circ} 49^{\prime}$ Lat. N. $73^{\circ} 18^{\prime} 45^{\prime \prime}$ Long. E. Depth 1,370 fathoms. One specimen. Station $321.5^{\circ} 4^{\prime} 8^{\prime \prime}$ Lat. N. 80²2' Long. E. Depth 660 fathoms. One specimen.

Station 330. $12^{\circ} 49^{\prime} 30^{\prime \prime}$ Lat. N. 96'24' 30” Long. E. Depth 693 fathoms. One specimen. Gulf of Mannar. Depth 597 fathom. One specimen.

In all these specimens, the arms are broken at a more or less great distance from the base, except one of the individuals from Station 321 that was $96 \mathrm{~mm}$ from the mouth. This arm appears nearly complete and it should be about $100 \mathrm{~mm}$ in length. $r$ is 25 to $26 \mathrm{~mm}$. In the other specimens, the values of $r$ are $22 \mathrm{~mm}$ for the specimen from Station 330, $21.5 \mathrm{~mm}$ for that from Station 127 and 10 to $20 \mathrm{~mm}$ for that from the Gulf of Mannar.

The specimen from Station 126 and that from the Gulf of Mannar were studied by Alcock and reported by him as Nymphaster basilicus Sladen. This latter species was created by Sladen according to a specimen in bad condition and, according to author, very near Dorigona ternalis Perrier. However, Sladen did not mention, in N. basilicus, the structure of the adambulacral plates that Perrier had described in D. ternalis. I want to talk about the vertical projection of these plates after the twenty-fourth in the type observed by Perrier. It advances with its congener in separating the successive pairs of tube feet. It seems that this structure does not exist in N. basilicus. It is found to the contrary in the four specimens collected by the INVESTIGATOR. It shows up moreover well before the twenty-fourth adambulacral plates. These specimens appear to me to have the principal characters of $D$. ternalis, without however any of them corresponding absolutely to the type of Perrier. They are not moreover identical to each. It is precisely this variability that allows attributing a lesser important to the slight differences I observe. The principal three are related to the lower number of ventral marginal plates, the value of $r$ that appears comparatively smaller and finally to the form of the adambulacral plates whose internal apophysis appears sooner than Perrier indicated. Nevertheless, I do not believe I made a mistake in referring these specimens to $D$. ternalis and not to D. (Nymphaster) basilica, all the more so that this latter species does not appear to be clearly established and that its characters are very uncertain.

Here are the characters I have observed in the specimens that were sent to me.

The disk is large. The marginal plates are of medium size, the arms are strong. The ensemble of the animal is robust.

The plates that cover the dorsal region of the disk are irregularly polygonal and dispersed without order in the central region. They become regularly hexagonal, at the same time that they are arranged in regular longitudinal series in the radial areas where we see three or four rows on each side of the median row. The plates of this last are large, scarcely wider than long. Their dimensions decrease very slowly in the following rows. In the interradial triangular areas, the plates become smaller, but they remain in general distinct. They are confluent only in the immediate area of the dorsal marginal plate. These interradial areas form a triangle whose base widens corresponding to the first three marginal plates of each side. We recognize sometimes, at some distance from the center, five primary interradial plates a little larger than the adjacent one, especially in the specimens of Station 330 and from the Gulf of Mannir. These plates are not apparent in those of Station 126. They are not recognizable in the fourth. All the dorsal plates are covered with spherical granules, small and dense. In the largest, we distinguish about a dozen central granules surrounded by a circle of peripheral granules. In the radial areas, a papula is seen 
in the corners of the plate. The papulae are particularly apparent and very regular in the specimen from Station 330 whose dorsal surface I have represented in Pl. VIII, fig. 5. The dorsal plates of the disk there are comparatively larger and the granules that cover them a little more numerous, while in the specimen from Station 126 these plates are a little smaller. Very small alveolar pedicellariae are seem on the dorsal plates. They are very rare in the individual from Station 330 and more abundant in the others, especially those from Station 321 and that from Mannir.

The madreporite is very large, round or oval, with divergent furrows. It is surrounded by four to five very large plates, especially in the specimen from Station 126. It is very near the center of the disk.

The dorsal marginal plates are very developed, but, however, they do not encroach very much on the dorsal surface of the disk. The union of the plates of each side at the base of the arms is immediately after the fifth pair. But in an individual from Station 321, which is larger, the plates of the sixth pair are still separate. These plates are wider than long and the width increases gradually from the first to the fifth that is very wide. The following plates become narrower, as wide as long. They end by being a little longer than wide. The dorsal surface of these plates is more or less oblique in the interbrachial area where the sides of the body are thin. On the arms, the dorsal surface and the lateral surface are united with a right angle. The dorsal surface is slightly swollen. The external border is a little raised. The dorsal marginal plates are covered with very fine granules, spherical and dense. We can recognize a border row in which the granules have the same dimensions or are a little thinner that the others. Among these granules are seen some small and very rare alveolar pedicellariae.

On the entire arm of the specimen from Station 321, I count thirty-eight dorsal marginal plates. But on others, these plates are certainly less numerous because not only is this specimen is larger but the marginal plates there are shorter than elsewhere.

The ventral interradial areas are large. They extend up to the point of union of the fifth and sixth ventral marginal plate and even beyond the sixth in the specimen from Station 321 . We see, immediately outside the adambulacrals, a first row of regular plates a little wider than long. They are a little shorter than the corresponding adambulacral plates. Outside is a second role of polygonal plates, smaller than the preceding. The other plates forming more or less apparent oblique series, as is the case of the specimen represented in Pl. VIII, fig. 6 where they are arranged without order. The plates are less numerous and, at the same time, a little larger than in the specimen from Station 126. The ventral areas there are a little reduced. The latero-ventral plates are covered with very large, dense spherical granules, but projecting and well separated. There is not the least trace of pedicellariae.

The ventral marginal plates extend a little over the dorsal marginal plates above. They correspond to them nearly exactly. They are very wide in the middle of the interbrachial arcs. They are also longer than wide up to the fifth or sixth plate, then they become longer than wide. In the specimen from Station 126, the first encroaches a little more on the ventral surface than the others.

The adambulacral plates are large and a little longer than wide. They have in the groove a comb of eight spines arranged in a fan. Outside and separated from the preceding spines by a more or less conspicuous groove are three very regular rows. In addition, at the proximal and internal corner of each plate, we find very apparent relatively large pedicellariae that take the place of one or two granule of the internal row. This pedicellaria is bivalve or trivalve. It is formed by the union of two or three small erect spines. It is well developed and is very constant in the specimens from Stations 126 and 321, as well as from the Gulf of Mannir. It is less constant in the individual from Station 330. 
At some distance from the mouth, a distance that varies with the individual, the adambulacral plates have on their internal border a projection or apophysis, a little nearer their proximal side. This projection becomes more and more conspicuous on the following plates. They advance to meet their congeners so that each pair of tube feet is located in a small cylindrical compartment that is separated more and more from the adjacent compartment, as explained by Perrier. But the four specimens collected by the INVESTIGATOR have, from this point of view, some variations. In the specimens from Station 321, the ambulacral grooves are nearly completely closed for a length of about $15 \mathrm{~mm}$. The apophysis is scarcely to be seen before the fifth adambulacral plate. Toward the twentieth plate, the apophyses are very close to each other and, toward the twenty-fifth, these apophyses that are localized in the proximal part of the plate, border a well-defined cylindrical compartment whose diameter is nearly equal to half the length of the plate.

In the specimen from Station 126, the apophyses appear toward the twelfth plate. The inner border of the plates is constituted by a series of arcs that are accentuated on the following plates, in bordering small circular openings. But the grooves are a nearly completely closed all along their length and no tube feet project outside. In the individual from Station 330, the apophysis appears on the tenth adambulacral plates. The grooves are very narrow. But, on the arms, the tube feet leave by openings that are relatively larger than in the specimen from Station 321. Finally, in the specimen from Mannir (Pl. VIII fig. 6), the ambulacral grooves are very widely open and allow the tube feet to project outside. The adambulacral plates already show toward the third or fourth plate. These apophyses make contact with their congener toward the fifteenth plate.

The teeth have eight or nine spines on their free border that continue those of the groove. On their ventral surface, we find an external row of small, pointed spines, separated from the preceding by a furrow, and inside, two or three more or less regular rows of granules. In the specimen from the Gulf of Mannir, the spines of the free border of the teeth are thinner, more numerous and denser than in the others.

The individual from Station 126 is bright red in color. The other are completely colorless.

Dorigona Belli, nov. sp.

(Pl. VII, fig. 2, 3 and 4)

Andaman Islands. Depth 250 fathoms. Two specimens.

The specimens are in very good condition, but most of the arms are broken at some distance from the base.

In the larger individual, $R=53.5 \mathrm{~mm} ; r=17 \mathrm{~mm}$. A single arm is complete. In the other, $r=$ $14 \mathrm{~mm}$. The disk is relative very large and the arms are remarkably thin and slender. The dorsal marginal plates are small and narrow. They encroach a little onto the dorsal surface of the disk. The ventral marginal plates are wider. The disk and the arms are not thick. The entire ensemble of the animal is weak and delicate.

The dorsal surface of the disk is covered with polygonal plates, arranged irregularly in the central region in a circle 8 to $9 \mathrm{~mm}$ in diameter. They form regular series in the radial region where we note a principal median row and, on each side, at least three lateral rows. In the median row and the first lateral row, the plates are very enlarged and their width often is two times greater than their length (fig. 4). The eight or ten first plates of each of these rows keeps nearly the same dimensions. They then rapidly become much smaller. The plates of the second and third rows are 
naturally smaller than the preceding. We sometimes distinguish a fourth lateral row. In the interradial area, the plates are extremely small. They even become continuous. All these plates are covered with very regular, dense, spherical granules. On the plates of the median row, we usually see two transverse rows, more or less regular and a circle of peripheral granules. On the other plates, there is in general only a single transverse row containing two or three granules. In the radial rows, the plates are very separated from each other. We see five or six papulae per plate. The papular pores are very small.

The anus is central, very distinct and surrounded by five or six plates. The madreporite is small and round, with divergent furrows. It is surrounded by four plates. It is found very near the center, nearly a fourth the distance between it and the border of the disk. One plate is distinguished by its yellow color from the other plates of the disk that have a different color, generally pink.

The dorsal marginal plates form a relatively narrow border. I count twenty-five plates on each side of the arms that are entire. The five first plates are a little wider than long. The plates of the fifth pair are a little larger and especially a little wider than the preceding ones. Each plate of this pair is in contact with its congener for half of its length. After this pair, the plates become nearly as long as wide, then a little longer than wide. They alternate more or less regularly. The first plate on each side is about $3 \mathrm{~mm}$ in width. At the base of the arms, at the fifth pair of marginal plates, the width is about $9 \mathrm{~mm}$. At the seventh pair, the arms are no more than $4 \mathrm{~mm}$. They taper very rapidly up to the end that is very thin and pointed. Thee plates are covered with spherical granules, thin and dense, identical to those of the dorsal plate. They lack pedicellariae.

The ventral interradial areas are of medium size. The ventral marginal plates form a wide border that encroaches very strongly onto their surface. These areas extend nearly to the place of union of the fourth and fifth ventral marginal plates. They have a first regular row parallel to the adambulacrals, a little wider than long. These plates have nearly the same width as the adambulacrals. The first of them corresponds nearly exactly and the following alternate with them. This row has thirteen or fourteen plates. Outside, we see a second row of smaller plates, nearly as long as wide, and sometimes still a third row of about a half dozen plates. Some other plates that complete the ventral areas are arranged irregularly. All these plates are uniformly covered with dense spherical granules of the same size.

The ventral marginal plates have the same number as the dorsals, to which they correspond more or less exactly. The first three on each side are very large and wider than long. The fourth is still very large, but the following rapidly become much smaller. They are first wider than long and, finally, longer than wide and very narrow. They are covered with granules identical to those of the dorsal marginal plates. They do not have pedicellariae.

The ambulacral grooves are of medium width. The tube feet are very apparent, at least in the first half of the grooves. The small adambulacral plates are nearly square with a slight apophysis on the middle of their internal border. They each have, in the groove, a row of seven to eight small spines, unequal, cylindrical and erect that follow their contour. On the ventral surface of these plates, we see three more or less regular rows of granules. Those of the first row are a little elongated. It is constituted of very short, small spines that are parallel to the spines of the groove. The other granules are shorter and merge gradually with those of the latero-ventral plates. On the arms, the internal apophyses of the adambulacral plates approach the proximal border. As the groove narrows, they go to meet their congeners in a way to border the small incomplete compartment in each of which is a pair of tube feet. These characters are less conspicuous than in D. ternalis, but however at the end of the arms, the apophyses touch each other. 
The color of the larges specimen in alcohol is pink and the tube feet are clear red. The other specimen is discolored.

SIMILARITIES AND DIFFERENCES. - These two asteroids were called Nymphaster protentus Sladen by Alcock. But it is certain that they cannot be assigned to this species as we can prove immediately by comparing the figures that I have given in Pl. VIII, fig, 2 and 3 to the figures that have been published by Sladen (89), Pl. I, fig. 3 and 4; Pl. LIII fig. 9 and 10.

$N$. protenus, which has been found again in the Atlantic Ocean, has a comparatively smaller disk. The dorsal marginal plates are wide and the strongly encroach onto the disk. In $D$. belli, the dorsal plates of the disk are wider in the radial areas. The ventral interradial areas are lager and the arms are excessively slender and narrow. The dorsal marginal plates are, in a general way, more developed in $N$. protentus because there are twenty-nine to thirty of them in the type of Sladen in which $R=71 \mathrm{~mm}$, while they number twenty-seven in $D$. belli in which $R$ is only $53 \mathrm{~mm}$.

$D$. Belli is evidently different from $D$. ternalis that I describe above and that it recalls by the structure of the adambulacral plates. But it is much more delicate than the latter. If we compare the specimens whose disks have nearly the same dimension (in the specimen of $D$. ternalis from the Gulf of Mannir, $r=19$ to $20 \mathrm{~mm}$ and consequently its value is very near that $\mathrm{I}$ have indicated in $D$. Belli), we see that the body is much more robust and the arms much larger and stronger in D. ternalis than in D. Belli, where they are very slender. Moreover, there is not the least indication of pedicellariae in this latter species.

I would like to ask F. Jeffrey Bell of the British Museum, to whom science is indebted for numerous investigations on echinoderms, to accept the dedication of this species.

Dorigona Ludwigi, nov. sp.

(Pl. IX, fig. 5 and 6).

Station $126.8^{\circ} 49^{\prime}$ Lat. N. $73^{\circ} 18^{\prime} 45^{\prime \prime}$ Long. E. Depth 1,370 fathoms. One specimen.

The disk is pentagonal with concave sides, No arm is entire. The largest is $78 \mathrm{~mm}$ from the mouth, $r$ is $22 \mathrm{~mm}$. The dorsal surface and the ventral surface are completely flat. The sides of the disk and the arms are vertical. The arms are completely rigid. They are moderately wide at the base and taper slowly.

The dorsal surface of the disk is covered with hexagonal plates with granules arranged irregularly in the central region. But they form longitudinally very regular rows in the radii. We see a carinal row and, on each side, at least three series of plates whose dimensions are a little less than those of the median row and whose size decreases rapidly from the base of the arms. These radial plates are hexagonal, nearly as long as wife, except the median row that is a little wider than long. They form, all together, five conspicuous petals, outside of which the large interradial areas have the form of nearly equilateral triangles whose bases correspond to the first four marginal plates on each side. The plates of these areas remain very large and very distinct in the proximal half. They become confluent in the immediate area of the marginal plates. The borders of the plates are clearly indicated in the radial areas by the very apparent, but very narrow furrows. We scarcely distinguish the openings of the papular pores. The first five interradial plates are in general very distinct and larger than the neighboring ones. All these plates are covered with round granules, dense but non-contiguous. Among them we see four to eight central granules and peripheral 
granules that do not form a differentiated border row. On some of these plates we see a small alveolar pedicellaria whose width does not exceed that of a granule. It is raised a little above the adjacent granules. These pedicellariae are not very abundant.

The anus is small but very distinct. The madreporite is not larger than the first interradial plates. It is surrounded by four plates. It is located very near the center of the disk. It is remarkable for its clear brick red color that is deeper than the slightly pink color of the rest of the body.

I count twenty-four dorsal marginal plates on the length of the arm. The first six plates of each row limit the border of the disk. The union of these plates in the dorsal median line is toward the middle or at the end of the end of the sixth pair. The eighteen plates that follow extend over a length of $55 \mathrm{~mm}$. The first marginal plates are much wider than long. They become square toward the twelfth or fourteenth. Beyond, they are a litter longer than wide. Their external border is a little convex. They are slightly overcome below by the ventral marginal plates that correspond to them exactly. They are separated from the latter by a very deep groove. The transverse furrows that separate the successive plates are thin but very apparent. On the very conspicuous dorsal median line they are united to their congeners following a zigzag line that is not very conspicuous. Sometimes they alternate more or less regularly. Sometimes they correspond to the plates of the other side. The dorsal marginal plates are uniformly covered with very projecting spherical granules that are close to each other but not contiguous. We see a little smaller border row. Toward the external border of plates, some of these granules elongate and become a little more conspicuous. Some plates have a very small alveolar pedicellaria, but these are very rare.

The ventral interradial areas are of medium size. They extend nearly to the fifth or sixth ventral marginal plate. The plates that cover them are very distinct and very regularly arranged in longitudinal rows. The first row that is immediately outside the adambulacrals has rectangular plates of which the first nine or ten are very regular while the dimensions of the following decrease very rapidly. The first plates correspond nearly exactly to the adambulacrals. Then they become a littler smaller than the latter. Outside this first row we see a second, a third and even a fourth that become smaller and smaller and leave only a small space covered with irregularly arranged plates. All these plate are covered with large spherical granules, very distinct and dense but without however becoming absolutely contiguous. We do not see a pedicellaria among these plates.

The ventral marginal plates correspond to the dorsals. The first are large, nearly two times wider than long. They encroach onto the ventral triangular areas. Their width decreases very rapidly. They are as long as wide towards the fifth and they then become notably longer than wide. The granules that cover them are identical to those of the latero-ventral plates. But they have a tendency to become a little larger in the area of the external border of the plates. Some of them are elongated a little and make a sight projection. On some of these plates, I find a small pedicellaria, but these are still rarer than on the dorsal marginal plates.

The adambulacral plates are very large. They are at first a little wider than long. Then they become as long as wide. They have, on their ambulacral border, very thin spines, short, not flattened and arranged like a fan. There are generally nine spines on the first adambulacral plates and ten on the following. The median spines are a little longer than the others. The two end spines, especially the distal spine, are very small. The ventral surface of the adambulacral plates has two very regular rows of granules separated by a furrow of small internal spines. Each row has five or six granules. There is not the least trace of pedicellariae on these plates. Toward the thirteenth of fourteenth adambulacral plate, i.e., at the point where the first row of latero-ventral plates has disappeared, the adambulacrals make contact with the ventral marginals. The first becomes a little wider. Their free border, that is already a little convex, accentuates this convexity. Some 
supplementary granules are added to those of the ventral surface of the adambulacrals. The regular order of these granules is thus disturbed and we can then count three more or less irregular rows. The convexity of the ambulacral border is always accentuated. This ends by forming an apophysis that advances in front of its congener to the twenty-fifth plate. As a result, the pairs of tube feet are separated from each other. Each is found in a cylindrical space as in D. ternalis.

The teeth are very small. They have on their free border about a dozen spines that remain identical to the adambulacral spines. The latter alone become a little longer. On the ventral surface we see a row, parallel to the suture, of seven to eight granules, a little elongated and conical, whose next to the last and especially the last are more elongated. Outside it are some other irregular granules.

SIMILARITIES AND DIFFERENCES. - This asteroid was identified as Nymphaster basilicus, but it is quite different from this species as well as the other known Dorigona. I consider it new. It is characterized immediately by two rows of granules that cover the ventral surface of the adambulacal plates. Moreover, the latter do not have the least trace of pedicellariae. These two characters clearly separate $D$. Ludwigi from $D$. ternalis that it however recalls by the characters of the adambulacral plates in the second half of the arms.

I dedicate this species to Professor H. Ludwig of Bonn, to whom we owe so much fine work on echinoderms.

\section{Iconaster pentaphyllus (Alcock)}

Dorigona pentaphylla, Alcock (93 a), p. 93.

I mention here this beautiful species, whose type is represented by a single specimen that I have been able to examine, only to avoid the confusion between the name adopted by Alcock and those that I use. The English naturalist scholar has applied, in fact, to this asteroid the name of Dorigona pentaphylla. This gives the genus Dorigona an importance it no longer has. As I mentioned above, Dorigona is exactly synonymous to Nymphaster. If we previously understood Iconaster longimanus (Mobius) to be in the genus Dorigona, Perrier and Sladen agree this form is the type of a separate genus, Iconaster, separated by Sladen from the genus Nymphaster and by Perrier, the genus Dorigona. The asteroid designated by Alcock as Dorigona pentaphylla reenters the genus Iconaster as defined by Sladen.

\section{Pentagonaster (Tosia) Annandalei, nov. sp.}

(Pl. XII, fig. 1, 2 and 3)

Station $277.5^{\circ} 48^{\prime} 15^{\prime \prime}$ Lat. N. $80^{\circ} 56^{\prime}$ Long. E. Depth $859-880$ fathoms. Only one specimen.

This specimen is in good condition. It is missing only some marginal plates.

The disk is very large. It is very widely continuous with the five arms. The arms are triangular, very wide at the base, but tapering rapidly to the end that is obtuse. These arms remain relatively large. The interbrachial areas are large and very concave. Three arms are a little smaller than the 
others and their end appears to have been broken and then regenerated. The longest arm has $R=$ $80 \mathrm{~mm}, r=11$ to $12 \mathrm{~mm}$.

The body is flat. The specimen that I have in before me has a concave dorsal surface as a result of the fairly conspicuous elevation of the arms. The marginal plates form a moderately wide border. Some plates are missing in three interradial arcs. The whole animal is robust and rigid.

The dorsal surface is covered with small plates, irregularly polygonal or rounded, unequal, some slightly larger, others are smaller, but their diameter scarcely exceeds $1.2 \mathrm{~mm}$. These plates are arranged without any regularity, both on the disk and on the arms. About a centimeter from the center of the disc, we see in each interradius a spine a little bigger than the adjacent ones, but there is no distinct centro-dorsal. The arms do not have an apparent median row, but only on the sides are some indications of transverse rows that reach the marginal plates. The area filled by these plates is large. Is width is $11 \mathrm{~mm}$ at the ninth dorsal marginal plate. It extends up to the apical plate, separating the two rows of marginal plates to the end of the arms. They are always very wide.

The plates of the disk and the arms are covered with round granules, very large, of uniform dimensions and dense. The arrangement of the granules on the plates is a little irregular and they are never numerous. Often we see a large central granule and six peripheral granules, all of the same size. On others, we find only three, four or five granules. Each of the five larger interradial plates have six or eight large central granules and a circle of about a dozen peripheral granules. All these granules, in the central part of the disk and toward the border of the interbrachial arc and on the arms, are about $0.4 \mathrm{~mm}$ in diameter. Between the dorsal plates are numerous, very small papulae. There are three or four papulae around each plate. Each papula is contiguous with three or four plates. Some alveolar pedicellariae are seen on the dorsal surface. But they are not seen on all the plates. These pedicellariae are small. However, they exceed the adjacent granule by 0.5 to $0.6 \mathrm{~mm}$. Their valves are slightly narrower in the middle. Then they are enlarged a little in thickening their distal border. They are always found located toward the border of the plates.

The very small anus is a little eccentric. The madreporite is round, with a slightly irregular contour. It is $4 \mathrm{~mm}$ in diameter. It is applied against one of the five primary interradial plates that is much small than it is. It is nearer the center than the border of the disk. Its surface has numerous divergent furrows.

There are fifteen dorsal marginal plates, counted on one side of one of the arms where they are complete. Three arms are shorter than the others. The ends are regenerating as I said above. The marginal plates are naturally less numerous in these arms. They are moreover malformed or indistinct at their ends. The dorsal marginal plates are of medium size. The border they form at the periphery of the disk is not very wide. They are rectangular, wider than long and are $8 \mathrm{~mm}$ in width at the base of the interbrachial arc. Their dimensions remain nearly constant toward the ninth. Beyond, they rapidly decrease. The last plate of each series always remains well separated from each other at the end of the arm. The surface of these plates is covered with granules, except on a round area whose diameter is nearly equal to a third of the width. These are found nearer the internal border than the external border of the plate. The granules are fine round, flat, a little unequal and irregularly arranged, except along the adjacent borders of the plates where they form a very regular row. Their dimensions are the same as the other granules of the dorsal surface to which they merge without a line of demarcation. Here and there, a small alveolar pedicellaria is seen toward the sutural border of a plate. But these pedicellariae are not very numerous.

The apical plate, of medium size, is bare. It has the form of a shallow cone with a round end. 
The ventral interradial areas are large, triangular and covered with large plates arranged in regular longitudinal and oblique rows. The first row, contiguous with the adambulacrals, has hexagonal plates, wider than long and extending to the end of the arm. These plates have the same width as the adambulacrals with which they alternate regularly. After them is a second row of equally hexagonal, but a little shorter, plates alternating with those of the preceding row. It extends to the ninth marginal plate. Outside it, we can still observe a third row, less distinct than the two others and that does not pass the fifth marginal plate. The other, smaller plates, irregularly polygonal, are arranged in inconspicuous oblique series. Their size decreases as they approach the base of the interbrachial arcs. All these plates are covered with round granules, dense but not exactly contiguous. On the largest plates, we recognize more or less numerous granules surrounded by a very regular peripheral border of slightly finer granules. Small alveolar pedicellariae, identical to those on the dorsal surface, are seen on the ventral surface. In general, each large plate has one. The position of these pedicellariae is variable. But they are always found near the border, inside the peripheral row of granules.

The ventral marginal plates are a little less developed than the dorsals. The border they form with the ventral surface of the asteroid is sensibly less wide and a little less apparent than on the dorsal surface. They correspond nearly exactly to the dorsal marginals that they slightly encroach onto below. They are uniformly covered with granules, identical to those of the rest of the ventral surface, on all their surface. They are arranged in regular rows all along the adjacent borders. The pedicellariae are very rare on the plates.

The ambulacral grooves are narrow. The adambulacral plates have on their borders a row of six to seven thick spines, cylindrical, rounded and obtuse at the end. The first spine is sometimes a little shorter than the others and conical. On the ventral surface, the plates have a first row of large granules, thick and strong and a little elongated. Then, outside it, are other smaller granules, identical to the granules of the latero-ventral plates, sometimes forming two irregular rows. Outside them, the first four or five adambulacral plates have an alveolar pedicellaria whose position is variable.

The short teeth are not conspicuous. They have, on their free border, a row of about a dozen spines that are continuous with the spines of the groove and become stronger toward the end of the tooth. On their ventral surface, we see along the sutural border, a row of granules separated by a narrow interval of the corresponding row of the other tooth. Then, outside it, other granules form two irregular rows.

SIMILARITIES AND DIFFERENCES. - P. Annandalei belongs to the sub-genus Tosia and should be placed in the section Ceramaster of Verrill.

It is near Pentagonaster (Tosia) micropella Fisher of the Hawaiian Islands. It differs from this species by the much more numerous and smaller latero-ventral plates, by larger and less numerous dorsal and ventral marginal plates, by the uniform covering of the ventral marginal plates with granules without the bare area, by the dorsal plates with les numerous granules, by the slightly different armature of the adambulacral plates, by the arms thicker at the base and finally by the presence of pedicellarie on both surfaces of the disk [Fisher (06) p. 105 said that the pedicellariae of $P$. micropella are found only on the actinal surface. Then he describes them on the abactinal surface, while he does not mention them in studying the actinal surface].

I ask Dr. Annandale, Superintendent of the Museum of Calcutta to kindly accept the dedication of this species, in memory of our excellent association. 


\title{
Pentagonater (Tosia) Cuenoti, nov. sp.
}

\author{
(Pl. III, fig. 7; Pl. VI, fig. 3)
}

Station $276.7^{\circ} 11^{\prime \prime}$ Lat. N. $70^{\circ} 35^{\prime} 30^{\prime \prime}$ Long. E. Depth 1006 fathoms. One specimen.

This single collected specimen is in good condition. $R=38 \mathrm{~mm} . r=17.5 \mathrm{~mm}$.

The disk is large and bordered by two strongly concave sides. The arms are very conspicuous. They are wide at the base and triangular. They are slightly raised toward the end that is pointed. The body is rather thin. The dorsal surface of the disk and arms is covered with small plates, whose contours are nearly completely hidden by the granules that cover them. We can however distinguish the borders of the plate in the central region of the disk and the radial area and recognize that these plates are very small, round and slightly unequal. They are generally a little smaller in the central region of the disk and a little larger in the radial areas where we find a median row that extends to the end of the arm, but that is scarcely distinct from the adjacent ones. In the triangular interradial areas, the plates become very small and are confluent. Each plate is covered by five to seven small granules, small, dense and arranged without order. In each radial area, we see a large number of pores, placed irregularly. They make a kind of papularium, commencing very near the center and extending very far onto the arms, up to the seventh or eighth dorsal marginal plate. These papular areas attain a maximum width of about $6 \mathrm{~mm}$. We see equally some alveolar pedicellariae on the dorsal plates. They are more numerous in the interradial region, but also are found in the radial region. The dorsal plates extend to the end of the arms and separate their entire length the two rows of dorsal marginal plates.

The anus is distinct. It is surrounded by some plates that are slightly larger than the adjacent one. The madreporite is small, not projecting and slightly circular although its contours are a little irregular. It has very fine divergent furrows. It is located nearer the center than the edges.

The dorsal marginal plates form a border of medium width. There are thirteen on each side, plus a very small plate located below the apical plate that cannot be seen when we look at the animal from above. These plates are a little wider than long. Their dorsal surface is slightly swollen and inclined obliquely to the outside. The greater part of this surface is bare. We have seen, in the external region, only three or four rows of small granules, round, flat and dense that continue in a single row on the adjacent borders of the plates. They merge with the granules of the dorsal surface of the body that they resemble. In general, each marginal plate, or at least the first ones, have one or two pedicellariae identical to those of the dorsal surface. They are located very near their internal border.

The apical plate has a lozenge shape, with a convex dorsal surface and the distal corner truncated. This has a small spine, conical and short and, on each side, another smaller spine.

The ventral interradial areas are large. They are filled with plates whose contours are very clear. We distinguish, among them, a row parallel to the adambulacrals of rectangular plates, wider than long. These plates, which at first are nearly as long as the adambulacrals, then become a little shorter than them. They extend to the eighth or ninth ventral marginal plate. Outside them is a second row, more or less as long as wide. We still can sometimes see a third row. The rest of the surface of the ventral area is filled by irregularly polygonal plates, arranged without order. All these plates are uniformly covered with spherical granule, very dense but not exactly contiguous. The pedicellariae are not very numerous. 
There are thirteen ventral marginal plates. They correspond at first to the dorsal marginals. Then they become slightly longer and are a little in front of the latter that they overlap a little below. They are always wider than long. They have, like the dorsal plates, a bare part. But this is a little smaller than on the latter. We see constantly along their internal border, a regular row of granules to which is added sometimes a second more of less complete row, at least on the first plates. The row that is found along the adjacent border is sometimes also double. The external part of the plate is covered with three or four rows of granules. The pedicellariae are more abundant on the ventral marginal plates than on the dorsals. We have usually found three or four per plate, at least in the first. They then become less frequent.

The ambulacral grooves are very narrow and closed. The adambulacral plates are very wide and nearly square. They have, on their internal border, a comb of seven spines, flat, unequal and round at the end. Outside them, and separated by a furrow of the preceding spines, is a very regular row of three large granules. The proximal granule is generally replaced by a bivalve pedicellaria. Following, we see a last row of four smaller granules.

The teeth are small and a little elongated. They have, on their external border, about a dozen spines that are continuous with those of the groove. The proximal one is a little larger than the others. On their ventral surface are two or three more or less regular rows of granules.

SIMILARITIES AND DIFFERENCES. - Alcock repored (93 $a$, p. 80) a P. arenatus coming from Andaman at a depth of 271 fathoms. I have not seen this Pentagonaster, but the one I have just described is certainly not a $P$. arenatus. Its form recalls well that of this species, but it differs from it by the dorsal and ventral marginal plates in large part bare, by the smaller dorsal plates with less numerous granules, by the very abundant pedicellariae on the dorsal and ventral marginal plates and finally by the armature of the adambulacral plaes. I do not see any other species that can approach $P$. Cuenoti. It is completely different from $P$. pulchillus Alcock that the INVESTIGATOR has encountered. It is separated, in fact, by its larger, less numerous marginal plates, all with a bare central space, as well as by its very apparent and very numerous pores.

I dedicate this species to my excellent colleague Cuénot, Professor at the University of Nancy, well known for his anatomical studies on the echinoderms.

Pentagonaster Dőderleini, nov. sp.

(Pl. VIII, fig. 7, 8 and 9)

Laccadive Islands. Minnikoy. Depth 1,200 fathoms. One specimen.

$R=20 \mathrm{~mm} ; r=13 \mathrm{~mm}$.

The disk is large. The arms, although short, are distinct from the disk. They are very pointed. The sides of the body are profoundly concave. The two surfaces are flat. The body is rather thick.

The dorsal surface of the disk and arms is covered with small rounded plates, keeping nearly the same dimensions but becoming naturally a little smaller toward the border. They are $1.2 \mathrm{~mm}$ in diameter on average. Between the largest plates are smaller and much less numerous ones. These latter are without order in the central region of the disk. But they are arranged more regularly in small parallel rows in the five radial areas where four or five papulae are found around each plate. 
These papulae do not penetrate onto the arm strictly speaking. They stop at about $10 \mathrm{~mm}$ from the center at the middle of the second dorsal marginal plate. Beyond, the plates continue to form more or less apparent longitudinal rows. We count five of these rows at the third dorsal marginal plate and three at the fifth. A little further, there is only a single row that has completely reached the apical plate. The last plate is found at the next to the last dorsal marginals. However, the two last marginals are not in contact in the median line because they are separated by at least one row of granules. Beyond the papular areas, the dorsal plates are exactly contiguous.

The largest part of the surface of the dorsal plates is smooth and bare. We observe only a peripheral circle of very fine and flat granules that are arranged with a great regularity on most of the plates (Pl. VIII, fig. 9). This regularity is altered in the area of the marginal plates, where we distinguish two or three rows of granules without plates. Likewise, in the distal half of the arms, not all the plates have this regular circle of granules. We continue to find, in the immediate area of the marginals, one or two rows of granules. These are the ones that continue toward the apical plate, separating as I said above the two last pairs of marginal plates.

At the center of the disk, we see a very distinct anus surrounded by four plates a little larger than the adjacent ones. The madreporite is small and slightly projecting with shallow furrows. It is surrounded by five plates that are a little larger than the others. It is located nearly halfway between the center and the internal border of the marginal plates.

There are eleven dorsal marginal plates, plus an extremely small and triangular last one. We cannot see it from above. It is compressed between the apical plate and the eleventh marginal. The plates are very narrow and longer than wide. Toward the end of the arms, they become as long as wide and even a little wider than long. They are completely bare and have only very fine marks. But we fine at the periphery of each plate a border row formed of extremely small granules identical to the adjacent large dorsals with which they are continuous.

The apical plate of medium size is slight projecting, triangular and with a round top.

The ventral interradial areas extend to the union of the fourth and fifth marginal plates. The edges of the plates are masked a little by the round granules, spherical and dense that cover them. These granules are larger than those of the dorsal plates. The granules at the center of the plates are stronger than those of the border. We can however recognize easily the longitudinal and transverse rows the plates form. The first are moreover more distinct. I count four successive longitudinal rows. The last, containing only four or five plates, ends at the point of union of the first and second marginal plates. The plates of the first row, parallel to the adambulacral row, are a little wider than long. They are barely smaller than the last. Those of the following rows are nearly square. The other plates are arranged without order. In some places, I see some rare granules taller than the adjacent ones, but no pedicellariae.

There are at least a dozen ventral marginal plates that correspond nearly exactly to the dorsals. These plates are all a little longer than wide. Their surface is bare, except at the periphery where there is a row of excessively fine granules as on the dorsal marginal plates. However, these granules become a little less fine as we approach the ventral plates that are covered with slightly larger granules.

The adambulacral plates are nearly as long as wide. They have, on their ambulacral border, a comb of eight small spines, short, perfectly erect against each other, flattened and with an obtuse end. Outside them are granules usually forming three very distinct rows. The first row has three, but the first proximal granule is generally replaced by a small alveolar pedicellaria that is not larger than the adjacent granule. The four granules of the second row are a little smaller than the 
preceding. Those of the third row are still a little smaller, less regular and merge with the granules of the latero-ventral plates.

The teeth are small, united by a narrow and simply linear suture. They have on their free border a row of twelve to fifteen spines, at first identical to those of the groove, but becoming larger toward the tip of the tooth, especially the last. On the ventral surface, we see a regular row of seven to eight very large spines, parallel to the suture and very near the row formed by their congeners on the other tooth. Outside them are two other rows of smaller and less regular granules.

The color of a living individual, noted by Alcock, was salmon red.

SIMILARITIES AND DIFFERENCES. - This asteroid was reported by Alcock as Pentagonaster intermedius Perrier (93 $a$, p. 9). We can see, by the description that precedes it, that it is very different.

Pentagonaster intermedius is, in fact, a very special and clearly characterized form with very thin arms and very small marginal plates, the last ones being in contact at the median line. These plates have granules that are especially well developed on the ventrals. The integument of the dorsal surface of the body is very soft and the papular pores, very rudimentry and not numerous, are scarcely visible on dried specimens. The teeth are large with a wide suture. Verrill has created the sub-genus Litonotaster in order to distinguish P. intermedius. Up to now, this type is the only one that has particular characters. They are very different from of the species I just described and I consider it as new.

P. Döderleini has some relationship with the species of the sub-genus Plinthaster of Verrill, but it is distinguished from known species, such as P. Perrieri, nitida, compta etc. by the dorsal marginal plates that are not contiguous with their congeners toward the end of the arms. It seems difficult to me to place P. Döderleini in the sub-genus Eugoniaster, whose type is Pentagonaster Invesigatoris Alcock. It is distinguished immediately by the form of the body that has very distinct arms as well as less developed papulae and pedicellariae.

I ask Professor Dőderlelin, well known for his fine works on echinoderms, to accept the dedication of this species.

\section{Pentagonaster (Philonaster) Mortenseni, nov. sp.}

$$
\text { (Pl. IV, fig.5 and 6; Pl. IX, fig. 7) }
$$

Station $310.13^{\circ} 29^{\prime} 30$ "' Lat. N. $95^{\circ} 29^{\prime}$ Long, E. Depth 900 fathoms. Two specimens.

The specimens are very well preserved. They measure respectively $R=55$ and $45 \mathrm{~mm}, r=28$ and $23 \mathrm{~mm}$.

I shall take the large specimen as type in the description that follows.

The body is pentagonal with concave interbrachial arcs. It is elongated after the left anterior part of the arm. The arms are triangular, short and merged with disk at their base. They are slightly raised at their end that is very narrow but obtuse. The dorsal surface is a little swollen. It is even slightly depressed in the interradial spaces. The ventral surface is flat. The body is thick, absolutely rigid and very strong.

The dorsal surface is covered with plates in the form of paxillae. They are very regularly arranged in longitudinal rows in the radial areas and on the arms. They form, in the interradial 
areas, staggered oblique rows. They are separated by deep and relatively wide grooves. In the central region of the disk, the arrangement of plates is, however, irregular in a circle about $12 \mathrm{~mm}$ in diameter. Among these plates, we distinguish a centro-dorsal and five primary interradial plates located about $6 \mathrm{~mm}$ from the centro dorsal. These six plates are round and a little larger than the others. In the radial regions, the plates form at least four or five rows on each side of the median row. In these, the dimensions decrease very slowly. The median row is not larger than the adjacent ones. These plates are hexagonal and scarcely longer than wide. Their width is about 1.2 to 1.3 $\mathrm{mm}$. Outside these principal rows, the plates form some oblique rows. They become progressively smaller without, however, ceasing to be distinct and without losing their very regular staggered arrangement. It is only in the extremely small and very narrow triangular space along the first dorsal primaries that the plates become absolutely contiguous without, however, losing their outline.

The grooves separating the plates are more conspicuous and wider as the plates are larger. They are always very deep. We see five or six papulae at the bottom that are very small and regularly arranged around each plate. These papulae are seen on nearly the entire dorsal surface of the body except in the interradial areas. But I have seen them clearly only in the small specimen. Because of the depth of the grooves that separate them, we can consider the plates as being made up of an extremely short body that is cylindrical or prismatic, having on its free base a covering of granules. These granules are arranged with a very great regularity. Most of the plates have a large central granule surrounded by a circle of six peripheral granules. On the larger plates of the principal radial rows, we see very often two central granules and eight peripherals. The large central is round. The peripheral granules are slightly narrowed in the form of wedges in their internal region. These granules are not contiguous. They are separated by very conspicuous grooves. Their regular arrangement is generally not modified when the plates become smaller toward the marginals. Their size alone decreases. In the central region of the disk, where the paxillae are irregular, the granules are themselves irregularly arranged and variable in number. The six primary plates that are larger than the adjacent ones, have a larger number of granules. The centro-dorsal has a central group of five or six granules surrounded by a peripheral border of granules identical to the preceding. The primary interradial plates are covered with granules that are smaller than on the other plates. They are a little flat. They form two irregular circles surrounded by a regular border.

The dorsal plates are continuous nearly the entire length of the arm. In the small specimen, the marginal plates of the last pair alone are in contact at the median line, while in the large specimen, the two last pairs are in contact. I also notice in the latter that the apical plate of the three left anterior arms, left posterior and right posterior right, instead of forming the end of the arm, move backwards and come to lie on the dorsal side, between the last two or three pairs of dorsal marginal plates in the form of a large oval and convex plate.

The madreporite is small. It is joined with one of the interradial primaries. It is nearly the same size as the latter. It has numerous furrows, dense and irregular. The anus is very small but, however, very distinct. It is located at the border of the central dorsal plate.

The dorsal marginal plates form a rather narrow border. There are thirteen or fourteen in the large specimen and thirteen in the small. They are very small, nearly as long as wide, or a little wider than long. These plates have fine granules, dense and flat. They are arranged in more or less regular transverse files. We always recognize a very distinct marginal row. The granules leave bare at first an oval space, longer than wide, very near the internal border. It is separated from the border by a row of granules only. This space keeps nearly the same dimensions on the first four or 
five plates. But after the sixth, it increases gradually and takes a circular form. Finally, it becomes wider than long and fills nearly the entire surface of the plate, so that on the last three, it is bordered inside and on the two adjacent borders of the plates only by a single row of granules. At the same time, the bare space becomes a little convex and ends in forming a very accented ridge. In the small specimen, the first three of four marginal plates of each row are completely covered with granules. The bare space appears only in the following ones.

The apical plate is small, triangular and very projecting above in the small specimen and on the two arms of the large specimen where it has not been displaced.

The ventral interradial areas are very developed. They are covered with rectangular or square plates, small and separated by very fine furrows that even end by becoming indistinct near the ventral marginal plates. These plates form both longitudinal rows parallel to the adambulacrals and oblique rows going from the adambulacrals to the marginals. The first two rows, parallel to the adambulacral, have plates a little wider than long. In general, their separating edges cease to be distinct at the fifth marginal. The plates of the first row are nearly as wide as the adambulacrals to which they correspond very exactly. Outside these two rows, the plates become square and we can still distinguish three or four longitudinal rows. These plates form at the same time oblique rows. Their dimensions decrease gradually toward the ventral marginals where they become completely confluent. They are covered with extremely fine, very dense granules. On the first longitudinal rows of plates, they have a very regular transverse arrangement.

The ventral marginal plates are still a little narrower than the dorsal marginals. The number is not constant. In the large specimen, I count thirteen on the anterior arm and on the right anterior, arm in each of which the apical plate has not been displaced. But in the others, in which the apical plate was pushed backward on the dorsal surface, the ventral marginal plates are more numerous. I count fifteen or even sixteen of them. It seems that it is the development of these plates that has provoked the displacement of the apical plate. The ventral marginal plates are a little longer than wide. Only the first corresponds to the dorsal plate. On the arms, the ventral marginals are a little a little ahead of the dorsals. They finish by alternating with the dorsals.

In the small specimen, the first ventral marginals are a little larger than the dorsals. But toward the middle of the arms, they become a little smaller. In general, there are one or two more than the dorsals on each side.

These plates have flat granules, very dense and very fine, on the ventral surface. They become a little larger on their lateral surfaces. The border row on the dorsal surface has larger granules. These are identical to those of the dorsal marginal plates. The row that borders the adjacent sides is formed of granules that are a little larger. The internal border has one and sometime two distinct rows of granules, but these are not larger than the adjacent ones. These granules form as on the dorsal plates some more or less apparent transverse rows. The surface of the first six or seven ventral marginal plates is completely covered by granules. But on the following plates, we see a bare space near the internal border. It enlarges rapidly in a way to fill a good part of the surface of the latter plates.

The ambulacral grooves are very narrow. The tube feet are not protruding and we see only their disks.

The adambulacral plates are small, short and a little wider than long. They have on their internal border, four very short, flat spines with a round end and directed obliquely toward the groove. The first spine is wider than the others. On the ventral surface, and separated from the preceding spines by a very deep groove, is a first row of three short spines, flat and prismatic, with a truncated end. The adoral spine is generally located a little outside the two others. Following the preceding spines 
is another row of three spines with a round end, shorter than the latter and merging with the granules of the adjacent ventral plates.

The teeth are small and not projecting. They have on their free border eight or ten spines that are continuous with those of the groove. They are, like them, short and flat. The proximal spines are hardly larger than the others. The ventral surface has outside a row that continues the first ventral row of adambulacral spines. It is likewise separated from the preceding spines by a furrow. There are five to six spines. The proximal two or three are a little stronger than the others. Inside is a row of granules arranged along the suture that is very narrow and hardly visible. These granules, a little larger on the side of the mouth, are not distinguished, near the distal end of the plate, from the adjacent granules that cover the ventral plates.

Pedicellariae are extremely rare. On the bare parts of the first dorsal marginal plates we sometimes encounter one, and very rarely two small alveolar pedicellariae whose valves are extremely short. Otherwise, in their place, is a small scar. These pedicellariae do not exist on all the plates and never are found on the distal half of the arm. The ventral plates do not have them. I have seen a single pedicellaria at the meeting of a dorsal marginal and a ventral marginal. Pedicellariae are still rarer on the small specimen.

SimILARITIES AND DIFFERENCES. - $P$. Mortenseni can, in a strict sense, be referred to the subgenus Ceramaster of Verrill, but it differs from all known species by the arrangement of the plates on the dorsal surface of the disk that has very regularly arranged paxillae and whose granules are not numerous and have themselves a very regular arrangement. This species cannot be referred to the genus Mediaster. I am of the opinion to make it the type of a subgenus of Pentagonaster that I propose to name Philonaster.

I am happy to dedicate this new species to my excellent colleague and friend, Dr. Th. Mortensen, whose fine works on echinoids have the admiration of zoologists.

\section{Mediaster ornatus, Fisher}

(Pl. X, fig 4)

Mediaster ornatus, W. K. Fisher (06), p. 1046.

Station $355.29^{\circ} 49^{\prime} 54^{\prime \prime}$ Lat. N. 59 $48^{\prime}$ Long. E. Depth 492 fathoms. Three specimens.

These specimens conform very well to the description and figures of Fisher. The only important difference that I note regards the adambulacral spines of the groove. These spines, generally five, are unequal, the median being longer than the others. The arms are very slender and appear thinner than the type of Fisher. I do not believe this character is sufficient to necessitate specific separation.

In the largest individual, the pedicellariae are very frequent. But in the second, they are very rare on the paxillae in the center of the disk and the radial areas. They are scarcely to be seen in the interradial areas where the paxillae are confluent. In the small individual, pedicellariae are totally missing. 
I have represented the ventral surface of the medium specimen that gives a good idea of the form of the body. In the drawing of Fisher (06, Pl. XX, fig. 2), the only arm drawn is very short and has an extremely wide and obtuse end, while in the drawing of the dorsal surface, the arm narrows gradually.

\section{Astroceramus Fisheri, nov. sp.}

(Pl. II, fig. 2, 3 and 4)

Station $248.8^{\circ} 37^{\prime}$ N. $75^{\circ} 37^{\prime} 30^{\prime \prime}$ Long. E. Depth 224-284 fathoms. Three specimens.

The specimens are in very good condition. Their respective dimensions are, $R=58,56$ and 47 $\mathrm{mm}, r=25.22$ and $21 \mathrm{~mm}$.

The largest individual is the best preserved and I shall use it as the type in the description that follows.

The body is very flat and not thick. The ventral surface is completely flat. The dorsal surface is slight depressed in the interradial spaces while the radial parts are a little projecting. The lateral surfaces of the disk and arms that are not thin are vertical. The disk is very large and the arms are, to the contrary, relatively short. They are very developed at the base by which it is widely continuous with the disk. They taper very rapidly in the first half and much more slowly afterwards to the end that is round. The interbrachial arcs are strongly concave.

The dorsal surface of the disk is covered with numerous and very small plates. They are regularly arranged, except in the central region in a circle about one centimeter in diameter where they are irregularly polygonal. From this circle leave radial rows among which we can see a principal median row. On each side are at least three other rows. The plates of the median row are hexagonal and a little wider than long.

The first eight or ten are about $2 \mathrm{~mm}$ in width. They then become smaller and smaller. The plates of the other rows, that are also hexagonal, are nearly as long as wide. Their dimensions decrease more rapidly than those of the median row. Beyond the third row, we can sometimes distinguish a fourth row. Then the plates cease to form regular series. They become smaller as they near the dorsal marginal plates while remaining distinct from each other. The plates of the median and lateral rows continue for about $35 \mathrm{~mm}$, measured on the largest specimen from the center to the point of union of the dorsal marginal plates that is found toward the fifth or sixth pair. This union is at the fourth pair on the two other specimens.

The plates of the dorsal surface of the disk as well as the arms are very near each other. They are separated by very fine grooves, and a little wider between the plates of the median row and the first lateral row. The papulae are small and found at the six corners of the plates of the median row and the first lateral row. We rarely see them between the following rows. They do not exist in the interradial areas. Each plate has, at its periphery, a border of extremely fine granules, round, a little flat, with contiguous edges. They appear to detach easily. The remainder of the surface of the plate is bare. But this surface is not smooth. It has a kind of very delicate tread formed by small rounded impressions that are very close to each other and separated by scarcely visible ridges. This structure has been observed already by W. K. Fisher in A. callimorphus. He noted that it is not due to scars of granules that had accidentally been detached because they are always absent at the surface of the plate. It is not completely the same with A. Fisheri, because I find in some plates, and especially 
in the interradial areas near the dorsal marginal plates, small round granules, mostly only one and sometimes two on the same plate. These granules are missing on the plates of most of the dorsal surface. At least this is what I observe in the large specimen. In the two others, these granules are more abundant. They appear here and there on the border of the disk. It can have there up to three or four on each plate, but generally there is only one or two. These granules are spherical and a little larger than the marginal granules. Perhaps they uniformly cover the plates of young individuals, but I do not believe that. In adults, they exist in a constant manner on all the surface of the plates because the impressions they show are too close to correspond to broken granules. There are no pedicellariae on the dorsal surface of the disk.

The madreporite, very near the center of the disk, is very distinct although of small size. It scarcely reaches the size of the three or four plates that surround it. It is even a little smaller than the plate at the distal border with which it is contiguous. It is pentagonal, a little longer than wide. It has fine, dense radiating furrows. The anus is not distinguished from papular openings.

There are thirteen dorsal marginal plates on each side. They are very large and very apparent. In the large specimen, the fifth plate is separated from its congener by a group of three plates, then by a single plate. Beyond that, the plates are united at the median line by half or three-quarters of their length. The plates of each side generally correspond exactly. But they alternate sometimes irregularly toward the end of the arm. On one of the arms I note, at the point of union of the fifth and sixth pair of plates, a small, isolated lozenge-shaped plate, recalling the arrangement indicated by Fisher in A. callimorphus. However, on this arm, the plates of the fifth pair are contiguous, as usual, for about half their length.

The dorsal marginal plates are rectangular, a little longer than wide. They are about $4 \mathrm{~mm}$ by $3.5 \mathrm{~mm}$ in length. The keep nearly the same size to the eighth. Beyond, they decrease very rapidly and become very small. Their surface is a little irregular and mammellated. They have small, round spaced granules. They appear to detach very easily. The scar is a small circular depression. The granules do not reach the internal border of the plate. They become denser as they near the external border. Then they merge onto the lateral surfaces. They reach the line separating the dorsal and ventral plates. In addition, there is on the borders of each dorsal marginal plate, a marginal row of granules much smaller and very dense. They form a very regular border. The number of granules on the surface is variable. They are more numerous in the small specimen than in the two others. I have not observed any pedicellariae on the dorsal marginal plates.

The apical plate is small, nearly as long as wide. The proximal border is a little wider than the distal border that is round and on which we sometimes find the scar of two spines.

The ventral interradial areas, very large, are covered with plates of medium size. Their edges are not very apparent. We can distinguish two more or less regular rows parallel to the adambulacrals. The others are disposed irregularly. They become smaller and smaller. The plates of the first row are nearly as long as wide. They are first polygonal. Then they become nearly square. They are larger than the adambulacrals. Three of them correspond to nearly two of these. They extend to the point of union of the fifth and sixth ventral marginal plates. The plates of the second row are smaller. They remain nearly as long as wide. But their form is very irregular and sometimes pentagonal. The other plates are also irregularly polygonal. These plates are separated by very fine lines. They have on their surface some granules that never cover them completely. These granules are very large and projecting. In addition, there is always a very regular border row formed by smaller, contiguous granules. The plates of the first row that immediately follows the adambulacrals have near their middle, in a very constant way, a small alveolar pedicellaria identical to the Fisher observed in A. callimorphhus. The valves are fan-shaped. Their convex 
border has small teeth. These pedicellariae are also seen on the plates of the second row, but they are much less numerous. They can also be found on other latero-ventral plates, but they are never very abundant.

There are fourteen ventral marginal plates. They correspond to the dorsal marginals in the interbrachial arcs. But on the arms, they alternate irregularly with them. The last are even shorter than the dorsals. This explains why the ratio is greater than one. The first four or five plates are as long as wide, sometimes even a little wider then long. They then become longer than wide. The last are still narrower. The granules are arranged as in the dorsal marginal plates, i.e., they are round, non-contiguous and more or less abundant. They do not reach the internal border, but are especially developed in the external part of the plate. There is always a very regular border row of smaller granules. Pedicellariae are completely missing.

The ambulacral grooves are narrow. The small tube feet end in a large disk. The adambulacral plates are rectangular, a little wider than long. They have on their free border a comb of generally five, and rarely six small spines that are cylindrical, divergent and directed obliquely toward the groove. The middle spines are a little longer than the others. The first plates on the ventral surface have a row of three erect spines, short, enlarged and flat with a truncated end. The proximal spine is shorter than the others, hardly more than a granule. The following plates have two spines. Outside them is a row of six to eight granules, irregularly arranged. They are hardly larger than the granules of the adjacent latero-ventral plates.

The teeth are small. They have on their free border a row of spines that continues those of the groove. They become longer and stronger toward the end of the tooth. The ventral surface has, along the suture, a regular first row of seven to eight granules. The proximal ones are elongated into small spines.

SIMILARITIES AND DIFFERENCES. - The genus Astroceramus was established by W. K. Fisher to classify a new asteroid from the Hawaiian Islands. The species collected by the INVESTIGATOR is very close to $A$. callimorphus, but it differs immediate by the respective differences of the disk and arms. In A. callimorphus, in fact, $R=32 \mathrm{~mm}$ and $r=24.5 \mathrm{~mm}$. I.e., the disk is small and the arms are comparatively long, while it is the contrary in A. fisheri. The dorsal plates of the disk, not numerous and located without order in the species from the Hawaiian Islands, are very numerous and arranged in regular radial series in my species. The ventral interradial areas are larger and the latero-vental plates are more numerous and smaller. The dorsal and ventral marginal plates are small and become contiguous in the dorsal median line of the arms after the fifth pair in A. Fisheri.

I dedicate this species to Walter K. Fisher, who has made numerous investigations on the echinoderms of the Pacific and has published a very fine work on the asteroids of the Hawaiian Islands.

\section{CIRCEASTER, nov. gen.}

The genus Circeaster belongs to the family Antheneidæ, It is separated from all known forms by a conspicuous difference in size between the dorsal plates of the disk and arms. In fact, the dorsal surface of the disk is covered with very small plates, while the plates on the arms are much larger. In addition, in the two known species, there is no transition between these two kinds of plaes. The enlargement is made very abruptly at the base of the arms. All the plates are surrounded 
by a regular circle of granules. The ventral surface has very large valvular pedicellariae, recalling those of Anthenea and Hippasteria and that are especially developed on the adambulacral plates. The elongated arms are very distinct from the disk.

The genus Circeaster is represented in the collections of the INVESTIGATOR by two species of large size. I do not see, among the Antheneidæ, any genus to which we can better relate it.

Circesaster Marcelli, nov. sp.

(Pl. IV, fig. 1 and 2; Pl. VI, fig. 1)

Station $320.7^{\circ} 23^{\prime}$ Lat. N. $75^{\circ} 14^{\prime}$ Long. E. Depth 1,653 fathoms. One specimen.

The specimen is in very good condition although two arms are incomplete or broken.

The dimensions of the large ray cannot be indicated exactly because of the curve of the arm that is greatly raised from the dorsal side. It is about $120 \mathrm{~mm} . r=45 \mathrm{~mm}$.

The disk is completely distinct from the arms. It is pentagonal, with the sides vertical or slightly convex when regarded by the dorsal surface. The dorsal surface and the ventral surfaces are parallel and the borders are vertical. The diameter of the disk is $85 \mathrm{~mm}$ and its thickness is about $12 \mathrm{~mm}$. The thin arms are clearly separated from the disk, especially when we look at it from above, not only because the base is narrow and not continuous with the disk, but also because the plates that cover the dorsal surface are completely different from those of the disk. They measure 22 to $24 \mathrm{~m}$ $\mathrm{n}$ width at the base. They taper gradually to the end that is pointed. The lateral surfaces of the disk and the arms are vertical and bordered by the dorsal and ventral marginal plates. The arms appear delicate and brittle.

The dorsal surface of the disk is covered with small plates, irregularly polygonal with rounded corners. Their diameter can reach $2.5 \mathrm{~mm}$, but is generally is not greater than $2 \mathrm{~mm}$. In the central region of the disk, the dimensions of the plates are very uniform. However, we can recognize among the larger plates, other small and much less numerous plates. Toward the periphery of the disk and as we approach the interbrachial arcs, the plates become smaller. Each of them has, at its periphery, a very regular circle of fifteen to twenty contiguous granules, very large, flat, and square with rounded corners. This border is never missing. The rest of the surface is bare and perfectly smooth. It hardly so on some very rare plates. We find by chance a small granule. The borders of the plates touch. They leave free only some four or five openings of papulae that are small and short. They are seen only in the radial areas on a width of about one centimeter. There is not the least indication of pedicellariae. The plates have no regular arrangement either in the central region or toward the periphery of the radius.

At the line of the separation of the disk and the arms, the plates become abruptly much larger. They take a polygonal shape, often pentagonal. The line of separation between these two kinds of plates is very clear. It marks the boundary between the disk and the arms. The largest of these plates that are found at the base of the arms reach and exceed $4 \mathrm{~mm}$ in width. They are sometimes as large as the dorsal part of the corresponding marginal plates. At first they are enlarged transversely. Then they become as wide as long at the same time that their size decreases a little. They are moreover unequal. Toward the middle of the arm, they are still larger than the plates of the disk. At this point, they are not much smaller than the dorsal marginal plates. Beyond twothirds of the arm, their size decreases greatly and they become very small. At the base of the arm, there are only two plates on the same transverse line. Then we find three. They are moreover 
arranged without the least regularity and do not form a series, neither longitudinal nor transversal. All these plates are surrounded by a very thin border of excessively small granules, flat and dense, that occupy only an extremely reduced part of their surface, which remains bare and perfectly smooth.

The madreporite is round and very small. Its diameter is scarcely $3 \mathrm{~mm}$. It is located nearer the center than the border. It remains at the level of the adjacent plates. It has fine furrows on its surface. In the central region they are irregularly arranged. Toward the periphery, they are radial. The very small anus is scarcely distinct from the nearby pores.

The dorsal marginal plates form on the dorsal surface of the body, a border that is neither large nor very apparent. I count thirty-eight on each side from the middle of the interbrachial arc to the apical plate. Each side of the pentagonal disc is bordered by ten plates. There are thus thirty-five along each arm. These extend onto the vertical surface of the disk and the arms without reaching exactly the middle of the surfaces. The rest is filled by the ventral marginal plates. On the arms, these generally alternate with the dorsals. Seen from the dorsal surface, the dorsal marginal plates are square or sometimes pentagonal because they can have an internal corner. The three first plates of each series are nearly as long as wide. But the fourth, the fifth and the sixth, i.e., the two last plates of the disk and the first of the arm, are sensibly wider than long and larger than the others, especially the fifth and the sixth. Then the plates become as long as wide. At the same time, their size is gradually reduced on their external border. The dorsal marginal plates have very small conical spines, kinds of pointed granules that detach easily and whose scar forms a small pit. There are about fifteen of these spines on each plate the border the disk. They gradually decrease on the plates of the arms. The rest of the surface of these marginal plates is bare. We see only a very thin and extremely regular border of very fine granules, flat and contiguous. Thee granules are smaller than those that are found at the periphery of the plates of the dorsal surface of the body.

The apical plate is small, round. It has two thick, short spines.

When we look at the disk from the ventral side (Pl. VI, fig. 1), we see that the dorsal marginal plates slightly overlap the ventral marginals. The line formed by the external border of the latter is vertical or very slightly concave. The separation of the disk and the arms is thus less marked and less abrupt on the ventral surface than on the dorsal surface.

The ventral interradial areas are filled with numerous polygonal plates. They are separated by extreme fine grooves. They form at the same time longitudinal rows and oblique rows that are more or less regular. These areas are nearly limited to the disk. Only the first row of plates, parallel to the adambulacrals, continues on the basal part of the arms. But it does not pass the tenth ventral marginal plate. The plates of this first row are rectangular, narrow, nearly two times wider than long. Three of them correspond to nearly two adambulacral plates. Outside this first row, we can still, at least at some points, distinguish a second row of plates wider than long, but that is not very conspicuous. The other plates are irregularly polygonal. They form, with the plates of the two preceding series, more or less regular rows going from the adambulacrals to the marginals and in which the plates become smaller as they approach the latter. All the latero-ventral plates are covered with very large, round granules, dense but exactly contiguous. We see central granules, more projecting and larger and a peripheral border of granules, smaller, less projecting and less apparent. Near the marginal plates, some granules are raised a little and become conical. Here and there, we can recognize, toward the border of a plate, a very small alveolar pedicellaria with very short valves. But these pedicellariae are very rare. I have seen scarcely about a dozen in each area. Finally, on two plates, I have found a valvulate pedicellaria similar to those that I have just reported, but smaller. 
The number of ventral marginal plates is like that of the dorsals, but they correspond to them only on the disk because, on the arms, they alternate more often with them. The first five plates that border the disk, from each side of the median interradial line, are relatively large. They are a little wider than long. The width decreases moreover a little from the first to the fifth, while the length increases so that this last plate is nearly as wide as long. On the arms, the size of the ventral marginal plates decreases gradually. These plates remain nearly as wide as long. All of the ventral marginal plates are covered with granules that are raised into a small cone with a pointed end. They extend uniformly on the entire surface. At the periphery, we see a regular border of small, flat granules. I do not see pedicellariae on these plates.

The ambulacral grooves are partly open on the disk and more or less completely closed on the arms. The tube feet end in a very large disk. The adambulacral plates are very large, square or a little wider than long. They have, on their free border, a comb of seven or eight short, thick spines with a blunt end. The proximal spine is a little stronger than the others. Its end is round, while the distal spine is instead conical. The others are all the same height.

Outside the preceding spines, and separated by a more or less deep furrow, is a large valvulate pedicellaria. It is very elongated and occupies nearly all the length of the plate, at least in the first plates where it is separated from the distal border by only one granule. On the following plates, the pedicellaria is shorter. It is followed by two, or even three granules that extend to nearly the distal border of the plate. From the middle of the arms, the pedicellaria occupies only half the length of the adambulacral plate. Outside, the rest of the surface of this latter is occupied by granules identical to those of the latero-ventral plates. They form three very distinct rows.

The teeth are small, triangular, backed by their large side. On their free border, they have a row of spines that are at first identical to the spines of the groove that they continue. They become a little larger toward the end of the tooth. The ventral surface is filled with granules. Some form a regular row along the suture. They become larger toward the end of the tooth. The others form two or three more or less apparent rows.

I dedicate this species to my son Marcel.

\title{
Circeaster Magdalenæ, nov. sp.
}

\author{
(Pl. V, fig. 1, 2 and 3; PI. VI. fig. 2)
}

Station $192.15^{\circ} 11^{\prime}$ I.at. N. $72^{\circ} 28^{\prime} 15^{\prime \prime}$ Long. E. Depth $912-931$ fathoms. One specimen.

This specimen is in an excellent state of preservation. It is large. $R$ is about $150 \mathrm{~mm} . r=45$ $\mathrm{mm}$. The value of $R$ cannot be evaluated in a precise manner because of the form of the arms that are raised.

The disk is large and thick, bordered by concave sides. It is continuous insensibly with the arms that are strong, wide and thick at the base. They taper gradually to the end that is pointed. The lateral surfaces of the disk are a little oblique. The ventral marginal plates overlie the dorsal marginals. The dorsal surface of the disk has some folds. The ventral surface is convex and the arms more or less curved. Three arms are more or less shorter than the others. They perhaps have been regenerated but there is no trace of this. The whole animal is robust and strong.

The dorsal surface of the disk is covered with unequal, irregularly polygonal plates, rounded and small. The diameter hardly reaches $2 \mathrm{~mm}$ in width. Among these plates that all are nearly the 
same size, we recognize also some other smaller ones. Toward the border of the disk, in the interradial spaces, the size decreases gradually and the diameter is hardly $1 \mathrm{~mm}$. All these plates are arranged without any regularity. They are contiguous and have between them some very fine openings by which pass the papulae that are moreover not apparent in the specimen. There are four or five pores on the periphery of each plate. These pores are seen especially at the base of the arms. They are less numerous than in C. Marcelli. The outlines of the plates are well indicated. Each of them has at the periphery a border of granules, flat, contiguous and very fine. All these arrangements are, up to now, little different from those that we have seen in $C$. Matcelli, but what clearly distinguishes the two species is that, in C. Magdalena, the surface of the plate, instead of being smooth and bare, always has two to four round granules per plate that are a little larger than the peripheral granules (Pl. V, fig. 2). These granules ae completely constant. Toward the base of the arm we see in addition some rare and very short alveolar pedicellariae.

On the arms, the plates become much larger, like those in $C$. Marcelli. But there is no transverse line of demarcation between the two kinds of plates as we have seen in the preceding species. The small plates of the disk ate continuous on the basal part of the arms in covering a narrow triangular and pointed area 15 to $20 \mathrm{~mm}$ in length. On each side of it is a row of large plates. These latter are always a little smaller than in $C$. Marcelli. None of them reach the size of the corresponding marginal plates, but they have the same characters as in the latter species. Their surface is absolutely smooth and bare. They have only a regular border of extremely small granules.

The madreporite, located nearer the center than the border, is small and slightly projecting. It is elongated transversally and its contour is irregular. It measures $4.5 \mathrm{~mm}$ in the greatest width. Its extremely fine furrows are directed without order in all directions. It is larger than in the preceding species and is nearer the center. The anus is very small.

There are thirty-six dorsal marginal plates on each side. They are a little larger and stronger and make a thicker border than in $C$. Marcelli. The first three are very small. The fourth is a little larger. The fifth and sixth are still larger. Then the size decreases very gradually. They correspond very exactly to the ventral marginals in the interbrachial arcs and on the first part of the arms. Then they alternate, more or less irregularly with the latter in the second half of the arms. The regular arrangement of the dorsal and ventral marginal plates is moreover a little disturbed on three arms. They have in one place some irregularity in their form, width as well as size of some marginal plates. There must have been at these place a repaired break or regeneration. The successive plates are, moreover, not as disturbed.

Seen by the dorsal surface, the dorsal marginal plates have a nearly square form, except the fifth and sixth that are a little wider than long. On these arms, they often become pentagonal as a result of breakdown of their internal border into two small sides limiting an obtuse corner. The dorsal surface of these plates is continuous with the lateral surface by a round border. On their external border, the marginal plates have, as in C. Marcelli, small conical spines, about twenty per plate. They form small oblique rows that are continuous on their lateral surfaces. The rest of their surface is bare. I have seen no pedicellariae.

The apical plate is small, conical. If forms a very conspicuous projection. It is ended in a short spine, rounded at the end.

The ventral interradial areas are large (Pl. V, fig. 3; Pl. VI, fig. 2). They are continuous with the basal part of the wider arms more broadly than in C. Marcelli. The plates have an arrangement similar to that I have described in the latter species. But the longitudinal and oblique rows are still less apparent. They row immediately outside the adambulacrals has plates at first rectangular and wider than long. Then they become irregularly polygonal. They are a little larger than the 
corresponding plates of $C$. Marcelli. They go up to the eighth ventral marginal plate. The following irregular row continues to the sixth marginal plate. The plates that cover the rest of the ventral areas are irregular. They become smaller and smaller toward the ventral marginals. All these plates have the same covering of granules as in C. Marcelli, but they are distinguished immediately by the presence of numerous valvulate pedicellariae, very apparent and occupying a good part of the width of the plate. The presence of these very abundant pedicllariae that we find even on the plates adjacent to the ventral marginals, give the ventral interradial areas a very characteristic appearance.

The first ventral marginals are a little square. We do not see between the first plates that border the sides of the body and the following ones that continue onto the arms, differences that I reported in C. Marcelli. On the arms, the plates become a little longer than wide. They do not correspond exactly to the dorsal plates. They have, in their arrangement, some irregularities that are more marked than on the dorsal plates and that we can see in the arm shown in Pl. VI, fig. 2. The two or three first plates of each series usually have a small valvulate pedicellaria oriented transversally.

The adambulacral plates are large. They have in the groove a comb of eight to nine spines, flat, dense against each other, parallel to each other and all having nearly the same length. On the ventral surface of the plate and separated from the preceding spines by a furrow, is a large valvulate pedicellaria, generally a little shorter than in $C$. Marcelli and followed by two or three granules (Pl. V, fig. 3). Outside are granules forming nearly four or even five rows. But these are distinct only on the proximal plates.

The teeth are a little shorter than in $C$. Marcelli. They have on their free border a row of twelve to thirteen spines that continue those of the groove. On the ventral surface, we note a row of granules along the suture and, outside, some irregularly arranged granules.

SIMILARITIES AND DIFFERENCES. - It has appeared necessary to me to separate C. Marcelli and C. Magadlena. These two species are very close in general structure. But they have however important differences. C. Magdalena is very robust. The disk, thick and strong, continuous broadly with the arms that are also very strong, while in $C$. Marcelli, the arms are thin, delicate, and completely distinct from the disk that is nearly circular and less thick. The first species is distinguished in addition by the dorsal plates of the disk, whose surface is always filled with granules and that are continued on the base of the arms in forming a narrow triangular area instead of being separated from the arm plates by very clear transverse line. The latero-ventral plates have abundant valvulate pedicellariae. The dorsal marginal plates are also larger and have four or five rows of granules outside the valvulate pedicellariae. The teeth are a little smaller than in $C$. Marcelli. Finally, the apical plate is ended by a single spine while it has two in the latter species.

I dedicate this species to my daughter, Madeleine.

\section{LYDIASTER, nov. gen.}

The body, solid and robust, has the form of a star. The disc is continuous by its angles with the arms that are elongated and strong and whose length is approximately equal to the diameter of the disc. The dorsal surface of the disk is covered with small plates, each having in addition to the granules, an alveolar pedicellaria with spatulate valves that can fall back into depressions on the 
surface of the plates, as in the salt-cellar pedicellaria. On the arms, the plates become a little larger, while the pedicellariae disappear. The granules also become less abundant and disappear in their turn, so that the surface of the plates is bare. But they always retain a marginal border. The plates of the arm end thus by being different from those of the disk. But the transformation is gradual and there is not a distinct line of demarcation between the two kinds of plates. All the plates of the dorsal surface of the disk and the arms are arranged irregularly. They do not form very apparent series. The latero-ventral plates are covered with granules. Each of them also has a pedicellaria. The same pedicellariae are found also on the dorsal and ventral marginal plates as well as on the adambulacral plates. The teeth are small and at the level of the latero-ventral plates. There is an anus. All the plates have very distinct edges. They are not hidden under the integument.

The genus Lydiaster greatly recalls the genus Circeaster that I describe above by its appearance and size. The only species of the genus Lydiaster recalls $C$. Magdeleno. There is, in fact, a difference between the dorsal plates of the disk and the arms, but here the transition is gradual and without a line of abrupt demarcation at the base of the arms as in the preceding genus. The valvulate pedicellariae of Circeaster are replaced in the genus Lydiaster by alveolar pediicellariae. In the single species known, they are found, nearly without exception, on all the plates of the body.

The genus Lydiaster is very near the genus Antheniaster. But it is immediately distinguished by the great development of the arms, by the absence of a membrane on the surface of the body, and by the importance and form of the pedicellariae etc.

Lydiaster Johannæ, nov. sp.

(PI. III, fig. 9; Pl. VII, fig. 1 and 2; Pl. VIII, fig. 10)

Station $333.6^{\circ} 31^{\prime}$ Lat. N. $79^{\circ} 38^{\prime}$ Long. E. Depth 401 fathoms. Four specimens.

The specimens have very similar dimensions. $R=120$ to $125 \mathrm{~mm} ; r=39$ to $41 \mathrm{~mm}$.

The disk is pentagonal with strongly concave arms. At its angles, it is broadly continuous with the arms. The arms are thick at the base but, however, very distinct from the disk. They decrease gradually to the end that is thin. The entire animal is rigid and robust. In all the specimens, the arms are more or less raised toward the top. The makes measurement of their length not very precise. The border formed by the dorsal and ventral marginal plates is wide and very apparent. The dorsal surface is a little convex. The ventral surface is nearly flat. The disk is not very thick. It measures about $14 \mathrm{~mm}$ in the center.

The dorsal surface of the disk is covered with small pentagonal or round plates. They are 2.5 $\mathrm{mm}$ in diameter in the central region and radial parts. They become a little smaller approaching the marginal plates. They are arranged without any order. Their borders always touch while leaving outside each of them four or five very apparent openings by which leave the very developed papulae. These plates have on their surface a few non-contiguous granules that are very large, round and often of two different sizes. At their periphery, we see a very thin border of fine granules, dense, nearly flat but very distinct. Each plate has, in addition, in its middle, a beautiful, very apparent alveolar pedicellaria whose values are very narrow at the base but then enlarge abruptly into a fan. Their convex free border has about a half dozen teeth. When the valves are united and closed, these teeth engage with one another. The pedicellaria then forms a very apparent projection. On each side we see two depressions on the surface of the plate. These receive the values when they are depressed. This arrangement recalls thus completely that which know in the salt-cellar pedicellariae. We very frequently see on the plates the following arrangement: In the middle of a 
plate are two large round and projecting granules, separated by a narrow interval. At the base of this is the pedicellaria whose valves, in coming together, bring their edges in the same plane as the line which connects the centers of two granules, while the two depressions in which the valves can be lowered are perpendicular to this line (Pl. VII, fig. 2). Between these two central granules and the border that form the very fine peripheral granules, we see some other isolated secondary granules. These never completely cover the surface of the plate. A more or less large part of the plate remains bare.

The plates of the dorsal surface of the disk is continued on the arms. But they gradually lose the pedicellariae and the granules of their surface so that only by a thin border of peripheral granules is preserved. The loss of the granules and pedicellariae is in a more or less rapid manner according to the specimen. In two of them, this loss is complete in the first half of the arm while it occurs only beyond this half in the others. These plates are arranged without order. However, in the two individuals where the granules and pedicellariae are lost more rapidly, we see a certain tendency for the formation of two or three series more or less apparent in the middle of the arms. We can also observe that the plates, whose surface is nearly flat on the first two-thirds or threefourths of the arm, become a little convex and swollen toward the end. This character is more marked in the two specimens where the plates keep their granules and pedicellariae for a longer time. Finally, in these two same individuals, some plates at the base of the arms are a little larger than those of the disk, while in the two others, there is never an appreciable difference in the size of the plates.

The madreporite, of medium size, is round and a little projecting. It has numerous radiating furrows, especially visible in the periphery. It is located nearer the center than to the dorsal marginal plates. The very small anus is scarcely distinct from the adjacent pores.

There are thirty-three to thirty-five dorsal marginal plates on each side. The first three are nearly square. Then the width increase gradually to the sixth or seventh that are sensibly larger than the preceding. Then the length decreases so that the ninth and tenth plates are nearly the same size as the first three. Beyond, the size decreases very slowly on the three-quarters of the arm length. It is only in the last fourth that the plate becomes rapidly very small. The marginals are especially developed in the dorsal part. The lateral surfaces of the arms are not very tall, the plates not reaching a great thickness on these surfaces. In general, the dorsal marginals do not coincide with the ventrals. There is sometimes concordance and sometime alternation at different places of the same arm. The first plates of each series, usually the first four, are covered on all their surface with fine granules, round, non-contiguous although very dense in the external region of the plate, and separated more from each other in the internal region. On the following plates, the granules become less and less dense in the latter region. Finally, they are seen only in this external and rounded region of the plate. This decrease of the granules on the marginal plates occurs at the same time as those I reported above on the dorsal plates of the arms. In the two specimens where the granules are lost rapidly on these plates, those of the marginal plates also decrease more quickly than in the other two. In the middle of these granules, we can distinguish, at least in the first plates, some pedicellariae that also are lost gradually. The first two or three plates can each have four or five. The following four or five, one or two. Beyond the tenth plate, pedicellariae are rare or completely absent. Whatever their row, the dorsal marginal plates always have on their border, a very regular row of granules, finer than those of the surface.

The apical plate is small, obtuse, a little wider than long. It has on the distal border the scars of two spines. 
The ventral interradial areas are covered with polygonal plates, irregularly arranged in more or less distinct rows. Some are parallel to the adambulacrals, others oblique and going from the adambulacrals to the ventral marginals (Pl. III, fig. 9; Pl. VIII, fig. 1). Outside the adambulacrals, and parallel to these plates, we see a very regular first row of plates, a little shorter than the adambulacrals and more or less alternating regularly with them. These plates are continuous on a good part of the length of the arms. They pass the fifteenth marginal plate. Outside, we can still distinguish a second and even a third row. But, beyond, these plates that become smaller and smaller as they approach the end of the areas, no longer form parallel rows. The contours of all these plates are very distinct. Their entire surface is covered with round granules, sometimes very slightly conical, distributed irregularly except at the periphery where they are arranged in a very regular border row. The granules of this border are nearly the same dimension as the others or scarcely smaller. Finally, in the middle of the plates, we see a beautiful pedicellaria, nearly as developed as those on the proximal plates of the dorsal surface. They become smaller on the others. All the plates of the ventral areas have a pedicellaria, except some of the smallest plates adjacent to the border of the interbrachial areas.

The number of ventral marginal plates is the same as the dorsals. Sometimes they correspond exactly, as generally for the first; sometimes they alternate more or less regularly with them. They form a very large border. Their form is a little square. Their surface is covered with granules identical to those of the latero-ventral plates, with a border a little finer. After the first third of the arm, the granules separate from each other. They gradually become less numerous and end by disappearing completely on the last third or last fourth, except those that form the border row. We also find on each plate, three or four small pedicellariae that disappear at the same time as the granules.

The ambulacral grooves are of medium width. The tube feet end in a well-developed disk. The adambulacral plates are large, wider than long. They have on their ambulacral border, a comb of seven to nine enlarged spines, flat, very short, parallel to each other and dense. Their end is truncated. Outside these spines, and separated from them by a more or less accentuated groove, we see on the ventral surface of the plate, a row of three or four spines, strong, thick and short, among which is a pedicellaria. Generally, there is first a proximal spine, then the pedicellaria, then a large conical spine, and finally a last more or less smaller spine. The structure of the pedicellaria is very interesting. Two values are rarely so different from each other. Generally, the external valve is constituted as usual. It is in the form of a fan with the free border crenulated. To the contrary, the internal valve is most often like a simple spine whose end is flat but not enlarged. It sometimes has some indications of lobes. We can thus see the transition between the simple spine and the well-formed valve. The rest of the ventral surface of the plate is covered with granules, round, dense, placed irregularly except on the three proximal borders, distal and external, where they are dispersed in a regular border. They take even the form of short, cylindrical spines, a little enlarged at the end with some small irregular lobes. Some granules of plates adjacent to the adabulacrals also have this same form (Pl. III, fig. 9).

The teeth are very small. They have on their free border fifteen spines continuing those of the ambulacral groove, but stronger than those, especially the proximal two or three. These spines are dense and pressed against each other, which gives them a flat form. On the ventral surface of the teeth, we see, parallel to the external row, a little less regular row of four or five flat, spaced spines. Among them is a pedicellaria with more or less differentiated valves. This row is separated from the external spines by a furrow. The rest of the surface is covered with cylindrical granules or very 
short spines whose truncated and enlarged end is divided into small round lobes. Some of these spines form a row along the suture. The others are irregularly distributed.

Evoplosoma Augusti, nov. sp.

(Pl. XI, fig. 1, 2 and 3)

Station 333. $6^{\circ} 31^{\prime}$ Lat. N $79^{\circ} 38^{3 / 4^{\prime}}$ Long. E. Depth 401 fathoms. One specimen.

This specimen is in excellent condition and of very large size. $R=$ about $110 \mathrm{~mm} ; r=42 \mathrm{~mm}$.

The disk is very large, very thick. The dorsal surface is slightly convex. At the periphery, the body becomes sensibly thinner. The border that together forms the dorsal and ventral plates is less thick that the rest and edges are thin. On the dorsal surface, the disk is separated from the marginal plates by a depression that continues on the arms where it gradually disappears. That is probably due to shrinking of the tissues in alcohol. The sides of the disk are concave. The interbrachial arcs are wide. The arms originate on the disk by a very wide base. They taper, at first very quick in the proximal third, then more slowly to the end that is very narrow but obtuse and not tapered. The width of the arms at the base, measured from the middle of an interbrachial base to another, is about $50 \mathrm{~mm}$. Toward the tenth dorsal marginal plate, the width of the arm is $22 \mathrm{~mm}$. It falls to 14 $\mathrm{mm}$ toward the twentieth plate. The integument is thick and resistant. The animal is completely rigid. In the single specimen that I have before my eyes, the arms are more or less strongly curved and raised toward the dorsal side.

The dorsal surface of the disk is covered with small plates, round and unequal. It is very difficult to recognize the contours that are hidden by the integument. Their diameter varies between 2 and $3 \mathrm{~mm}$. Each plate has, in its middle, a large tubercle, elongated and conical with a blunt point. Sometimes we see two or three tubercles on the same plate. Outside is found a circle of ten or fifteen small granules, round, contiguous and dense. The contours are a little obscure and follow exactly the edge of the plate. Between this peripheral circle and the central granule is a bare space. The edges of the plates and the granules become more apparent toward the periphery of the disk. At the same time, the tubercles elongate and develop to become small spines. Between the plates with large tubercles, there are others that are smaller, lacking tubercles and having only the peripheral circle of granules reported above, which leaves the center of the plate bare. Even in the smallest plates, the circle occupies the entire plate without leaving a free central space. On the arms, the plates have the same arrangement as on the disk.

Around the periphery of the large plates, we see pores through which the large and wide papulae pass, on the disk as on the arms. These papulae are numerous and we count three or four around each large plate. These have the same dimensions as the large conical tubercles. They have nearly the same form and same color. It is difficult to distinguish them other than by their firmness. Finally, the plates of the disk dorsal surface and the arms can have bivalve pedicellariae embedded in a depression. The valves, in the form of a spatula, are narrow at the base and large toward the free border that often has small lobes. These pedicellariae are identical to those that Fisher reported in E. forcipifera. They are particularly numerous in the area of the border of the disk in the interradial areas.

The madreporite is slightly oval, rather small because its large diameter is hardly $4 \mathrm{~mm}$. It is slightly convex, with very dense radiating furrows. It is nearer the border than the center of the disk. 
The dorsal marginal plates are very small. The border that they form is narrow and not important. As I noted above, they are separated from the disk by a depression that continues onto the arms where it gradually disappears. There are about forty-five plates on each side of the arm. In the base of the interbrachial arcs, they are nearly square and measure 2.5 to $3 \mathrm{~mm}$. They keep nearly the same size in the first third of the arms. Then they become small and in the last third of the arms they are extremely reduced. These plates have a variable number of obtuse small spines or elongated tubercles identical to those that are seen on the peripheral dorsal plates. They appear to be detached very easily. They usually form two small groups. One has two to four spines near the upper border of the plate. The other has three to six near the lower border. Each plate has, in addition, one or two spatulate pedicellariae. It is surrounded by a circle of a granules, a little larger, more distinct and less dense than on the other plates of the dorsal surface. However, the dorsal plates that are immediately contiguous to the dorsal marginals have, on their external border, a row of very developed granules that touch the internal row of granules of the marginal plates that exactly follow the contours.

The apical plate is small and triangular. It has no trace of spines.

The ventral interradial areas are very developed. They extend very far toward the end of the arms. They are covered with numerous small plates, arranged both into longitudinal series parallel to the adambulacrals and oblique series extending from the adambulacrals to the marginals. The first row, parallel and contiguous to the adambulacrals, is very regular and very apparent. It extends to the area at the end of the arms. The plates that constitute it are a little wider than long. They are nearly the same size as the adambulacrals. They sometimes correspond and sometimes alternate with them. Outside this first row, we can recognize a second, still very regular but less apparent, and a third, still less distinct than the second. The other plates no longer form rows parallel to the preceding. But they are part of the oblique rows that extend from the adambulacrals to the marginals, and in which the size decreases as they near the latter. The intitial plates, contiguous to the adambulacrals, are 3 to $4 \mathrm{~mm}$ in width and $2.5 \mathrm{~mm}$ in length. The adjacent plates of the ventral marginals are only 1.5 to $2 \mathrm{~mm}$ by 1 to $2 \mathrm{~mm}$. The rows are not very apparent in the proximal regions of the ventral areas immediately outside the teeth. We see sometimes a single row, sometimes a double row of alternating plates ending at the initial one.

All the latero-ventral plates have elongated granules. Some remain isolated in the central region of the plate. Others form a peripheral border. On the adjacent border of the plates of the row that are immediately after the adambulacral, the granules that are elongated into very small spines have a tendency to be arranged in parallel files and opposite their congeners. We still find traces of this arrangement on the plates of the following row. Nearly all the latero-ventral plates have, independently of the granules, an alveolar pedicellaria with widened and crenulated valves on their free border, identical to those of the dorsal surface. These pedicellariae become rarer on the small plates near the ventral marginals.

These latter form a very narrow border. They correspond to the dorsal marginals, but they are sensibly thinner than the later. They do not measure more than $3 \mathrm{~mm}$ in height on their lateral border at the base of the interbrachial areas. Seen by the ventral surface, they are square or sometimes a little wider than long at the base of the arcs. Their size decreases like those of the dorsal marginals, i.e., very slowly at first, then more rapidly as they approach the end of the arms. Each plate has a peripheral border of granules identical to those of the latero-ventral plates. But on the external border of the plate that touches the corresponding dorsal plate, these granules become larger and more projecting. They thus are stronger than those of the dorsal marginals. The granules that extend along the adjacent border of the plates are arranged very regularly. They even have a 
tendency to intersect with those of the adjacent plate. On the rest of their surface, the plates have non-contiguous granules arranged without order. Toward the external border of the plate, they are elongated into small obtuse spines like those on the dorsal marginals. But here the spines form only one group of four to ten spines. Finally, among these granules, we find on each plate a pedicellaria, sometimes two, on those at the base of the interbrachial arcs.

The ambulacral grooves are not very wide. Only one is open. The tube feet are thick and end in a disk with a diameter greater than that of the tube.

The adambulacral plates have, in each groove, a comb of eight scaly spines, flat in the proximal-distal direction, parallel and very dense to each other with a truncated end. On the ventral surface, each plate has first one or two cylindrical spines, strong and obtuse and in a constant manner an alveolar pedicellaria. Outside, we find a variable number of spines arranged very regularly in a semi-circle that roughly follows the external border of the plate. Finally, a second row of two or three spines is added to the preceding.

SIMILARITIES AND DIFFERENCES. - The species collected by the INVESTIGATOR appears to me to find its place in the genus Evoplosoma described by W. K. Fisher after an asteroid discovered at the Hawaiian Islands at a depth of 682 to 508 fathoms. But the integument that covers the body is here much thinner than in E. forcipifera. The single specimen given to me is noticeably larger than the type of the genus that measured only $R=56 \mathrm{~mm}$ and $r=25 \mathrm{~mm}$. All the characteristics of the genus Evoplosoma are found in E. Augusti, but the latter is distinguished easily from $E$. forcipifera by their arms continuing broadly at their base with the disk, by the absence of spines strictly speaking on the dorsal surface, by the number and regular arrangement of the latero-ventral plates that have numerous pedicellariae but lack in contrast large tubercles, by the characters of the dorsal and ventral marginal plates and finally by the armature of the adambulacral plates.

The discovery of a second species of the genus Evoplosoma is very interesting

I dedicate this species to my brother-in-law, August Lumiere.

\section{Palmipes Ludovici, nov. sp.}

(PI. I, fig. 6; PI. IIL fig. 10; PI. X, fig. 1 and 2)

Station 258. $8^{\circ} 23^{\prime}$ Lat. N. $76^{\circ} 28^{\prime}$ Long. E. Depth 102 fathoms. Two specimens.

One of the specimens is whole and in very good state of preservation. The other is not complete and is in pieces. Both appear to be the same size.

In the individual in good condition, $R=112$ to $115 \mathrm{~mm} ; r=72$ to $75 \mathrm{~mm}$.

The body is pentagonal with concavesides. It is completely flat. The arms are triangular, very wide at the base and round at the end where we note the apical plate that is small, round and projecting. The width of the arms at the base is, on average, $80 \mathrm{~mm}$ and the length of their side from the base of the interbrachial arc to the end of the apical plate is $75 \mathrm{~mm}$. These measurements are from the individual in good condition. In the other, the arms are a little longer, a little narrower and more distinct from the disk. But it is not possible to give precise numbers because of the bad state of preservation.

I shall study successively the skeleton of the central part of the disk and the web. 
The central region of the disk (Pl. X, fig. 2) is slightly swollen. It is a circle $15 \mathrm{~mm}$ in diameter, covered with small irregular plates with inconspicuous edges and dispersed without order. Between them are found numerous pores that are indicated precisely by the contours of the plates. From this central region leave five projecting radial bands to form the sides of the arms. These bands reach about a centimeter in width at their base. They decrease gradually to the end of the arms. They are formed by plates arranged in irregular longitudinal rows, seven or eight at the base of the arms. They continue the plates of the central region. These plates are round, unequal, a little enlarged transversely and smaller than the adjacent plates of the web to which they pass gradually to the borders of the radial sides. The longitudinal rows that these plates form are, moreover, less conspicuous as they go from the axis of the arm to arrive at the plates of the web. These rows become naturally less and less numerous as we approach the end of the arm. At the same time, the projection formed by the sides becomes smaller. From each side of the median line, we can see on the sides four very irregular rows of pores, identical to those of the central region and to which I shall return when we have finished the study of the plates of the dorsal surface.

The central plates have small, very fine and short spinules. The number, always small, varies from one to four or five per plate. Generally, these spinules remain isolated on the surface of the plates. They rarely form small groups. On the plates of the radial sides, these spinules become a little stronger. They very often form small groups of three to four, in which they are a little larger than when they are isolated. We can find, on the same plate, one of these groups and two or three isolated spinules. These groups are inserted on a projection of the plate. They have the same arrangement as those that we shall soon encounter on the web. They are, like them, united by a membrane and lying on the plate. Finally, on some plates, moreover, a little larger than adjacent ones, we see these groups take a very a very great development. They no longer form a simple group of spinules, but a large bundle of spines, about a dozen, whose length is variable and can be 3 to $4 \mathrm{~mm}$. These spines are supported by a cylindrical projection of the plate that is raised in a large projecting tubercle, rounded at the end and as high as wide (Pl. X, fig. 2). The spines of the bundle, whose proximal end is cut squarely and not rounded, are connected to these tubercles by some soft tissues, among which I distinguish fibers, probably of a muscular nature. The spines, which are narrow and elongated, keep the same width for nearly all their length. They taper near their end that is obtuse. They are nearly completely smooth and have only some teeth toward the end. These bundles of spines constitute thus a kind of paxilla whose dimensions are variable and that are encountered in small numbers moreover on the sides and especially on the median line.

We also find some of these paxillae on the plates of the central region of the disk. We shall encounter them again on some plates of the web.

The madreporite, located very near the center of the disk, separated from it by $1 / 4 \mathrm{~mm}$, is very small and rounded. Its diameter does not exceed $2 \mathrm{~mm}$. It has the same level as the neighboring plates. It has fine furrows on its surface that diverge from the center. I cannot distinguish the anus.

The plates that extend between the dorsal sides have the usual arrangement of the genus Palmipes. They are considerable in number and form numerous series that go from the radial sides to the dorsal marginals. They are also arranged in rows parallel to the radial sides. These rows are very regular. They remain parallel. The proximal plates are about $1 \mathrm{~mm}$ in length and in width. Their dimensions are reduced in approaching the border. This reduction is especially seen after the after the fifteenth or twentieth last plates of each transverse row. It results in a space about 5 to 6 $\mathrm{mm}$ in width. The plates become very small and very narrow. They can hardly be distinguished except by the low projection of the group of spinules with which each of them is armed. Their contours are not apparent to the naked eye. The rows that they form are separated by the lines a 
little more widened than for the preceding. Thanks to this arrangement, the body has all around its dorsal surface, a band whose aspect is a little different than the rest of this surface.

The dorsal plates of the web includes an enlarged proximal region whose border is round. They are narrowed, to the contrary, in the distal part. They are imbricated so that the distal end is covered by the proximal part of the plate that follows it. Toward the proximal corner, each plate has a slight round projection on which is inserted a small group usually containing three divergent spines, very fine and pointed, forming by their union, a small comb on the plate and surrounded by a thin membrane. These spines always remain very small. They are far from reaching the length of those that we find on the ventral plates. The median is usually a little longer than the others. In addition to this bundle, each plate has two to four isolated spinules of nearly the same size as those of the comb. As the plates become smaller, the spines also decrease in number and dimension. Also, the last fifteen or twenty plates of each row have only a small comb of three spines, accompanied or not by an isolated spinule. At some points, in a completely irregular and unexpected manner, we see (PI. X. fig. 1) a plate becomes a little larger. Its spines become much longer, stronger and more numerous, so to constitute one of those bundles in the form of paxillae, identical to those we saw on the radial sides. The entire central part of the plate is then raised into a more or less developed tubercle that has the bunch of spines. In this case, the plate, of which almost the entire surface is occupied by the paxilla, does not have isolated spinules.

In general, the paxillae of the web and the radial sides are more developed and more numerous in the specimen in bad condition than in the other. I also note that the paxillae, always separated from each other in the latter, are sometimes seen in the first two, three and even four successive plates in the same transverse row.

On the border of the body, we recognize a series of dorsal marginal plates, and, below, a series of ventral marginals. These extend beyond the first and can be seen from the dorsal surface over almost their entire extent. These small marginal plates have an arrangement very close to that described and figured by Ludwig (97, p. 257; Pl. VIII, fig. 13). The dorsal marginal plate and the corresponding ventral plate together form a small row arranged obliquely to the transverse series of plates of the web (PI. III, fig. 10). The dorsal marginal plates are nearly opposite the interval that separates two consecutive series and the ventral marginal plate in front. The dorsal marginal is oval, longer than wide. It has two or three small isolated groups of two to four spinules. The ventral marginal is rounded. It has several irregular rows of spinules on its thick free edge.

Towards the top of the triangular dorsal areas, the plates of the web, which had up to now the constant characters indicated above, become abruptly a little larger and lose their regular shape. They cease to be imbricated. The spinules are distributed in isolation on their surface. They thus gradually merge with the plates of the central region of the disk. We can distinguish, at the top of each dorsal area, an interradial median row of four or five plates whose dimensions increase gradually up to the size of the proximal plate that is about $3 \mathrm{~mm}$. of diameter. On each side of this row, we note again one or two less important and less distinct rows of plates. These are separated by pores from each other from each other and the interradial median row. The proximal plate of one of these series is applied against the distal side of the madreporite.

The dorsal papular pores that are known in the genus Palmipes have, in P. Ludovici, a considerable development. They are not only very large, but they are still very numerous. On the arms, they form, as I had the opportunity to say above, four irregular rows on each side of the median line. Three of these rows belong to the plates of the sides of the brachials. The most external is found between the first plates of the web. Only two rows of each side reach the end of the arms. These rows always include the outer row and one of the inner rows without it being possible to 
recognize just which one. The other two stop at variable places toward the second third of the arms. The papular pores are very close together but the arrangement in rows is not very regular. They vary on the two sides of the same arm as well as on different arms. However, it seems that each papular pore of the external row corresponds to a transverse series of the plates of the web. These papular pores (Pl. I, fig. 6) have a very thick, projecting base on which are very strong spinules, enlarged at the base, conical and pointed, forming a circle of ten to twelve per papular pore. These spinules can fall back on the central opening and close it more or less completely when the papula is retracted.

The papular pores continue on the central region of the disc where they are very numerous. They naturally take an arrangement as irregular as that of the plates of this region. Finally, I recall that these papular pores are found between some rows at the top of the dorsal interradial areas, the proximal plates of the web. The plates of the web on the ventral surface have an arrangement identical to that of the plates of the dorsal surface. They form at the same time transverse series going from the adambulacrals to the marginals and some series parallel to the adambulacrals. They are a little smaller than the plates of the first row. Generally, five or six adambulacrals correspond to four or five ventral plates. These plates have a strongly convex proximal part that can have an angle with a round top and a thin distal part. They are imbricated like the dorsal plates. An oblique linear thickening near the proximal angle and the internal edge of the plate, has a comb of four or five very fine spines, elongated and pointed, lying on the plate. The two external spines are shorter than the median spines whose length nearly equals that of the plate. The armature of the ventral plates is thus more developed that that of the dorsal plates. At the base of the arm, there are about forty-five plates in each transverse series.

The ambulacral grooves, of medium width, have two rows of very large tube feet ending in a small disk.

The adambulacral plates, wider than long, have two parts. An internal part, directed toward the groove, has on the ambulacral side a comb formed of six to even very fine spines, slender and pointed, on the proximal plates. Their length increases from the external to the middle. Then an external part, rectangular and slightly more projecting, has an oblique, slightly curved crest on which are five spines identical to those of the plates of the web. All these spines are united by a thin membrane.

The teeth, small and very projecting, has on the free border a row of six to eight spines that are continuous with those of the groove. But they become noticeably longer than the latter as the proximal spines reach $4 \mathrm{~mm}$ in length. These quills are thin, cylindrical and pointed, joined by a membrane. On the ventral surface, the teeth have two groups of spines. One, proximal, that is more important, is formed of spines on an oblique crest like those of the ventral plates. The second group, distal, consists of only three or four smaller spines

SIMILARITIES AND DIFFERENCES. - $P$. Ludovici is very clearly characterized. It is immediately distinguished from all the known species of the genus by its numerous rows of dorsal papular pores as well as by the presence of bundles of extremely developed spines, a kind of paxilla that are on some plates of the dorsal surface of the body. It cannot be confused with any species of the Indian and Pacific Oceans. P. insignis Fisher, novemradiatus Bell and rosaceus Müller and Troschel have more than five arms. P. Sarrazini Loriol is small with a thick body. P. diaphanus Sladen and pellacidus Alcock are species of small size in which $R$ measures respectively 42 and $46 \mathrm{~mm}$ and are very different from $P$. Ludovici. 
As for P. pellacidus, I must now note that it comes from a region near where $P$. Ludovici has been collected by the INVESTIGATOR. I have not seen the type of this species, but only a little smaller specimen. As is clear from the description of Alcock, nothing in it recalls P. Ludovici. It thus is necessary to reject the hypothesis that $P$. pellacidus is a young $P$. Ludovici.

I dedicate this species to my brother-in-law, Louis Luière.

Fromia andamanensis, nov. sp.

(Pl. VII, fig. 5 and 6)

Andaman Islands. Depth 238-290 fathoms. One specimen.

The specimen is well preserved, but missing one arm that is broken near the base.

$R=27$ to $29 \mathrm{~mm} ; r=9 \mathrm{~mm}$.

The disk is very large. The arms, a little unequal, are wider at the base where it is about 10 $\mathrm{mm}$. Then it decreases gradually to the end that is very obtuse and not narrow as the arm is about $4 \mathrm{~mm}$ in width. The dorsal surface of the disk and the arms is convex. The ventral surface is flat. The ensemble is robust and rigid.

The dorsal surface of the disk and the arms is covered with round spines, irregular and unequal. The largest reaches or even exceeds $2 \mathrm{~mm}$ in width. These large plates are found on both the disk and the arms. They are located without any order and have not the least tendency to form longitudinal series. On the arms, the plates are often a little wider than long, while they are as wide as long on the disk, whose central region has some very large plates. These plates do not have any projection. Their sides are absolutely contiguous except where they have papulae. They are covered with round granules, fine, dense, arranged without order and not forming a distinct border row. Between these plates are seen numerous papular pores, always isolated and located without any regularity. We find three to six per plate according to size.

The madreporite is small, round, with fine furrows, numerous and radiating. It is located nearly equal distant between the center and the edge.

On the sides of the arms, we see a very regular row of plates, identical to the adjacent plates and not having any projection. These plates are very uniform in dimension. At the base of the arms, they are about $2 \mathrm{~mm}$ in height by $1.5 \mathrm{~mm}$ in width. I count about twenty on the largest arm. The first two or three plates of each series, especially the first, are a little larger than the others. These are obviously the dorsal marginals to which correspond, but not in an exact way, the ventral marginals. Between these plates and the plates of the dorsal surface, and between the dorsal marginal row and the ventral marginal row, are isolated papular pores identical to the papular pores of the dorsal surface.

The apical plate is small, round, very slightly projecting, a little larger than the neighboring plates and nearly completely bare.

The ventral triangular areas are small. But they extend to a great distance on the arms, so that they appear to me to even reach the end. The contours of these plates are indistinct because of the very dense granules that cover them. These granules are elongated in the form of spines, with an obtuse, round end. They are identical to the adambulacral spines on the neighboring plates of the latter. They then decrease gradually in length and size as they approach the ventral marginals to become fine granules that cover these plates. They are identical to those of the dorsal surface. From 
the grouping of these granules and the papular pores, we see easily there are four rows of lateroventral plates parallel to the adambulacrals. They plates are nearly as long as wide, except toward the end of the series where they are narrower. The first row extends to the end of the arms. The second extends to the fifteenth ventral marginal plate. The third extends to the twelfth. The fourth row is very reduced and includes only two or three plates. Each plate has, at the beginning of the arm, six to eight spines of elongated granules. Between them are isolated papular pores that are generally located at four corners, at least at the base of the arms.

The ventral marginal plates are small, nearly as long as wide and nearly as high as the dorsals. They are covered with granules like the latter. There is no very precise separation between the dorsal marginals and the ventral marginals. The separation between the two rows is less apparent than between the successive plates of each row. I have said above that the correspondence of one series with the other is not perfect.

The ambulacral grooves are wide. The tube feet, enclosed in the groove, have a disk whose red color is brighter than that of the tube itself, which is pink.

The adambulacral plates are narrow, but their borders of separation are completely indistinct. They each have a double row of two spines, one external, the other internal, which are parallel to each other. These spines are short, slightly flat. They keep the same width to the end that is round and obtuse. The external row merges with the spines of the latero-ventral spines to which they are exactly joined. The adambulacrals are a little shorter than the latero-ventral plates of the first row.

The teeth are small. The do not have any projection. They have on the free border, as well as on the ventral surface, small dense spines, identical to the adambulacral spines. There are about fifteen for each pair of teeth. The specimen in alcohol generally has preserved a pink color, while the disks of the tube feet are red.

SIMILARITIES AND DIFFERENCES. - It is evident that this asteroid can be placed only in the genus Fromia. It certainly belongs to this genus. It especially near $F$. milleporella (Lamarck), but its dorsal and ventral marginal plates are less apparent and less developed than in this latter species. The arrangement of the dorsal plates of the disk and the arms recalls a little that which was described and figured by $\mathrm{J}$. Bell in F. tumida, but the structure of the ventral surface is completely different.

It appears evident that Fromia andamanensis is the asteroid reported by Alcock in the genus Chaetaster and that he mentions as coming from Andaman at 238-290 fathoms (93 $a$, p. 104). The label of the specimen that was given to me has the same information. Alcock had brought it close to Chaetaster munitus. But we know this term is synonymous with Nectria ocellifera and it cannot be placed in the genus Nectria. I have moreover compared to the type in the Jardin des Plantes. There is no doubt about placing it in the genus Fromia.

\section{Zoroaster Adami, nov. sp.}

(Pl. V, fig. 5 and 6)

Station $331.11^{\circ} 46^{\prime} 30^{\prime \prime}$ Lat. N. $93^{\circ} 16^{\prime}$ Long. E. Depth 569 fathoms. One specimen.

Four arms are nearly complete, but two of them are shorter and regenerating toward the end. The fifth is broken at two centimeters from the base. 
The disk is small and very distinct from the arms. These are narrow and the taper gradually to the end that is small and pointed. They are no more than $6.5 \mathrm{~mm}$ wide at the base. The ventral surface is flat. The dorsal surface of the arms is round, with a slight projecting keel formed by a thickening of the carinal plates.

We distinguish on the dorsal surface of the disc, eleven primary plates that are round and equal. The radial and interradial plates are arranged so that they form a regular pentagon. Between them and the centro-dorsal are some other smaller plates with poorly defined contours. All these plates are uniformly covered with small, slightly elongated, pointed granules that more or less hide the contours. Among these granules, and in the intervals of the plates, we recognize some small straight pedicellariae, very few, a little longer than the granules.

The madreporite is small and round. It is located closer to the border than the center. It does not project above the other plates. The furrows that diverge from the center are few and very deep.

The arms first have a row of thick and convex carinal plates. On each side there are six longitudinal rows of plates. The plates in the row immediately following the carinals are narrow and do not quite reach the end of the arm. The plates of the following row are more developed and form a dorsal marginal row. The other rows are sub-equal. All these lateral plates form, at the same time, transverse rows that correspond exactly, but the carinal plates are larger. Two of them correspond on average to three lateral plates. The carinal plates are round or oval, a little longer than wide. They are not very clearly separated from each other. The transverse grooves are slightly marked, while they are better separated from the lateral plates of the first row. The papular pores form a longitudinal series very regularly arranged at the four corners of the lateral plates. The carinal plates and the plates of the first three lateral rows are covered with small conical and pointed granules, identical to those on the dorsal surface of the disc. These granules are hardly elongated on the plates of the second and third rows. In the grooves of separation, and in the vicinity of the papular pores, there are some straight pedicellariae, slightly larger than the adjacent spines. These pedicellariae are few. I cannot always find one beside each pore. On the plates of the fourth row, we see a small pointed spine near the middle of the plate. Its length equals that of the latter. At the same time, the granules that cover the rest of the plate are elongated a little. This structure is accentuated on both ventral rows, and especially on the row that immediately follows the adambulacrals, in which the spine lengthens and becomes stronger. The spines of the rest of the plate also elongate, but without taking a great development.

The adambulacral plates each have a small spine in the groove. On their ventral surface, they generally have two small spines. In addition, on two of these plates, we note an elongated strong spine, directed toward the groove. It has a group of three or four small pedicellariae, one of which is generally larger than the others.

The teeth have on their free edge a row of five or six spines, very large, longer than the adambulacral spines. They are much longer at the end of the tooth. These spines are cylindrical, very fine, with an obtuse point. On their ventral surface, the teeth have some elongated spines located inside the previous ones and a few others, much shorter, near the suture.

SIMILARITIES AND DIFFERENCES. - Z A Adami is close to Z. carinatus Alcock, from which it is distinguished especially by the dorsal plates of the disc and arms that are uniformly covered with simple granules without any indication of central spines

I dedicate this species to my excellent friend, Dr. Aloyse Adam. 


\title{
Hymenaster Alcocki, nov. sp.
}

\author{
(Pl. I, fig. 7 and 8, Pl. III, fig. 8)
}

Station $372.13^{\circ} 54^{\prime} 15^{\prime \prime}$ Lat. N. $94^{\circ} 02^{\prime} 15^{\prime \prime}$ Long. E. Depth 643 fathoms. One specimen.

$R=26 \mathrm{~mm} ; r=17 \mathrm{~mm}$.

The body is nearly exactly pentagonal. It is scarcely concave in the interradial areas. The arms are extremely short. The dorsal surface is flat with the ends of the arms slightly raised upwards. The ventral surface is convex. The body is surrounded by a very wide fringe, thick and soft in which we distinguish spines only towards the end of the arms. It has some firmness. The dorsal side of the disc has conical paxillae, wide, unequal and with an obtuse point. These paxillae are often indistinct in the central region of the disc and the interradial areas. They become finer, denser and a little more pointed near the end of the arms where they are very small. All of this surface is covered by a rather thick supradorsal membrane in which we can hardly distinguish some radial fibers toward the base and in the intervals of the paxillae. Between the latter, the dorsal membrane, thin and gray in color, allows recognizing some spiracles, very small, few and distributed without order between the paxillae. The osculum is large. Each valve, membranous, thin and transparent is supported by seven to eight strong spines, cylindrical and elongated, with obtuse ends. Outside the five valves of the osculum that are more or less tangled at their edges, we distinguish a series of other small spines united by a transparent membrane, forming like a second series of valves accompanying those that directly surround the osculum and smaller than the latter.

The latero-ventral spines are not numerous and very spaced. Approximately the first ten are separated by intervals measuring from 1.3 to $1.5 \mathrm{~mm}$. Only the first two or three spines meet their congeners on the median interradial line, without however making contact with them. The following ones are separated more and more from the opposite spines. The fourth and the fifth pairs are the longest. There are about twenty spines on each side. Their length increases gradually from the first to the fifth that attains nearly $5 \mathrm{~mm}$. On the following spines, the length decreases extremely slowly but the last five or six rapidly become shorter and very close together. The last two spines in each series are longer than the preceding. They project at the end of the arms in the form of two fine spinules arranged parallel to each other. With their congeners on the other side, they form a small bundle that ends the arm and whose length is about $1 \mathrm{~mm}$. These spines are visible as we look at the asteroid from the dorsal or the ventral surface.

The ambulacral grooves are wide and petaloid. The adambulacral plates, elongated and projecting, each has three spines in a very oblique line. On the first plates, it is even almost parallel to the axis of the groove. These three spines are nearly the length of the corresponding plate. However, the internal one is a little shorter and weaker. The median spine is longest.

The paxillae that cover the segmental openings are of medium dimensions. They are lanceolate with a short peduncle and one round end. They have a very distinct median rib.

The teeth, rather small, form by leaning against a rounded projecting keel. They have, toward their proximal third, a large cylindrical spine, elongated, widened at the base and with a blunt point. Then, toward the free end, another smaller spine. On their ambulacral edge are three small, conical and sub-equal spines (PI. I, fig. 8).

The specimen in alcohol has in general purple tint, lighter on the dorsal side and darker on the ventral side. On the dorsal surface, the marginal fringe is a little darker than the rest. The valves of the osculum are gray and almost completely discolored. The supradorsal membrane is greyish 
in the paxillar intervals. Their ends are whitish. On the ventral surface, the dark purple tint becomes a little lighter on the adambulacral plates. The tube feet are discolored. They have in general a dark gray color with a whitish tip.

SIMILARITIES AND DIFFERENCES. - H. Alcocki is distinguished easily from other Hymenaster having three adambulacal spines by the paxillae of the dorsal surface that are large, numerous and irregular, by the ventral spines that are not numerous and widely spaced, by the armature of the teeth and finally, by the presence outside the valves of the osculum of formations resembling the valves.

I am happy to dedicate this species to Dr. A. Alcock in memory of the very cordial relations that I have had with him as Director of the Calcutta Museum.

Hymenaser pentagonalis, Fisher.

Hymenaster pentagonalis, W.K. Fisher (06), p. 1099.

Station 375. Dundra Head. Ceylan. Depth 605 fathoms. One specimen.

$R=45$ to $50 \mathrm{~mm} ; r=42$ to $43 \mathrm{~mm}$.

The specimen conforms well to the type of Fisher. The dorsal surface is irregular but without the slightest trace of prominent paxillae like those which Fisher observed on some of his specimens. There are generally six spines.

The consistency of the body is absolutely gelatinous. The live animal looked like a Medusa.

The type of $H$. pentagonalis was collected by the ALBATROSS in the Hawaiian Islands at depths varying from 289 to 337 fathoms.

\section{Cribrella mutans, nov. sp.}

$$
\text { (Pl. VI, fig. 4; Pl. IX, fig. 8) }
$$

Andaman Islands. Depth 480 fathoms. One specimen.

$R=135 \mathrm{~mm} ; r=14.5 \mathrm{~mm}$.

The disc is small compared to the arms that are very long. These are slightly enlarged at the base and gradually tapering to the end that is thin and round. The dorsal surface of the disc is flat and sunken in the interradial areas. The dorsal surface of the arms is also flat but only on the first two or three centimeters. Then it is thin and round. The ventral surface is a little convex on the disc and flat on the arms.

The plates of the dorsal surface of the disc and the beginning of the arms form an extremely tight and fine network, not very projecting and with very small meshes that leave space only for the papulae. The plates have very small spines. On the sample I have in hand, they are folded and lying down. This means that we hardly see them except under a microscope. These spines are small and rugose. They are in small groups. This network is continuous with the same characters on the basal part of the dorsal surface of the arms. The length varies from one to three centimeters depending on the arms. At some places, even at the beginning of the arms, this network is even 
thinner than on the disc. Then we see the meshes abruptly becoming much larger. The network appears less dense and more prominent. The same modification is seen, moreover, on the lateral surfaces of the arms from their base. We thus pass to a much larger network. The meshes can be $1.5 \mathrm{~mm}$ wide and very irregular. In end of the arms, from the last fifth, the network becomes denser and less projecting while always remaining coarser than on the dorsal surface of the disk. We see, under the microscope, that the calcareous network consists of small convex plates, enlarged transversely, each with a row small spines, fine and pointed, six to eight per plate. They are stronger and at least twice as long as those on the dorsal surface of the disc. Meshes of this projecting network are filled by other very small plates, less convex and nearly flat. They also have very fine spines identical to the others, as with $C$. prastans. The meshes of the dorsal surface of the arms are irregular and unequal. The network that borders them is itself irregular, but their general form is rather round. On the sides of the arms, the plates tend to be more regularly arranged, one after the other. They then form small transverse rows that reach the adambulacral plates. On the ventral surface, the plates have more distinct contours. They become a little thicker and their spines, slightly stronger than on the dorsal surface, are arranged in two more or less apparent rows. These spines are inserted obliquely. Their end is directed towards the end of the arms. In particular, we can recognize a generally very distinct and vey regular row of parallel plates contiguous to the adambulacrals, a little shorter than the latter. The plates of this row are oval, two or three times longer than wide. Their spines on a double row are a little stronger than on the following plates. These plates are separated by bare spaces, in which we see neither papulae nor secondary plates.

At the base of the arms in the immediate area of the mouth, we see inside this row, another very short row containing only about a dozen plates, but more regular and clearer than the preceding.

Outside the latter that extends, in a more or less distinct manner, along the arms and parallel to the adambulacrals, the plates of the ventral surface are very small. They are arranged without order and form an irregular network, in which we do not see a longitudinal series but only a small more or less apparent transverse series.

All the spines of the dorsal, lateral and ventral plates are embedded more or less deeply in the integument. Only their distal ends are well separated.

The adambulacral plates are small, wider than long. They generally have on their internal border three spines directed into the groove. Two of these spines are usually horizontal. The third is directed more or less obliquely toward the bottom of the groove. It is somewhat isolated from the others. These spines are, like the others, covered by an integument. I note that, at the base of the arms, the end of the deepest spine is often enlarged as a result of the thickening of the membrane covering it. The ventral surface of the adambulacral plates has a variable number of spines that are placed one behind the other and generally united in pairs. The internal spines are elongated, cylindrical, broad at the base and very strong. Then the length and size gradually decrease, so that the external spines are hardly larger than those of the plates adjacent to the ventral surface.

The madreporite is clearly visible, round, a little wider than long. It is about $3 \mathrm{~mm}$ in width. It is nearly equal distance from the center and the edge of the disc. But, however, it is a little closer to the interradial area. It has large and irregular furrows. It has small spines similar to those of the other plates on the dorsal side. Despite the presence of these spines, its contours are very distinct. 
SIMILARITIES AND DIFFERENCES. - This Cribella was labeled C. praestans. It was to be part of the lot of four specimens that Alcock returned to this species, noting that the disc was relatively smaller than in C. prastans.

I have not believed it necessary to adopt this determination, at least as far as the single specimen that I had in my hand was concerned. This specimens is separated, in fact, very clearly from $C$. prasstans by the characters of the network the plates form on the dorsal surface of the body. This network is very thin and very tight on the disc and the beginning of the arms. It has, in these areas, very different characters from those Sladen described in this latter species. It is only at some distance from the base of the arms that it becomes abruptly larger and more projecting with larger meshes. It then resembles the network of $C$. prastans. On the ventral surface of the arms, we can see only one row of distinct plates, while Sladen described and represented several longitudinal rows of parallel plates in the ambulacral grooves. This scholar also mentions, on the lateral surfaces, two rows of more or less visible marginal plates, one dorsal row and a ventral row. I do not see anything similar my specimen. The armature of the adambulacral plates is also different. The madreporite is closer to the border than in $C$. proestans. Finally the arms are much longer in the specimen of the INVESTIGATOR than in the type of Sladen type, $\underline{R}=96 \mathrm{~mm}$; and $r=14$. I.e., for the same size of the disc, the arms are much larger in $C$. mutans.

This species is obviously close to $C$. prastans, but it appears necessary to me to separate it because of the differences that I have just indicated. It is to be noted that the type of $C$. prastans comes from a very different locality than the one where $C$. mutans was collected. The first species was, in fact, dredged by the CHALLENGER at Ile Crozet at 210 fathoms: It is therefore a subAntarctic species.

\title{
Brisinga gracilis, nov. sp.
}

\author{
(Pl. XIII, fig. 2 and 3)
}

Station $310.13^{\circ} 20^{\prime} 30^{\prime \prime}$ Lat. N. $95^{\circ} 22^{\prime}$ Long. E. Depth 960 fathoms. Two specimens.

One of the specimens, which is the largest, is in very good condition. There are thirteen arms, of which ten, attached to the disk, are preserved for more or less their entire length. The diameter of the disc is $11 \mathrm{~mm}$. and one of the arms is more than $110 \mathrm{~mm}$ length. In the other specimen, smaller, and whose disc measures $9 \mathrm{~mm}$ in diameter, there are fourteen arms. Six are attached to the disc. Only one has been preserved nearly its entire length. In both individuals, the arms are narrow and the whole is rather weak. These samples may be young.

The disc is a little projecting above the base of the arms. It connects to them by very oblique sides. Its dorsal surface is almost flat. The spines that cover it are numerous, very dense. They do not allow the underlying plates to be seen. The plates are cylindrical and short. Their surface is rugose, especially towards the obtuse end. Between them some are seen some pedicellariae. On the small specimen, the spines are finer and more elongated. Their end, which is not pointed but a little truncated, has two or three extremely short spinules. The surface of the spines is also more rugose than in the other individual. The madreporite is very apparent. It is oval with some divergent furrows and completely lacks spines.

The arms measure only $2.5 \mathrm{~mm}$ at the base. They are slightly swollen in the genital area whose width does not exceed $15 \mathrm{~mm}$. The plates, which were invisible on the dorsal surface of the disc, become distinct on the arms. They are irregular and round. Each has a small conical spine, pointed 
and rugose, wider at the base and shorter than on the disc. Some small crossed pedicellariae appear between the spines. Each plate has, in general, only one spine. They are first irregularly dispersed at the base of the arms and do not protrude. But they soon form transverse arches that are slightly projecting ribs. Some reach the adambulacral plates to which they are fused and others that are intercalated between the previous ones, do not reach them. We can distinguish eight or nine main arches that are separated at about 1.5 to $1.6 \mathrm{~mm}$ intervals. All are arranged in a regular way, perpendicular to the axis of the arm and parallel to each other, without forming sinuosities. The main and secondary ribs are armed with spines identical to those we observe at the beginning of the arms. But the plates between them are generally unarmed. The pedicellariae are not very abundant, at least in the proximal part of the genital area. They become more in the last third. Beyond this the region, the arms are slightly narrowed and we observe regular bands of small pedicellariae that correspond alternately to the middle parts of the ambulacral plates and the intervals betpween them.

Toward the eighth adambulacral plate, we see develop at the place of union of this plate and the side to which it is fused, a small lateral spine that soon greatly lengthens and reaches the length of the ventral adambulacral spine. i.e., 4 or $5 \mathrm{~mm}$. Compared to the dimensions of the arms, these spines therefore are very long. They are fine, pointed and surrounded by a sheath of pedicellariae. They are seen at each adambulacral plate because each of them receives a main arch. Beyond the genital area, when the arches have disappeared, these spines nevertheless continue to appear on each plate approaching the ventral spine. They are located immediately outside it.

On their ventral surface, the adambulacral plates have a spine that, on the first plates, is a little shorter than the following, but nevertheless reaches a length of $3 \mathrm{~mm}$. Its end is slightly enlarged. This end becomes sharp on the following spines at the same time as they lengthen. The length soon reaches that of the lateral spines.

The first seven or eight adambulacral plates are nearly square. They then become longer than wide. Beyond the genital area, they are twice as long as wide. Their internal border is slightly concave. It has a slightly marked distal process. Each plate has a small proximal spine directed transversely toward the furrow. The distal apophysis has a longer spine directed obliquely in the groove. These two spines have a crown of pedicellariae that is especially developed in the latter. Finally, inside and above the distal spines, we usually find a small spine, very short and directed transversely toward the furrow.

The teeth have on their ventral surface a very large elongated and pointed spine enveloped in a sheath of pedicellariae, longer than the spines of the first adambulacral plates. Its length exceeds $3.5 \mathrm{~mm}$. The two spines of the same pair go parallel to each other toward the mouth. Outside each large spine, we see another much shorter. On the oral border of the tooth are two small subequal spines directed horizontally toward the mouth. All of these spines are enveloped in a sheath of pedicellariae.

The pedicellariae of large adambulacral spines are much larger than those on the dorsal surface of the arms. They resemble those of B. panopla, but the jaws are much shorter and have no lateral teeth. They recall absolutely those that Fisher represented in B. Alberti and Odinia pacifica.

SIMILARITIES AND DIFFERENCES. - B. gracilis recalls a little the single arm, described and figured by Perrier, of $B$. hirsuta that comes from the boreal Atlantic. But in the latter, the main arches are fused to the adambulacral plates only in twos. B. gracilis is especially remarkable for the length of the spines. It perhaps is a young form, as I said above. But I see no species to which we can attach it. 


\title{
Brisinga panopla, Fisher.
}

\author{
(Pl. XII, fig. 7)
}

Brisinga panopla. W. K. Fisher (06), p. 1100.

Station $334.6^{\circ} 57^{\prime}$ Lat. N. $79^{\circ} 33^{\prime}$ Long. E. Depth 568 fathoms. Two disks and several fragments of arms.

One of the disks has no arms. The other, which is in poor condition, has three arms that are about 9 to $10 \mathrm{~cm}$ long. It has thirteen arms.

The diameter of the disk does not exceed $17 \mathrm{~mm}$. The width of the arms in the most developed part of the genital area varies from 6 to $6.5 \mathrm{~mm}$. It very rarely reaches $7 \mathrm{~mm}$. The specimens are therefore a little smaller than the type of Fisher that has a disk diameter of $26 \mathrm{~mm}$. and a maximum width, in the genital region of $10 \mathrm{~mm}$. The type has fourteen arms instead of thirteen. Besides this difference, the INVESTIGATOR specimens are completely like Fisher's description and drawings.

The type of B. panopla comes from the Hawaiian Islands where it was collected at depths varying from 319 to 528 fathoms.

\section{Brisinga parallela, nov. sp.}

(PI. X, fig. 5; PI. XII, fig. 8; PI. XIII, fig. 4)

Station 334. $6^{\circ} 57^{\prime}$ Lat. N. $79^{\circ} 33^{\prime}$ Long. E. Depth 568 fathoms. A single arm.

The single arm collected was associated with the Brisinga panopla that I have just described. It is $80 \mathrm{~mm}$ long and, except for two or three rings at the distal end, it only includes the genital region that is, as we can see, developed over a great length.

The arm, which is only $4.5 \mathrm{~mm}$. wide at the base, gradually widens. It is $9.4 \mathrm{~mm}$ at $22 \mathrm{~mm}$ from the base. The width then decreases very slowly. It is no more than $5 \mathrm{~mm}$ towards the end of the genital area.

It is easily distinguished from the numerous arms of $B$. panopla, first by a much greater development, then, especially, by the very great regularity with which successive ribs remain parallel to each other at very narrow intervals. The ribs only show some irregularities in the distal part of the genital area.

The ribs $3 \mathrm{~mm}$ behind the base of the arm first appear in the middle region as slight, incomplete creases that are continued on the sides by lines that first are hardly apparent. A centimeter from the base, the lateral parts of the ribs are nearly as developed as in the middle region. They go by pairs to the adambulacral plates. The ribs then continue to follow each other very regularly. Some, the main ribs, reach the corresponding adambulacral plate to which they are welded by their last enlarged ossicle. The intermediate or secondary ribs stop a short distance above the plate. Except for this difference, the main ribs and the secondary ribs have the same thickness and the same characters.

These ribs produce very pronounced projections, however less strong than in B. panopla. But they extend transversely to the axis of the arms following an almost straight path, or one that has 
only insignificant inflections, mainly in the distal region. They thus remain parallel to each other in a nearly geometric manner. All have small, very thin, short and sharp spines,much less strong and less numerous than in B. panopla, and especially of crossed pedicellariae that are here very abundant (PI. XII, fig- 8), while in the other species they are rather rare on the dorsal surface (PI. XII, fig. 7). In the soft parts that separate the ribs, we do not find spines but only some rare pedicellariae.

Each main rib arrives at the top of the adambulacral plate without changing direction that always remains nearly perpendicular to the axis of the arm and without abrupt curve that we see on the sides of the arms in B. panopla where the rib is welded, not on the adambulacral plate at its top, but at the plate located in front.

On each side of the arm, we see a row of small round or irregular plates that form a nearly continuous longitudinal line that connects the ribs to each other. These small plates appear at about $15 \mathrm{~mm}$ from the anterior end of the arm. They disappear in the last part of the genital area. Like the ribs, each has very fine spines. The two the longitudinal lines that they form extend in a regular manner some distance from to the row of adambulacral plates and parallel to it.

The adambulacral plates are nearly as long as wide. They are concave internally. They have at their internal and distal corner, a little apophysis. They have some pedicellariae on their surface. After the tenth, we see at the union of the rib and the adambulacral plate, a small spine that is longer on the following articles. It will reach a length of about $7 \mathrm{~mm}$. This spine exists on all the adambulacral plates. It is seen the entire length of the arm. It is thin, pointed and wrapped in a sheath containing crossed pedicellaria, very numerous and very developed. On their ventral side, the adambulacral plates have a spine that is first short and whose end is greatly enlarged. On the third plate, this spine is $4 \mathrm{~mm}$ in length. Then it gradually lengthens at the same time as its end thins. About the fourteenth it reaches the length of a lateral spine. The tip is pointed. This spine also has a sheath with pedicellariae. The spines of the groove are arranged as in B. panopla. We see, in fact, a fine proximal spine, pointed and directed horizontally. Then, on the distal apophysis, is a first fine and elongated spine. Above is a smaller spine, about the same length as the proximal spine. Each of these three spines has a small bunch of pedicellariae.

The pedicellariae of the large adambulacral spines are more developed than those on the dorsal surface of the arm. They reach 0.5 to $0.6 \mathrm{~mm}$ in length. They are identical to those of B. panopla, although most often they do have only two lateral teeth on each valve.

SIMILARITIES AND DIFFERENCES. - B. parallela is obviously very close to B. panopla with which it was associated. But it cannot be confused with it. By comparing the single arm collected with an arm of $B$. panopla, we see that it is distinguished by the length and the width of the genital area that is more developed, by the very regular arrangement of the ribs which are comparatively narrower, less projecting and with spines much smaller and less numerous, while the pedicellariae are more abundant. These characters are also more conspicuous as all the arms of B. panopla are narrower than those of $B$. parallela. We can easily recognize these differences by comparing the two drawings that I give (Pl. XII, figs. 7 and 8) of the arms of these two species at the same magnification. The arm of $B$. panopla figured has a maximum width of $6.5 \mathrm{~mm}$. in the genital area.

I do not see any other species to which I can refer $B$. parallela.

As the $B$. gracilis that I described above also has the same parallel brachial ribs. We might wonder if it would not be the young form of B. parallela. But this hypothesis is unacceptable. Among other differences, the ribs appear only at some distance from the base of the arms in $B$. gracilis, the dorsal surface at the base of the arm is covered with small, very distinct plates, each 
with a small spine. In $B$. parallela the ribs appear, so to speak, at the base of the arm and are separated by spaces where the integument is completely bare. These ribs are much more numerous and comparatively closer together. Their spines are shorter than in B. gracilis. The ventral adambulacral spines and lateral spines are also comparatively shorter. Finally, the pedicellariae have very elongated jaws and not shortened as in the latter species.

Odinia Clarki, nov. sp.

(Pl. XII, fig. 4, 5 and 6)

Station 217. $6^{\circ} 56^{\prime} 56^{\prime \prime}$ Lat. N. 72 53' 30" Long. E. Depth 450 fathoms. Four incomplete specimens.

The specimens are presented in the following way:

Two disks without arms and some detached arms.

One disk to which five arms have remained attached.

One disk with seven arms.

The disks are in a slightly oval form. I indicate here their dimensions as well as the number of arms.

Specimen No. 1 Disk alone. $\quad$ Dimensions $\quad 27 \mathrm{~mm} \quad 24 \mathrm{~mm} \quad 10 \mathrm{arms}$

Specimen No. 2 Disk alone. $\quad 30 \mathrm{~mm} \quad 26 \mathrm{~mm} \quad 17 \mathrm{arms}$

Specimen No. 3 Disk with 5 arms. $\quad 27 \mathrm{~mm} \quad 23 \mathrm{~mm} \quad 16$ arms

Specimen No. 4 Disk with 7 arms. $\quad 31.5 \mathrm{~mm} \quad 25 \mathrm{~mm} \quad 17$ arms

The disc is not very elevated and its sides are more or less oblique. The dorsal surface is flat. The arms are large, wide and robust. Their length exceeds $22 \mathrm{~cm}$. None of them is complete.

The dorsal surface of the disc is sometimes flat, sometimes depressed in the middle with slightly projecting edges. It has very strong spines, widened at the base, conical, with a round or truncate end and not very dense. In specimen number 3, their end is a little enlarged. It has some small spinules that are sometimes bifurcate. Elsewhere, the spines ae simply rugose. These spines are on very projecting plates with clearly visible contours. They come together in a network with meshes through which pass more or less numerous papulae that are elongated and vermiform. Between the spines, we can distinguish a few crossed pedicellariae. Towards the boarders of the disc, the plates become a little larger and their contours more distinct. We recognize in particular, in each interradius, two or three plates larger than the adjacent ones. Sometimes one of them is more specially noted for its dimensions. This is perhaps a basal piece as found in Brisinga. These plates are well located on the dorsal surface of the disc. They do not belong to the type of webbing that connects the arms to their base. They therefore do not correspond to the plates that Perrier called the basal marginals.

The location of the anus is not indicated by spines larger than the adjacent ones.

The very small madreporite is located very near the border. It is not very visible because it is hidden by the adjacent spines. It has a few very fine furrows.

The arms are fused together over a length corresponding to five articles. They are narrow at the base whose width is about $6 \mathrm{~mm}$. They start to widen 8 or $10 \mathrm{~mm}$ further and rapidly reach a width that can be $15 \mathrm{~mm}$. Then they gradually decrease and the genital area is not strictly limited 
to the distal part. Where the dorsal plates begin to disappear, the arm is 8 to $9 \mathrm{~mm}$. in width and total length of the genital area is 80 or $85 \mathrm{~mm}$. similarly, this region enlarges rapidly in the proximal part. It also rises very quickly to a height of $13 \mathrm{~mm}$ at 20 or 22 from the base. This height is maintained over a length of 2 to $3 \mathrm{~cm}$. Then it gradually decreases. The height and width of the genital area depends greatly on the state of preservation of the arms. In some, it is wide and flat. In others, it is narrow and high. The numbers given above are therefore not constant. On most of the arms, the genital area is rather flat.

The dorsal surface and the sides of the arms in the genital area have a tough integument that has calcareous plates that form a network. Their edges are not very apparent in specimens in alcohol. They appear clearly after drying. In the meshes, we can see either circular openings through which the papules pass, or the papulae themselves, which are large, elongated, vermiform and much more developed than on the disc. They reach several millimeters in length. On most plates, and particularly on the dorsal surface rises a strong spine, erect, conical and pointed. Its length can reach $4 \mathrm{~mm}$. It is surrounded on half or over two thirds of its length by a sheath of pedicellariae leaving its end bare. These spines sometimes have a tendency to form a half-dozen longitudinal series but these are never very apparent. At the twelfth adambulacral plate, we begin to see, especially on the sides of the arms, transverse arches. The first three or four are not very prominent. They are fully developed in the second and last third of the genital area. These arches usually every three articles, or about every $4.5 \mathrm{~mm}$. They are especially developed on the lateral surfaces of the arms and are less protruding on the dorsal surface. Each of them is made up of elongated and projecting plates. They are regularly arranged one after the other. The first ventral plate is fused to the corresponding adambulacral plate. The spines that the arch are generally a little larger than the others. It is especially the first ventral spine that develops first. Toward the fourth arch, it is almost a centimeter in length. Then we see successively the second spine, then the third and a little further on the fourth, elongate in turn. In the last third of the genital area, the first three spines have about the same length. At the same time, they become closer to each other and form thus a vertical shaft to which is usually added a fifth spine. Each bundle thus includes three large, very long ventral spines and two other smaller spines. Beyond the genital area, these groups of spines exactly located at the sides of the arms continue to show every three or every four rings; the arches were already reduced to some plates that support them. They approach the form of a conical projection on which the shaft is inserted. The number of spines soon decreases to four. This number is maintained for a large part of the length of the arms. The three ventral spines are always very long. They exceed one centimeter and are larger than the interval that separates them. This interval usually contains five articles at some distance from the genital area. Four spines perhaps continue to the end of the arms. In any case, I still find it $20 \mathrm{~cm}$ from the base.

The pedicellaria are numerous and dense in the genital region. Beyond, they become less abundant and they even disappear on the dorsal surface. They remain on the sides of the arms.

The adambulacral plates are rectangular, longer than wide, and longer in the genital area than on the rest of the arm. I count twenty over a length of $3 \mathrm{~cm}$. There are several isolated pedicellariae on their surface. They have, on their thin ventral surface, a large vertical spine measuring 4 to 4.5 $\mathrm{mm}$ in length, slightly flattened from outside to inside, with an enlarged end and sometimes bifid at the beginning of the arm. Beyond the genital area, this spine becomes longer, pointed, and its length exceeds $5 \mathrm{~mm}$. It is covered with a sheath of pedicellariae. In the groove, the adambulacral plates have, toward their distal corner that is not protruding, a small horizontal spine, fine, pointed and directed obliquely toward the groove. This has a collar of pedicellariae. 
The teeth have the shape that is usually found in the genus Odinia. They are thin outside and are enlarged inside to form an apophysis that goes to meet its congener of the other tooth but without fusing to it. Each tooth has on its oral border four fairly short, fine and pointed components. The first two, i.e., closest to the suture, are a little longer than the others and are directed toward the center of the mouth. The two external are directed obliquely outward and go to meet the two corresponding spines of the adjacent tooth with which they are joined. Every spine has a collar of pedicellariae. On the ventral surface, each tooth has, toward its distal border, a small vertical spine with a collar of pedicellariae. Some isolated pedicellariae also appear on this surface.

The pedicellaraie of the adambulacral spines are larger than those of the dorsal surface, especially those found at the base of these spines or on the adambulacral plates themselves. These pedicellariae resemble those of $O$. pacifica figured by Fisher, but they are a little more elongated and especially they have jaws longer than in the latter species.

RELATIONSHIPS AND DIFFERENCES. - Almost all known Odinia come from the Atlantic. We could believe that this genus was localized in this ocean before Fisher described O. pacifica in the Hawaiian Islands at depths of 281 and 528 fathoms. It is the fifth known species of the genus; the other four, 0. elegans, robusta and semicoronata described by Perrier, as well as O. pandina Sladen, come from the Atlantic. $O$. Clarki is especially remarkable for the great number and size of spines in the genital area and by the development of arches in the second half of this region. It can in no way be confused with $O$. pacifica. It recalls rather $O$. robusta but the latter's arches are less developed and the adambulacral plates do not have, according to Perrier's description, spines in the furrow.

I am happy to dedicate this species to Hubert Lyman Clark, well known by his important work on echinoderms.

I believe I should unite a specimen from station 333 (depth 401 fathoms) with $O$. Clarki and that was associated with another smaller Odinia which I describe below under the name of $O$. Austini. This specimen includes a disc with two attached arms attached and four detached arms. All these arms are incomplete and very short. The largest reaches $7 \mathrm{~cm}$. The others are only 4 to 5 $\mathrm{cm}$ in length. They are largely stripped of their spines and appear to have been subjected to abrasion. As a result of this, they have an aspect different from $O$. Clarki from Station 217. The genital area is, it seems to me, shorter and the arches are less developed than in the latter. The circular disc measures $27 \mathrm{~mm}$. in diameter. The papulae are more numerous and longer, the spines shorter and less numerous than in the type. The disc is also a little higher and its lateral surfaces are almost vertical.

It is not possible to determine with certainty this individual because of its state of preservation, but I do not believe it is necessary to separate it from $O$. Clarki. It cannot in any way be referred to the other Odinia species with which it was found.

Odinia Austini, nov. sp.

(Pl. IV, fig. 7; Pl. XII, fig. 5 and 6)

Station $333.6^{\circ} 31^{\prime}$ Lat. N. $79^{\circ} 38^{\prime}$ Long. E. Depth 401 fathoms. One specimen. 
The individual is in good condition. Only three arms are broken near the base. The others are preserved over most of their length and some are nearly complete.

The diameter of the disc is $16 \mathrm{~mm}$. The sixteen arms can reach a length of about 12 to $13 \mathrm{~cm}$.

The disc is protruding. Its dorsal surface, which is flat, is above the insertion of the arms. Its lateral surface is continuous obliquely with their base. The contours of the plates that cover the dorsal surface cannot be distinguished except toward the periphery where they are larger and more or less bare. We see, especially in each interradial space, a small group of elongated plates that are bare and round. The other plates have small spines, cylindrical and short with a truncated end that is more or less rugose, especially toward the end that sometimes even ends with a few fine spinules. Pedicellaiaes are rare. There are many papulae, elongated and vermiform. The anus, which is quite distinct, is eccentric and is not surrounded by vey developed spines. The madreporite, which is part of one of the interradial groups that I just mentioned, is of average size, not very distinct and hardly protruding. Its furrows are not very conspicuous.

The arms are joined at their base over a length of about $3.5 \mathrm{~mm}$ from the sides of the disc. This corresponds to five adambulacral plates. They are $4 \mathrm{~mm}$. wide at the base. They start to widen 8 or $9 \mathrm{~mm}$ from the base and are $6 \mathrm{~mm}$ wide without rising much. They then insensibly get thinner. The genital area is only 20 to $25 \mathrm{~mm}$ in length. The basal part of the arms has, on their dorsal and lateral surfaces, papulae interspersed with short spines arranged without order. But the arches soon appear. They become very noticeable by forming protruding ridges with very developed spines. We can recognize in the genital area seven or eight separate arches. The first arch, still rudimentary, corresponds to the fifteenth adambulacral plate. It does not reach the dorsal surface. Beyond, the arches continue regularly from three to three articles. However, it sometimes happens that some of them are only separated by one adambulacral plate instead of two. As we usually observe it in the genus Odinia, the first three or four ventral spines of the arches are stronger and closer to each other, while spines on the dorsal surface are shorter, although well developed. The latter are conical and pointed. The longest is $2 \mathrm{~mm}$ in length. We find some also in the intervals of the arches. Beyond the genital area, the arches of the dorsal surface cease. They remain on the sides of the arms, forming a conical protuberance that has a bundle of three subequal spines, fine and pointed. They are about $5 \mathrm{~mm}$ in length, but up to 6 and even $7 \mathrm{~mm}$. These bundles continue over the rest of the length the arms, but only in the last four rings. The have a sheath of pedicellariae, but this was most often abraded.

The adambulacral plates are a little longer than wide. They have on their ventral side, a spine that is first thick and short, with an enlarged end. It does not exceed $3 \mathrm{~mm}$ in length. On the following articles, this spine becomes longer and pointed, without quite reaching the length of the lateral spines. The adambulacral plates have, at their internal and distal corners, a slight apophysis directed backwards. But it was impossible for me to discover the least trace of spines. These are obviously missing. The adambulacral spines are in good condition. If there had been spines in the furrow, we would have seen some indication of them.

The small teeth have the usual shape. They have on their free border four or five small spines. The first two are directed towards the center of the mouth. The others are directed obliquely outside and intersect with their congeners. These spines are conical, with a round, completely smooth end. They have no pedicellariae on their surface. The teeth do not show the slightest trace of spines on their ventral surface. The first adambulacral plate that follows each tooth has, on its ventral surface, its usual spine without any accessory spines. The mouth frame is therefore as simplified as possible. The mouth has a diameter of about $10 \mathrm{~mm}$. 
The pedicellariae that cover the adambulacrals are larger than those on the dorsal surface of the disk and arms. They are very similar to those Fisher figured in 0. pacifica.

SIMILARITIES AND DIFFERENCES. - I believed I should distinguish this species of 0 . Clarki because of the complete absence of adambulacral spines in the groove, spines on the ventral surface of the teeth and pedicellaria on the tooth spines. As the only individual collected is quite small and was associated with a larger specimen likely belonging to $O$. Clarki, we may wonder if $O$. Austini is not the young form of $O$. Clarki. This hypothesis could be rigorously examined if it were only a question of the absence of pedicellariae on the tooth spines. But the total absence of spines in the ambulacral groove and on the ventral surface of the teeth, cannot be due to the young age of the subject, because these spines are too developed in adults so that at least one indication is not found in a specimen whose disc already has a diameter of $16 \mathrm{~mm}$. The creation of a new species was therefore essential.

I ask Austin Hobart Clark, author of remarkable works on crinoids, to accept the dedication of this species.

Freyella indica, nov. sp.

(Pl. X, fig. 7; Pl. XII, fig. 9 and 10)

Station $251.10^{\circ} 36^{\prime} 30^{\prime \prime}$ Lat. N. $93^{\circ} 40^{\prime} 15^{\prime \prime}$ Long. E. Depth $1595-1622$ fathoms.

One disc and four incomplete arms, the largest of which is $15 \mathrm{~mm}$. in length. The species has ten-arms.

The disc is considerably deformed and has become oval. Nearly two times longer than wide. This deformation is certainly accidental. It seems that one of the halves of the disc has been strongly stretched in the direction of two arms, which considerably lengthened this part, while the other half of the disc remained nearly. As a result of this deformation, the disc is $16 \mathrm{~mm}$ in length. At its widest part, it reaches $11 \mathrm{~mm}$. It measures only $8 \mathrm{~mm}$ in its narrowest part.

The dorsal surface of the disc is covered with very dense small plates. The edges are not apparent to the naked eye, but can be easily distinguished with the microscope. These plates become a little larger toward the periphery. They are round and unequal. They each have some small spines, very thin and short, enlarged at the base, cylindrical for most of their length and ended in a truncated or very slightly enlarged end that has a few small teeth. These spines constitute on the dorsal side of the disc a very dense covering. Among them, we can distinguish some small sparse pedicellariae. A very small anus appears in the central region. I cannot distinguish clearly the shape and the characters of the madreporite that is located in the deformed region of the disc and hidden in a fold.

On the lateral surfaces of the disc, we see, in each interbrachial area, an oval or triangular plate with rounded corners. The top is turned on the dorsal side. This plate is notably larger than the others, although it is no more than $1.5 \mathrm{~mm}$ in width. It is much closer to the ventral surface than to the dorsal surface. This means that we cannot see it when looking at the animal from the dorsal side. This plate is obviously of the same nature as the interradial pieces that I had the opportunity to report in various species of Freyella, such as F. Giardi Koehler and Edwardsi Perrier (09, p. 130). It is undoubtedly homologous to the odontophore. 
The arms are $3.5 \mathrm{~mm}$ in width at the base and hardly exceeds $4.5 \mathrm{~mm}$ at the genital area. Its greatest width is in about its first third. Beyond, it decreases very gradually. This region extends over a length of $20 \mathrm{~mm}$. The plates are much larger than on the dorsal surface of the disk. They can reach and even exceed $1 \mathrm{~mm}$ in width. They are round, a little longer than wide, slightly imbricated and armed with small spines, pointed and shorter than those on the dorsal surface of the disc. These spines are irregularly arranged in the proximal half of the genital area. In the other half, they are less dense and become less and less numerous. Some sparse pedicellariae appear among these spines. The lateral plates of the arms are slightly larger than the dorsal plates. Their spines are less numerous. They are attached to the outer surface of the adambulacral plates without having the least trace of a regular arrangement in rows. Beyond the genital area, the arms are no more than $2 \mathrm{~mm}$ in width. They should not be very long in living animals. Their protruding dorsal surface is covered with a fairly opaque membrane, which is bare in the middle of the arm and has, on the sides, dense pedicellariae.

It is about the ninth adambulacral plate, at the point where it joins with one of the lateral plates that we see the first lateral spine. These spines then continue on the following plates. However, they only appear in pairs. They lengthen progressively, but they always remain smaller and thinner than the ventral adambulacral spines that are found on each plate. These are at first short, thick, cylindrical and obtuse at the tip. They gradually lengthen at the same time become thin and sharp. The length of these spines reaches that of an article and a half in the middle of the genital area. Beyond, they become a little smaller. They have, like the lateral spines, a sheath of pedicellariae.

The adambulacral plates are rectangular with a concave internal border. Their distal and internal corner forms a round and poorly developed extension. This apophysis has a fine, pointed spine pointing perpendicularly to the groove. It has a crown of pedicellariae.

The spines of the first adambulacral plate are longer than the others. They almost reach the length of the tooth spines. Each tooth has on its ventral surface and in the middle, a large spine, strong and robust, almost $5 \mathrm{~mm}$ in length. The end is obtuse or even truncate. It has a thick sheath of pedicellaria. On the oral border is a row of three small spines, cylindrical and thin, and with pedicellaria. Their length increases from the internal spine, i.e., from that which is closest to the sutural edge, to the last. Finally, towards the outer border of the tooth, and above the large spine reported above, is another small directed horizontally. It is obviously the counterpart of the small distal internal spine of the adambular plates.

SIMILARITIES AND DIFFERENCES. - F indica is very distinct from the other ten-armed Freyella that we know in the Indian Ocean and in the Pacific Ocean. F. pacifca Ludwig has two large tooth spines. One is turned toward the mouth and the other toward the groove. There are also two spines on the ventral surface of the teeth. F. remex Sladen, which the CHALLENGER encountered S.-E. of New Guinea, at a depth of 2,440 fathoms, has large lateral spines and the tooth spines are atrophied. $F$. pacifica from Japan is a large species. The dorsal surface of the disc and the beginning of the genital area is covered by a membrane with spines in which are extremely thin plates for a length of $5 \mathrm{~cm}$. It has extremely thin plates which exist only for a length of $5 \mathrm{~cm}$. The genital area is therefore covered, for most of its length, by a simple transparent membrane. 


\section{GENERAL REMARKS}

The scientific explorations of the INVESTIGATOR have provided us with very important documentation on the abyssal fauna of asteroids in the Bay of Bengal and the Sea of Oman (English maps designate the latter under the name of Arabian Sea). The species collected are numerous. The total is eighty-eight if we add the ones that Alcock mentioned to those that I indicate in this memoir. This result is all the more interesting because we did not have much information on abyssal asteroids of the Indian Ocean. The only documents we have were provided by the CHALLENGER that explored various regions of this Indian Ocean, but did not enter the areas visited by the INVESTIGATOR, so that the abyssal fauna of the latter was completely unknown to us. The campaign of the INVESTIGATOR takes an even greater importance and it is good to emphasize them.

The scarcity of information we have on the abyssal asteroids of the Indian Ocean hardly makes possible any comparisons between this fauna and the one that the INVESTIGATOR discovered. But we have more complete and extensive data on the abyssal asteroids of the Pacific Ocean. Ludwig (05) described those that the ALBATROSS dredged off the coast of western equatorial America and W. K. Fisher made known those the same vessel collected around the Hawaiian Islands. All these forms, joined to those the CHALLENGER discovered, represent a significant total. It is interesting to investigate the relationships that may exist between this fauna and the one that the INVESTIGATOR made known to us in the Bay of Bengal and the Sea of Oman.

By noting in the works of Alcock, the species coming from the INVESTIGATOR campaigns reported by him, I find a total of fifty-eight, forty of which are new. Here is the list:

Pararchaster semisquamatus, Sladen. Bay of Bengal; 1664 fathoms.

Pararchaster Huddlestonii, Alcock. Bay of Bengal; 1520 fathoms.

Pararchaster violaceus, Alcock. Laccadives; 1200 fathoms.

Pontaster mimicus, Sladen. Laccadives; 1000 fathoms.

Pontaster cribellum, Alcock. Laccadives; 1200 fathoms.

Pontaster pilosus, Alcock. Gulf of Mannar; 507 fathoms.

Pectinaster (Pontaster) hispidus, Alcock and Wood-Mason. Laccadives; 1000 fathoms.

Dytaster exilis, Sladen. Bay of Bengal; 1748-1924 fathoms.

Dytaster anacanthus, Alcock and Wood-Mason. Bay of Bengal; 1748 fathoms.

Persephonaster croceus, Alcock and Wood-Mason. Gulf of Mannar; 738 fathoms.

Persephonaster rhodopeplus, Alcock and Wood-Mason. Gulf of Mannar; 738-902 fathoms.

Persephonaster colochiles, Alcock. Andaman; 230-250 fathoms.

Astropecten, sp. 
Astrogonium (Pseudarchaster) mozaicum, Alcock and Wood-Mason. Andanan; 188-220 fathoms.

Astrogonium (Mediaster) roseum, Alcock. Laccadives; 740 fathoms.

Styracaster horridus, Sladen.

Styracaster clavipes, Alcock and Wood-Mason. Bay of Bengal; I718 fathoms.

Styracaster armatus, Sladen. Bay of Bengal; 1748-1803 fathoms.

Porcellanaster coruleus, Wyville Thomson.

Porcellanaster sp. prox. coruleus.

Hyphalaster tara, Alcock and Wood-Mason. Bay of Bengal; 1748-1803 fathoms.

Dipsacaster pentagonalis, Alcock. Andaman; 112 fathoms.

Dipsacaster Sladeni, Alcock. Andaman; 250 fathoms.

Pentagonaster arcuatîs, Sladen. Andaman; 271 fathoms.

Pentagonaster Investigatoris, Alcock. Bay of Bengal and Delta Kistna; 678 fathoms.

Pentagonaster pulvinus, Sladen. Laccadives; 1200 fathoms.

Pentagonaster intermedius, Perrier.

Milteliphaster Wood-Masoni, Alcock. Andaman; 230-290 fathoms.

Iconaster (Dorigona) pentaphyllus, Alcock. Andaman; 271 fathoms.

Mediaster (Nymphaster) florifer, Alcock. Andaman; 130-250 fathoms.

Dorigona (Nymphaster) nora, Alcock. Andaman. 190 fathoms.

Dorigona (Nymphaster) protenta, Sladen.

Dorigona \{Nymphaster) basilica (Sladen).

Paragonaster tenuiradiis, Alcock. Bay of Bengal; 1748 fathoms.

Paragonaster sp. Bay of Bengal; 1748 fathoms.

Anthenoides sarissa, Alcock. Andaman; 130-250 fathoms.

Calliaster mamillifer, Alcock. Andaman; 112 fathoms.

Palmipes pellucidus, Alcock. Andaman; 112 fathoms.

Zoroaster Alfredi, Alcock. Bay of Bengal; 1300-1380 fathoms.

Zoroaster Barathri, Alcock. Bay of Bengal; 1520 fathoms.

Zoroaster planus, Alcock. Laccadives; 1200 fathoms.

Zoroaster angulatus, Alcock. Gulf of Mannar; 599 fathoms. Laccadives; 750 fathoms.

Zoroaster carinatus, Alcock. Andaman; 130-250 fathoms.

Zoroaster Gilesii, Alcock. Andaman; 490-500 fathoms.

Zoroaster squameus, Alcock. Laccadives; 1043 fathoms.

Zoroaster zea, Alcock. Gulf of Mannar and Laccadives; 597-705 fathoms.

Marsipaster hirsutis, Sladen. Bay of Bengal; 1997 fathoms.

Hymenaster nohilis, Wyville Tbomson. Bay of Bengal; 1748 fathoms.

Dictyaster xenophilus, Alcock and Wood-Mason. Andaman; 170-290 fathoms.

Chotaster, sp.

Cribrella proestans, Sladen.

Asterias mazophorus, Alcock and Wood-Mason. Andaman; 120-250 fathoms.

Brisinga insularum, Alcock and Wood-Mason. Laccadives; 1043 fathoms.

Brisinga andamanica, Alcock and Wood-Mason. Andaman; 405 fathoms.

Brisinga bengalis, Alcock and Wood-Mason. Bay of Bengal; 1840 fathoms.

Brisinga Gunnii, Alcock. Konkan coast; 559 fathoms.

Freyella tuberculata, Sladen. Bay of Bengal; 1840 fathoms.

Freyella benthophila, Sladen. Bay of Bengal; 1520-1997 fathoms. 
From this total of fifty-eight species, it is necessary to subtract nine species that I have studied in the previous pages and whose names have been changed, either because they have been reported to other species, or because I have described them as new. These nine species will be found further and the general account will not be altered. Here is the list:

\section{Astropecten, sp.}

Porcellanaster caruleus.

Porcellanaster, sp. prox. caruleus.

Styracaster horridus.

Pentagonaster intermedius.

Dorigona (Nymphaster) protenta.

Dorigona \{Nymphaster) basilica.

Chotasler, sp.

Cribrella prostans.

Astropecten sp. of Alcock is a new species that I have described under the name A. Griegi (p. 20). Porcellanaster caruleus must not, in my opinion, exist in the collections of the INVESTIGATOR and the asteroids related to this species are, either P. caulifer, or especially Sidonaster (see p. 33). Porcellanaster sp. prox. caruleus is Caulaster dubius (p. 34). Ludwig has already pointed out that the Styracaster called by Alcock St. horridus was identical to his St. caroli (p. 43). I consider as a new species the Pentagonaster reported by Alcock to P. intermediuss: I have described it under the name of $P$. Dôderleini (p. 71). The species designated by Alcock under the name of Nymphaster protentus is in the same case. I have called it Dorigona Belli (p. 58). As for Nymphaster basilicus, it seems to me to be related to the Dorigona ternalis Perrier (p. 54). The single specimen that Alcock referred with doubt to the genus Chotaster is a new Fromia that I called $F$. andamanica (p. 105). Finally, I believed I had to separate from Cribrella prastans a Cribrella that I consider to be new and which I have described under the name of C. mutans (p. 112).

There are therefore forty-nine species in all, forty of which are new. Their names are printed in bold in the previous table. I shall return later to on the other nine.

For my part, I found in the collection that was given to me a total of thirty-nine species, thirty of which are new and nine of which were already known but had not been mentioned by Alcock. (In reality, the number of these known species is considerably more because, independently of some species already described by Alcock and that I have pointed out in this memoir, I have found others, also studied by this scholar and of which I have not spoken, having no special remarks to be made about them. ${ }^{5}$ I do not have to consider these species since they appear in the previous list and their mention would only complicate our counting.)

Here is the enumeration of these thirty-nine species, with the indication of their provenance and depths. As in the previous list, the new species are printed in bold type.

Johannaster superbus, Kœhler. Laccdives; 912-931 fathoms. Cheiraster Snyderi, Fisher. Andaman; 809-913 fathoms.

\footnotetext{
${ }^{5}$ These species, moreover, not very numerous and nearly all appear to belong to the genera Zoroaster and Brisinga.
} 
Cheiraster inops, Fisher. Coast of Malabar; 401 fathoms

Pararchaster indicus, Kœhler. Coast of Malabar Island; 457 fathoms.

Persephonaster Roulei, Kœhler.

Astropecten Griegi, Kœhler.Andaman and coast of Malabar; 130-164 fathoms.

Phidiaster Agassizi, Kœhler. Nicobar; 888-930 fathoms.

Porcellanaster caulifer, Siaden. Sea of Oman and Bay of Bengal; 1165-1644 fathoms.

Caulaster dubius, Kohler. Bay of Bengal; 1748 fathoms.

Sidonaster Vaneyi, Kœhler. Sea of Oman; 733-833 fathoms.

Sidonaster Batheri, Koiler. Sea of Oman, Laccadives and Andaman; 669-1475 fathoms.

Styracaster Caroli, Ludwig. Bay of Bengal; 1520-1803 fathoms.

Thoracaster Alberti, Kœhler. Sea of Oman; 1506 fathoms.

Astrogonium Jordani, Fisher. Coast of Malabar and Gulf of Mannar; 446-1085 fathoms.

Dorigona ternalis, Perrier. Laccadives, Andaman and Ceylan; 597-1370 fathoms.

Dorigona Belli, Kœhler. Andaman; 250 fathoms.

Dorigona Ludwigi, Kœhler. Laccadives; 1370 fathoms.

Pentagonaster Annandalei, Kœhler. Ceylon; 859-880 fathoms.

Pentagonaster Cuenoti. Kœhler. Laccadives (Minnikoy); 1006 fathoms.

Pentagonaster Doderleini, Kœhler. Laccadives; 1200 fathoms.

Pentagonaster Mortenseni, Kœhler. Andaman; 960 fathoms.

Mediaster ornatus, Fisher. Sea of Oman; 492 fathoms.

Astroceramus Fisheri, Kœhler. S.-W. from Cape Comorin; 1053 fathoms.

Circeaster Marcelli, Kœhler. S.-W. from Cape Comorin; 1053 fathoms.

Circeaster Magdalenæ, Kœhler. Sea of Oman; 912-931 fathoms.

Lydiaster Johannæ, Kœhler. W. from Pointe de Galle; 401 fathoms.

Evoplosoma Augusti, Kœhler. W. from Pointe de Galle; 401 fathoms.

Palmipes Ludovici, Kœhler. Coast of Malabar; 102 fathoms.

Fromia andamanensis, Kœhler. Andaman; 238-290 fathoms.

Zoroaster Adami, Kohler. Andaman; 569 fathoms.

Hymenaster Alcocki, Kœhler. Andaman; 643 fathoms.

Hymemster pentagonalis, Fisher. Ceylon; 605 fathoms.

Cribrella mutans, Kohler. Andaman; 480 fathoms.

Brisinga gracilis, Kœhler. Andaman; 960 fathoms.

Brisinga panopla, Fisher. Ceylon; 568 fathoms.

Brisinga parallela, Kœhler. Ceylon; 568 fathoms.

Odinia Clarki, Kohler. Maldives; 459 fathoms.

Odinia Austini, Kœhler. Ceylon; 403 fathoms.

Freyella indica, Kœhler. South of Andaman; 1595-1622 fathoms.

I have not mentioned in this list the five species that have been identified by Alcock and that, for various reasons, are mentioned in my memoir, because they already appear in the list of species indicated by this scholar. These are:

Pectinaster hispixus (p. 12).

Pontaster pilosus (p. 13).

Astrogonium rosium \{p. 19).

Astrogonium mozaicum (p. 50). 


\section{Iconaster pentaphyllus (p. 64).}

Thus is reached the total of thirty-nine species, thirty of which are new; that I indicated above. In addition, I had to establish five new genera. It seems interesting to investigate the affinities of these new forms, either from the purely morphological point of view or from the zoogeographical point of view.

As far as the genera are concerned, it is very difficult to indicate their affinities because they rather stand out by their particular characters that separate them from already known genera. Thus the genera Circeaster and Lydiaster in the family Antheneidæ, have very special forms. The genus Johannaster is separated from other Plutoasteridæ by characters important enough that we hesitate to put it in this family. The two other types are less specialized and are remarkable, on the contrary, for the curious association of characters. Thus the genus Phidiaster, that recalls Psilaster, has large proximal tooth spines as in Persephonaster. The genus Sidonaster belongs to the first group of porcellanasterids whose genus Porcellanaster is the type. But its cribriform organs have the structure found in the second group of this family.

Among the new species, I will first call attention to Astroceramus Fisheri and Evoplosoma Augusti. They belong to two kinds of very recent origin, each represented by a single species from the Hawaiian Islands. Two other asteroids, Persephonaster Roulei and Brisinga parallela are also very similar to the Hawaiian forms $P$. cingulatus and $B$. panopla. The two new species of Odinia that I have described provide evidence that this genus, already reported from the Hawaiian Islands by Fisher, penetrates into the Indian Ocean. We had long believed it to be located in the Atlantic. I will make a similar remark regarding Thoracaster Alberti that represents, in the Indian Ocean, Th. cylindratus in the Atlantic and Th. magnus in the Pacific. The Astropecten Griegi and Palmipes Ludovici constitutes, on the contrary, very peculiar forms without affinities with already known species of their respective genera. I do not see anything special to say about other species. I will only point out they belong in large part to the Phanerozonia of Sladen. A glance at the list of species indicated by Alcock and at mine shows elsewhere that the fauna of the abyssal asteroids of the Sea of Oman and the Bay of Bengal contains many more Phanerozonia than Cryptozonia.

If we consider the nine species already known, we will come to interesting results from the point of view of zoogeography. We will notice indeed that six species have been encountered at the Hawaiian Islands and have not yet have been reported in other localities. Those are:

Cheiraster Snyderi.

Cheiraster inops.

Astrogonium Jordani.

Mediaster ornatus.

Hymenaster pentagonalis.

Brisinga panopla.

Styracaster Caroli has been encountered in the Indian Ocean and Porcellanaster caulifer in the Pacific Ocean. Alone, Dorigona ternalis was known only in the Atlantic.

With this exception, the already known species that I found in the collection of the INVESTIGATOR therefore have an exclusively Indo-Pacific character. We also notice a certain 
affinity with the fauna of the Hawaiian Islands. Not only of the nine known species, six had been encountered in these islands, but even new species have a close relationship to the Hawaiian forms.

This peculiarity seems all the more curious to me that I do not see, in the fauna of the abyssal asteroids of the Indian seas, no other feature of resemblance to the associations that we know in other regions. In fact, it should be noted that none of the new species described by Alcock have been found in the campaigns of exploration there, i.e., either off the west coast of equatorial America, or in these Hawaiian Islands that I mentioned earlier. Currently, the abyssal fauna of asteroids of the Bay of Bengal and the Sea of Oman contains a total of eighty-eight species of which seventy have not yet been encountered outside of these waters since Mr. Alcock reported forty new species and I myself have described thirty.

As for the already known species that Alcock reported and whose number seems to me should be reduced to nine, they belong, with one exception, to the Indo-Pacific domain.

I recall the names of these species with the indication of the localities where they had been encountered previously:

Pararchaster semisquamatus, Sladen. Japan.

Pontaster mimicus, Sladen. Arafura Sea.

Dytaster exilis, Sladen. South Pacific.

Styracaster armatus, Sladen. Equatorial Pacific.

Pentagonaster arcuatis, Sladen. Japan.

Marsipaster hirsutus. Sladen. Southern Pacific.

Hymenaster nohilis, Sladen. South of Australia, at $50^{\circ}$ S. Lat.

Freyella benthophila, Sladen. South Pacific.

Freyella tuberculata. Sladen. Equatorial Atlantic.

The first eight of these species therefore belong to the Indo-Pacific domain. Nevertheless, some of them, notably Hymenaster nobilis, come from southern stations and we were amazed to find them in equatorial regions. As for Freyella tuberculata, it had been encountered in the vicinity of Cape Verde, thus between the coast of Africa and Ascension Island. I cite these species according to the determinations of Alcock. I did not have the opportunity to study them. In reality, one could note in the work of the latter a slightly higher number of known species, because he had reported, among the asteroids collected by the INVESTIGATOR, the following species found previously at the localities that I indicate:

Porcellanaster caruleus, Wyville Thomson. North Atlantic.

Styracasler horridus, Sladen. Equatorial Atlantic.

Nymphaster basilicus, Sladen. Equatorial Atlantic.

Nymphaster protentus, Sladen. Equatorial Atlantic.

Cribrella præstans, Sladen. Crozet Islands.

By adding the first four species to Freyella tuberculata, we would have found that five out of fourteen species, or more than a third, were found both in the Atlantic Ocean and the Indian seas. In reality, these four species should not be taken into consideration here since they are new. There is therefore only one remaining species common to the Indian Oceans and the Atlantic: it is Freyella tuberculata. I deeply regret not having been able to study this species, moreover very remarkable by the peculiarities of its structure. 
I also recall, for the record, that one of the new species of Alcock, Pontaster pilosus, has very close affinities with $P$. venustus from the Atlantic, as I explained on p. 14.

In summary, the forty-nine species indicated by Alcock are distributed as follows:

Forty new species;

Eight Indo-Pacific species (three coming from southern regions);

An Atlantic species.

The thirty-nine species that I mention on my side include:

Thirty new species;

Eight Indo-Pacific species, six of which still have been found only in the Hawaiian Islands;

An Atlantic species.

The presence in our asteroid fauna of two Atlantic species, Freyella tuberculata and Dorigona ternalis, does not remove the special character of this fauna. Its particular character and its IndoPacific affinities remain very clear. Regarding the only one of the two Atlantic forms that I studied, Dorigona ternalis, I would point out that it has some polymorphism because none of the specimens from the Indian Ocean matches exactly the type of the Atlantic. It is possible more complete studies may distinguish two distinct varieties in the forms that the insufficiency of materials forces me to unite today. 


\section{BIBLIOGRAPHIC INDEX}

89. SLAdEN (W. PERCY). Asteroidea, Reports of the CHALLENGER, Zoology, vol. XXX. London 1880.

91. Wood-MASOn (J.) and AlCOCK (A.). Natural History Notes from H. M. Indian marine Survey Steamer INVESTIGATOR, Echinoderma. Ann. Mag. Nat. Hist. [6], vol. VII. London 1891.

93a. AlcocK (A.). Natural History Notes from H. M. Indian marine Survey Steamer INVESTIGATOR Series II, $\mathrm{n}^{\circ}$ 7. An account of the Collection of Deep-Sea Asteroidea. Ann. Mag. Nat. Hist. [(3], vol. XL London 1893.

93b. Alcock (A.). Natural History Notes from H. M. Indian marine Survey Steamer INVESTIGATOR. Series II, $\mathrm{n}^{\circ}$ 9. An account of the Deep-Sea Collection made during the Season of 1892-93. Journal Asiatic Soc. of Bengal, vol. LXII, part 2, n 4. Calcutta 1893.

94. AlCOCK (A.). Echinoderma, part. I and II, in: Illustrations of the Zoology of the Royal Indian Marine Surveying Steamer INVESTIGATOR. Calcutta 1894-95.

94. PERRIER (E.). Stellérides. Résultats des campagnes sclentifiques du TRAVAILLEUR et du TALISMAN. Paris 1894.

97. Lufwig (H.). Seesterne. Fauna und Flora des Golfes von Neapel. Berlin 1897.

99. VERRILL (A.-E.). Revision of certain genera and species of Starfish. Trans. Connecticut Acad., vol. X. New-Haven 1899.

05. Ludwig (H.). Report on an Exploration by the ALBATROSS... Asteroidea. Mem. Mus. Comp. Zool., vol. XXXII. Cambridge 1905.

06. FiSher (WALTER K.). The Starfishes of the Hawaiian Islands. U. S. Commission of Fish and Fisheries for 1903, part. 3. Washington 1906.

07. Ludwig (H.). Diagnosen neuer Tiefsee-Seesferne aus der Famille Porcellanasteriden. Zool. Anz., Bd. XXXI. Leipzig 1907.

08. Koehler (R.). Astéries, Ophiures et Échinides de l'Exrpédltion Antarctique Nationale Écossaise. Trans. Roy. Soc. Edinburgh, vol. XLVI. part. 3, 1908.

09. KOEHLER (R.). Échinodcrmes provenant des campagnes du yacht PRINCESSE-ALICE (Astéries, Ophiures, Échinides et Crinoïdes). Résultats des campagnes scientifiques accomjilies sur son yacht par Albert I", Prince Souverain de Monaco. Fascicule XXXIV. Monaco 1909. 


\section{EXPLANATION OF THE PLATES}

(Figures that do not have an indication of magnification are represented in natural size.)

\section{PLATE I}

Fig. 1. Johannaster superbus Kœhler. Dorsal surface.

Fig. 2. Johannaser superbus Kœhler. Magnified portion of the dorsal surface. Magnification: 6 .

Fig. 3. Astrogonium mozaicum Alcock. Dorsal surface.

Fig. 4. Sidonaster Batheri Kœhler. Ventral surface. Magnification: 4.

Fig. 5. Caulaster dubius Kœhler. Ventral surface. Magnification: 3.

Fig. 6. Palmipes Ludovici Kœhler. Magnified portion of a dorsal surface. Magnification: 7.

Fig. 7. Hymenaster Alcocki Kœhler. Dorsal surface. Magnification: 1.4.

Fig. 8. Hymenaster Alcocki Kœhler. Teeth. Magnification: 5.

\section{PLATE II}

Fig. 1. Johannaster superbus Kœhler. Ventral surface.

Fig. 2. Asteroceramus Fisheri Kœhler. Dorsal surface. Magnification: 1.5.

Fig. 3. Asteroceramus Fisheri Kœhler. Ventral surface. Magnification: 1.5.

Fig. 4. Asteroceramus Fisheri Kœhler. Plates of the dorsal surface. Magnification: 5.

Fig. 5. Sidonaster Batheri Kœhler. Dorsal surface. Magnification: 1.5.

\section{PLATE III}

Fig. 1. Thoracaster Alberti Kœhler. Dorsal surface.

Fig. 2. Thoracaster Allberti Kœhler. Ventral surface.

Fig. 3. Thoracaster Alberti Kœhler. Lateral view of the disk and of the beginning of an arm. Magnification: 2.5.

Fig. 4. Thoracaster Alberti Kœhler. Enlarged portion of the dorsal surface. Magnification: 10.

Fig. 5. Styracaster Caroli Ludwig. Enlarged portion of the dorsal surface. Magnification: 10.

Fig. 6. Sidonaster Vaneyi Kœhler. Dorsal surface. Magnification: 2.5.

Fig. 7. Pentagonaster Cuenoti Kœhler. Dorsal surface, very slightly enlarged.

Fig. 8. Hymenaster Alcocki Kœhler. Ventral surface. Magnification: 1.4.

Fig. 9. Lydiaster Johanna Kœhler. Portion of ventral surface. Magnification: 2.

Fig. 10. Palmipes Ludovici Kœhler. Portion of ventral surface. Magnification: 1.3 


\section{PLATE IV}

Fig. 1. Circeaster Marcelli Kœhler. Dorsal surface.

Fig. 2. CirceasterMarcelli Kœhler. Enlarged portion of the dorsal surface. Magnification: 4.

Fig. 3. Pararchaster indicus Kœhler. Very slightly enlarged portion of the dorsal surface.

Fig. 4. Pararchaster indicus Kœhler. Ventral surface. Magnification: 1.8.

Fig. 5. Pentagonaster Mortenseni Kœhler. Dorsal surface.

Fig. 6. Pentagonaster Mortenseni Kœhler. Ventral surface.

Fig. 7. Odinia Clarki Kœhler. Ventral surface of the disk. Magnification: 2.

Fig. 8. Sidonaster Batheri Kœhler. Spines of the cribriform organs. Magnification: 40.

\section{PLATE V}

Fig. 1. Circeaster Magdalence Kœhler. Dorsal surface.

Fig. 2. Circeaster Magdalence Kœhler. Plates of the dorsal surface. Magnification: 4.

Fig. 3. Circeaster Magdalena Kœhler. Portion of the ventral surface. Magnification: 2.

Fig. 4. Styracaster Caroli Ludwig. Ventral surface. Magnification: 1.6.

Fig. 5. Zoroaster Adami Kœhler. Dorsal surface. Magnification: 1.6.

Fig. 6. Zoroaster Adami Kœhler. Ventral surface. Magnification: 1.6.

Fig. 7. Thoracaster Alberti Kœhler. Teeth. Magnification: 2.5.

Fig. 8. Caulaster dubius Kœhler. Pedicellariae. Magnification: 85.

\section{PLATE VI}

Fig. 1. Circeaster Marcelli Kœhler. Ventral surface.

Fig. 2. Circeaster Magdalena Kœhler. Ventral surface.

Fig. 3. Pentgonaser Cuenot Kœhler. Ventral surface. Magnification: 1.7.

Fig. 4. Cribrella mutans Kœhler. Dorsal surface. Magnification: 1.3.

Fig. 5. Sidonaster Vaneyi Kœhler. Ventral surface. Magnification: 2.

\section{PLATE VII}

Fig. 1. Lydiaster Johannæe Kœhler.Dorsal surface.

Fig. 2. Lydiaster Johanna Kœhler. Portion of dorsal surface. Magnification: 5.

Fig. 3. Persephonaster Roulei Kohler. Dorsal surface.

Fig. 4. Astropecten Greigi Kohler. Dorsal surface. Magnification: 1.8.

Fig. 5. Fromia adamanensis Kœhler. Dorsal surface. Magnification: 2.

Fig. 5. Fromia adamanensis Kœhler. Ventral surface. Magnification: 2.

\section{PLATE VIII}

Fig. 1. Lydiaster Johanna Kœhler. Ventral surface.

Fig. 2. Dorigona Belli Kœhler. Dorsal surface. 
Fig. 3. Dorigona Belli Kœhler. Ventral surface. Magnification: 1.3.

Fig. 4. Dorigona Belli Kœhler. Plates of the dorsal surface of the disk. Magnification: 5.

Fig. 5. Dorigona ternalis Perrier. Dorsal surface.

Fig. 6. Dorigona ternalis Perier. Ventral surface. Magnification: 1.4.

Fig. 7. Pentagonaster Döderleini Kœhler. Dorsal surface. Magnification: 1.5.

Fig. 8. Pentagonaster Döderleini Kohler. Ventral surface. Magnification: 1.5.

Fig. 9. Pentagonaster Döderleini Kohler. Plates of the dorsal surface of the disk. Magnification: 8.

\section{PLATE IX}

Fig. 1. Phidiaster Agassizi Kohler. Dorsal surface.

Fig. 2. Phidiaster Agassizi Kœhler. Ventral surface. Magnification: 1.4

Fig. 3. Phidiaster Agassizi Kœhler. Lateral view of a portion of the disk. Magnification: 2.2.

Fig. 4. Persephonaster Roulei Kohler. Ventral surface.

Fig. 5. Dorigona Ludwigi Kohler. Dorsal surface.

Fig. 6. Dorigona Ludwigi Kohler. Ventral surface. Magnification: 1.4.

Fig. 7. Pentagonaster Mortenseni Køhler. Portion of the dorsal surface. Magnification: 3.

Fig. 8. Cribrella mutans Kœhler. Portion of the ventral surface of an arm. Magnification: 2.5.

\section{PLATE X}

Fig. 1. Palmipes Ludovici Kœhler. Dorsal surface.

Fig. 2. Palmipes Ludivoci Kohler. Bundle of spines in the form of a paxilla on the dorsal surface. Magnification: 12.

Fig. 3. Sidonaster Vaneyi Kœhler. Lateral view of an interradial area to show the cribriform organ. Magnification: 6.

Fig. 4. Mediaster ornatus Kœhler. Ventral surface.

Fig. 5. Brisinga parallela Kœhler. Dorsal surface. Magnification: 1.7.

Fig. 6. Astropecten Griegi Koehler. Slightly enlarged dorsal surface.

Fig. 7. Freyella indica Kœhler. Ventral surface of an arm. Magnification: 2.2.

\section{PLATE XI}

Fig. 1. Evoplosoma Augusti Kohler. Dorsal surface.

Fig. 2. Evoplosoma Augusti Kohler. Ventral surface.

Fig. 3. Evoplosoma Augusti Kœhler. Portion of the dorsal surface. Magnification: 3.

Fig. 4. Caulaster dubius Kœhler. Dorsal surface. Magnification: 3.

Fig. 5. Porcellanaster caulifer Sladen. Dorsal surface of a very young specimen. Magnification: 2.7.

\section{PLATE XII}

Fig. 1. Pentagonaster Annandalei Kohler. Dorsal surface. 
Fig. 2. Pentagonaster Annandalei Kohler. Ventral surface.

Fig. 3. Pentagonaster Annandalei Kohler. Portion of the dorsal surface. Magnification: 7.

Fig. 4. Odinia Clarki Kœhler. Lateral surface of an arm.

Fig. 5. Odinia Clarki Kœhler. Dorsal surface of an arm.

Fig. 6. Odinia Clarki Kœhler. Lateral surface of an arm. Magnification: 1.8.

Fig. 7. Brisinga panopla Fisher. Portion of the dorsal surface of an arm. Magnification: 7.

Fig. 8. Brisinga parallela Kohler. Portion of the dorsal surface of an arm. Magnification: 7.

Fig. 9. Freyella indica Kohler Dorsal surface of the disk. Magnification: 2.2.

Fig. 10. Freyella indica. Kohler. Dorsal surface of an arm. Magnification: 2.2.

\section{PLATE XIII}

Fig. 1. Porcellanaster caulifer Sladen. Ventral surface. Magnification: 1.6.

Fig. 2. Brisinga gracilis Kœhler. Dorsal surface. Magnification: 2.

Fig. 3. Brisinga gracilis Kohler. Ventral surface. Magnification: 2.5.

Fig. 4. Brisinga parallela Kœhler. Lateral surface of the arm Magnification: 1.7.

Fig. 5. Odinia Austini Kœhler. Dorsal surface.

Fig. 6. Odinia Austini Kœhler. Ventral surface. Magnification: 2.5. 


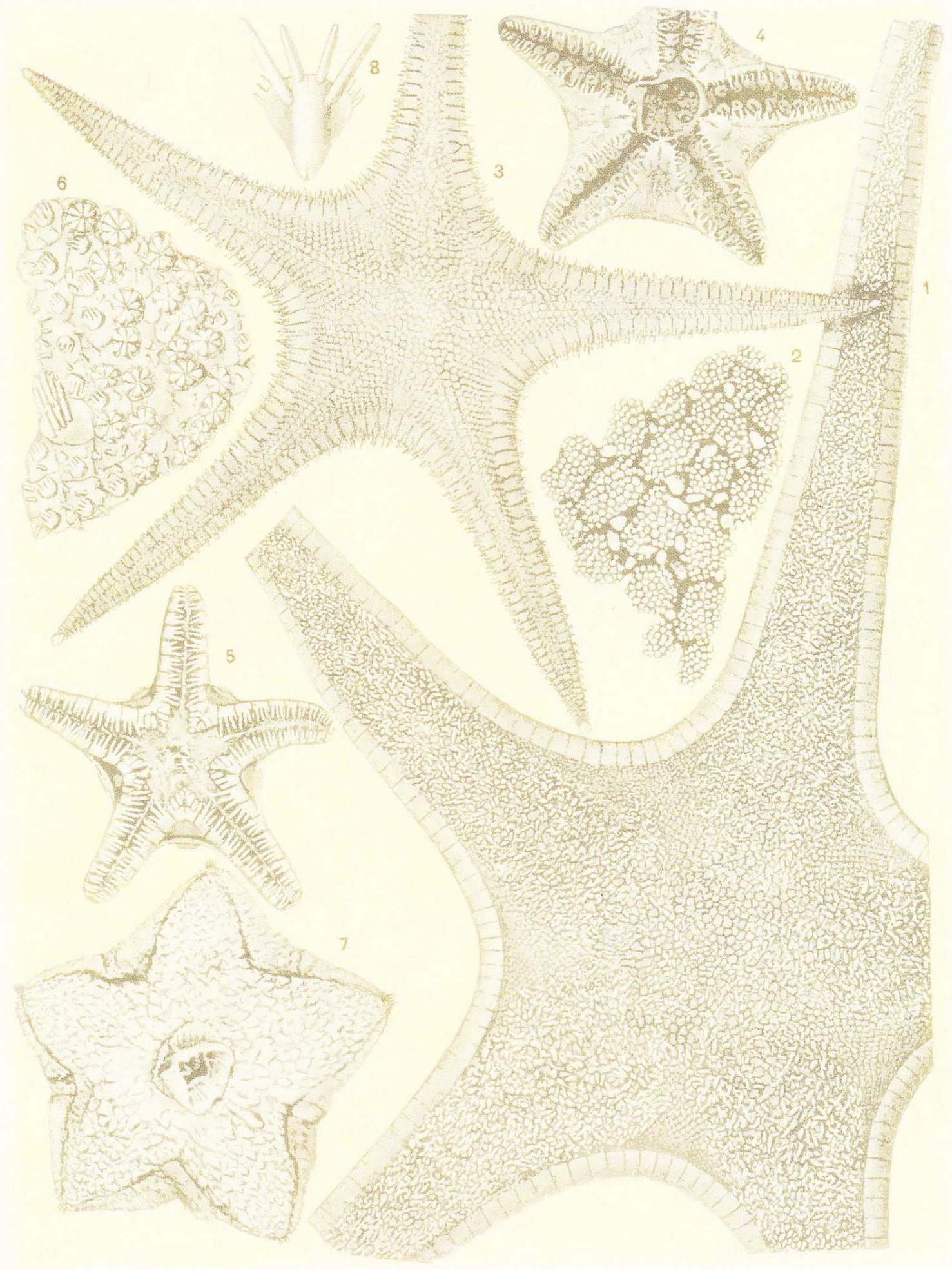




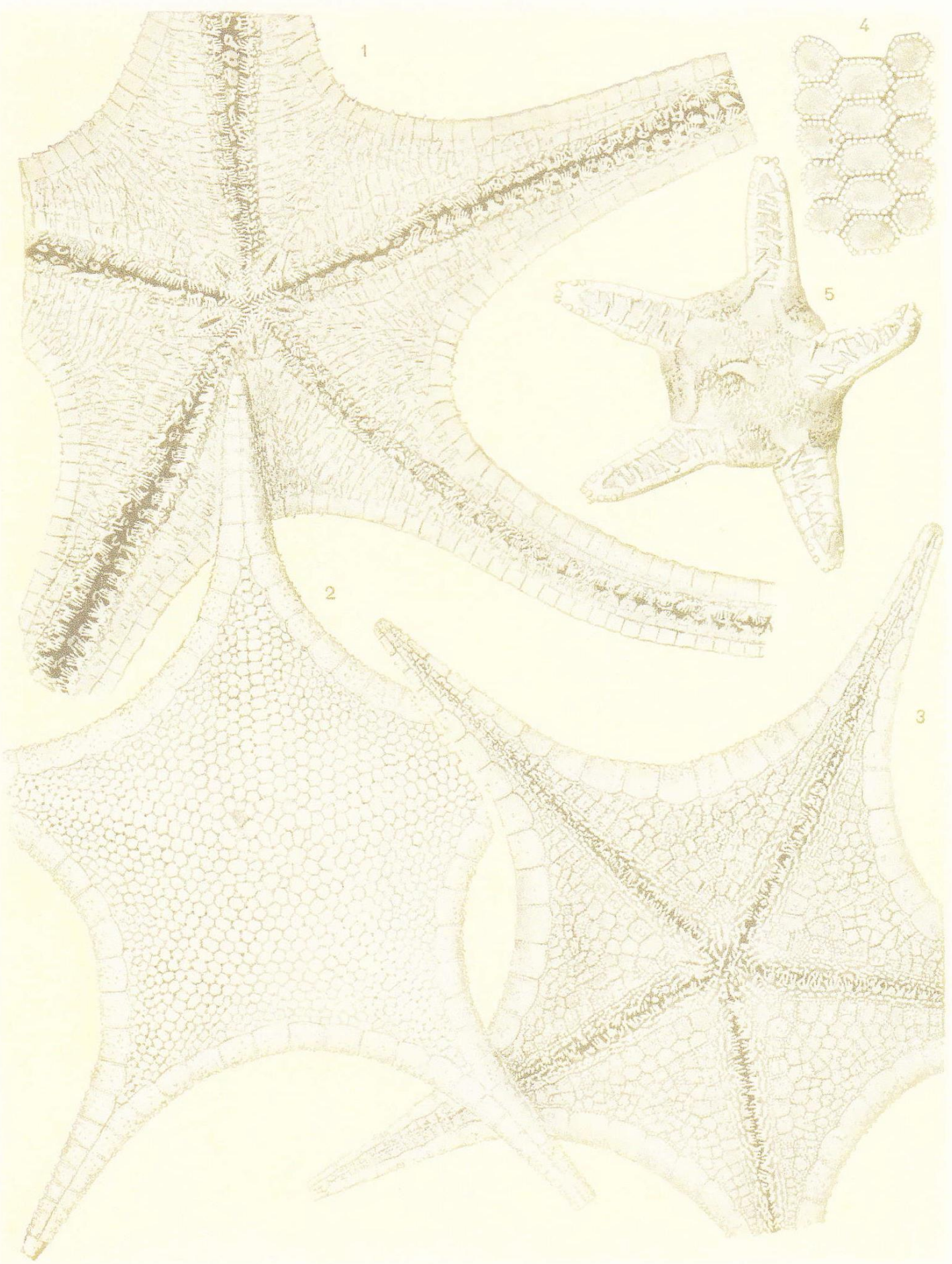




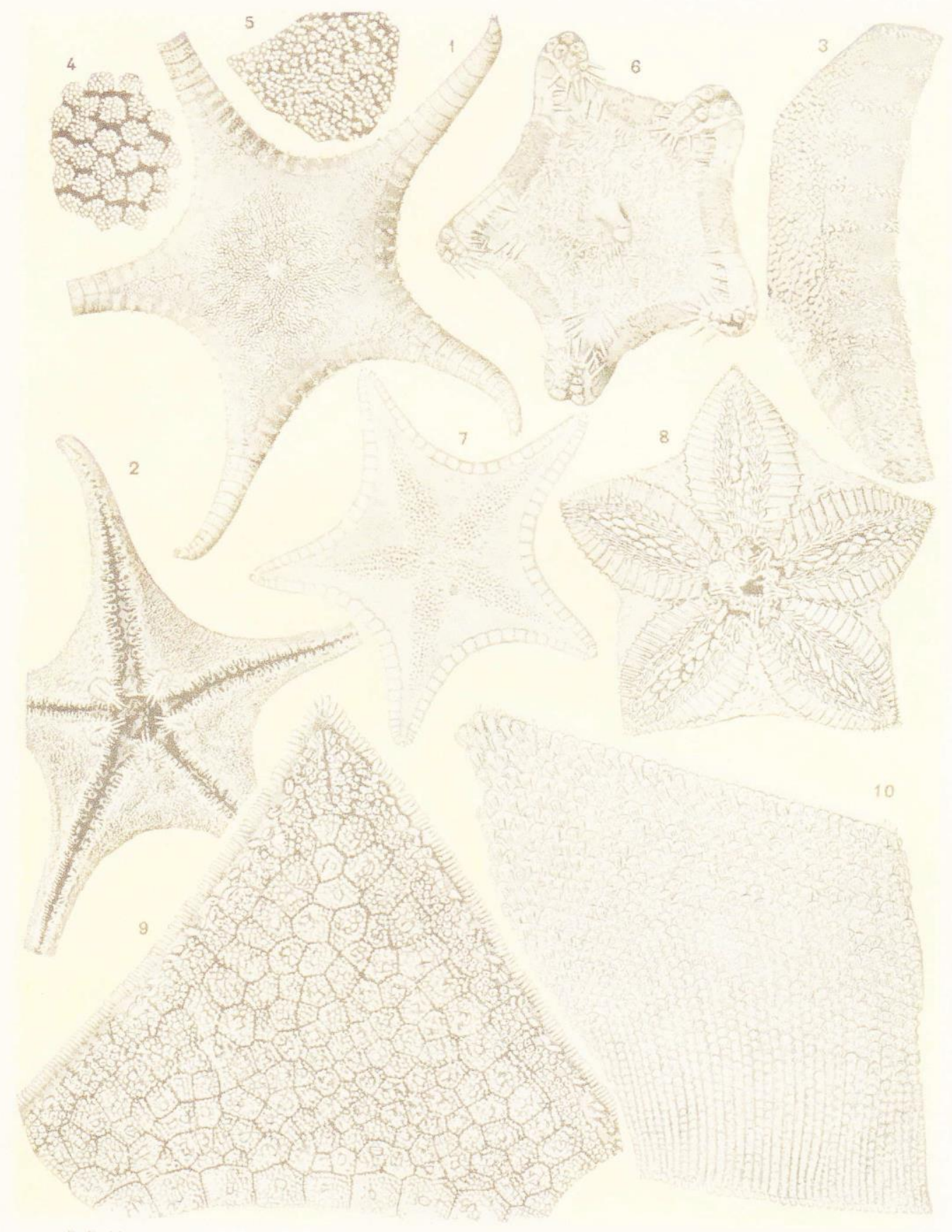

I THORAISTHR ALBHKI

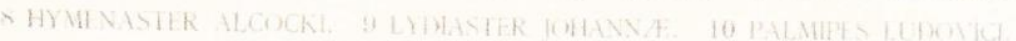




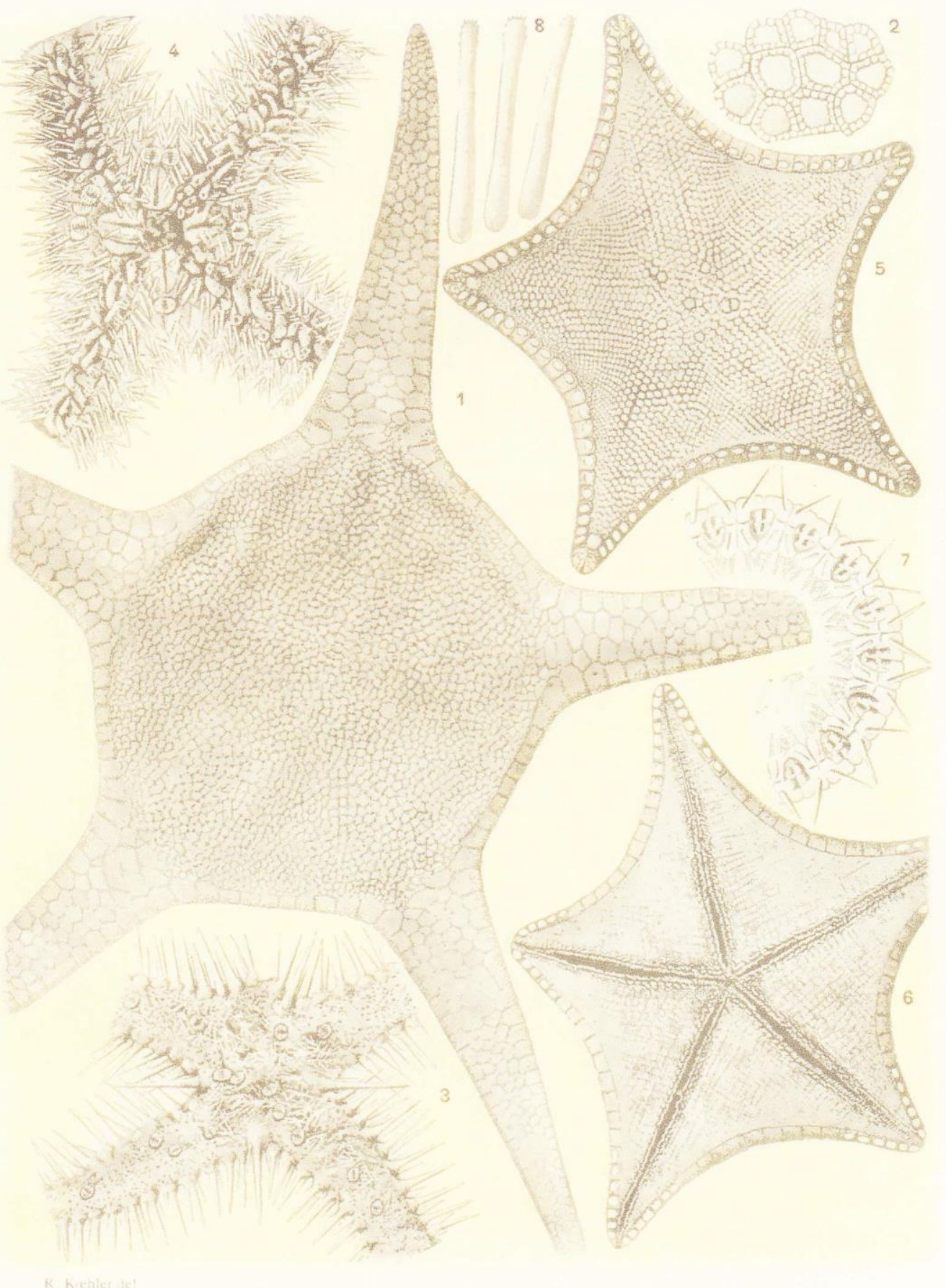




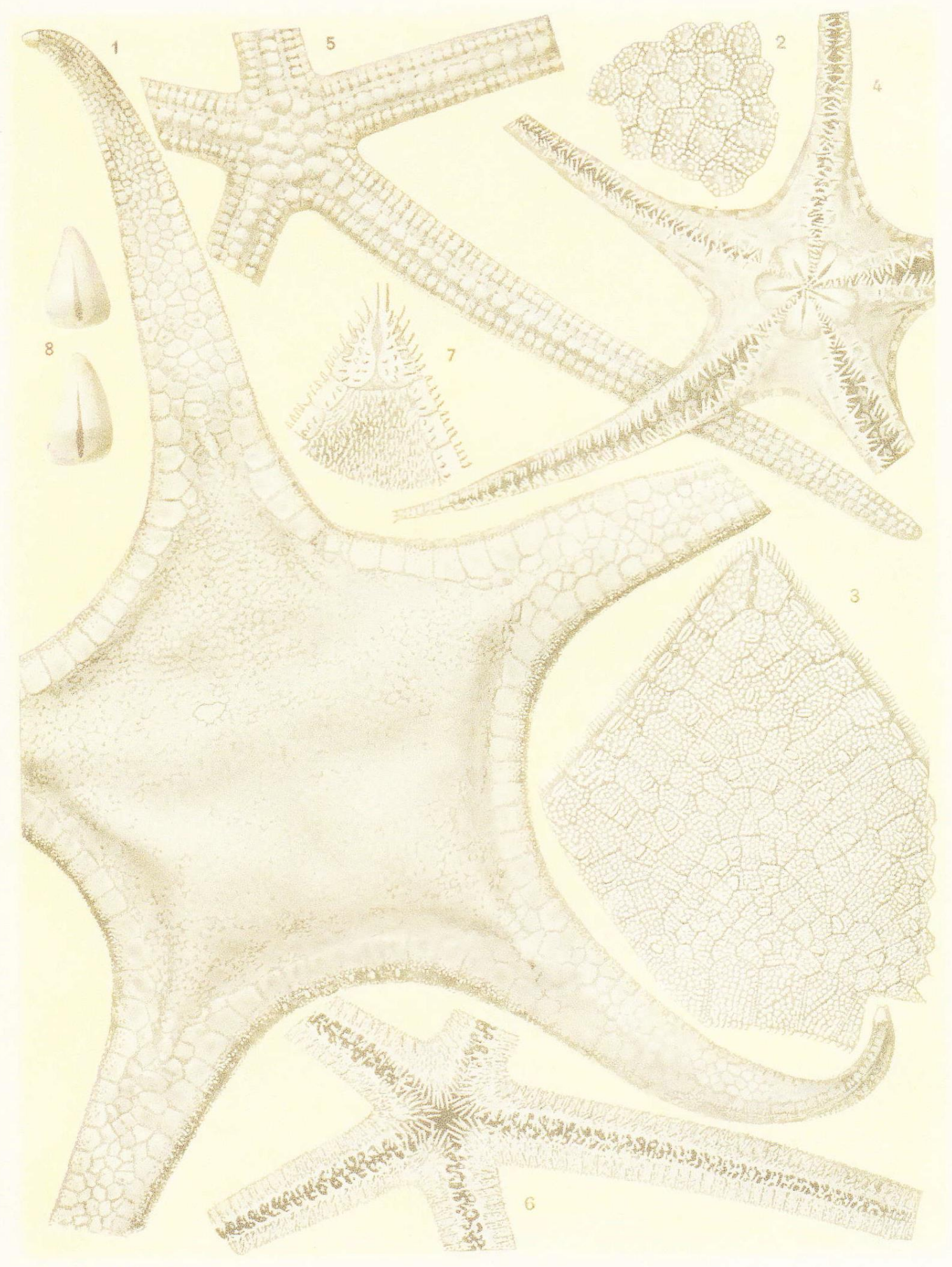




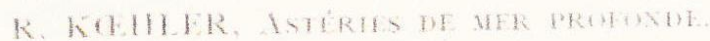

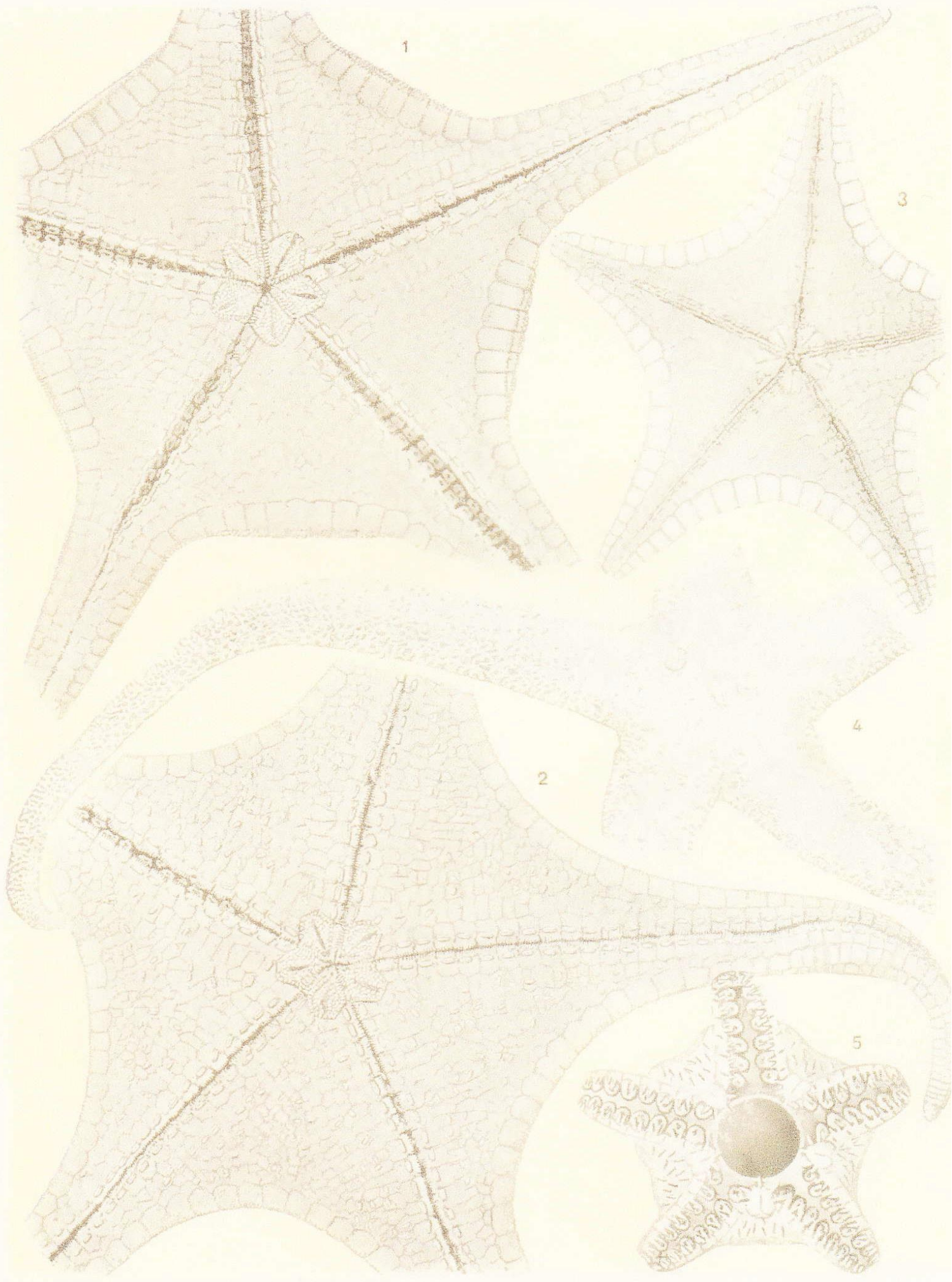




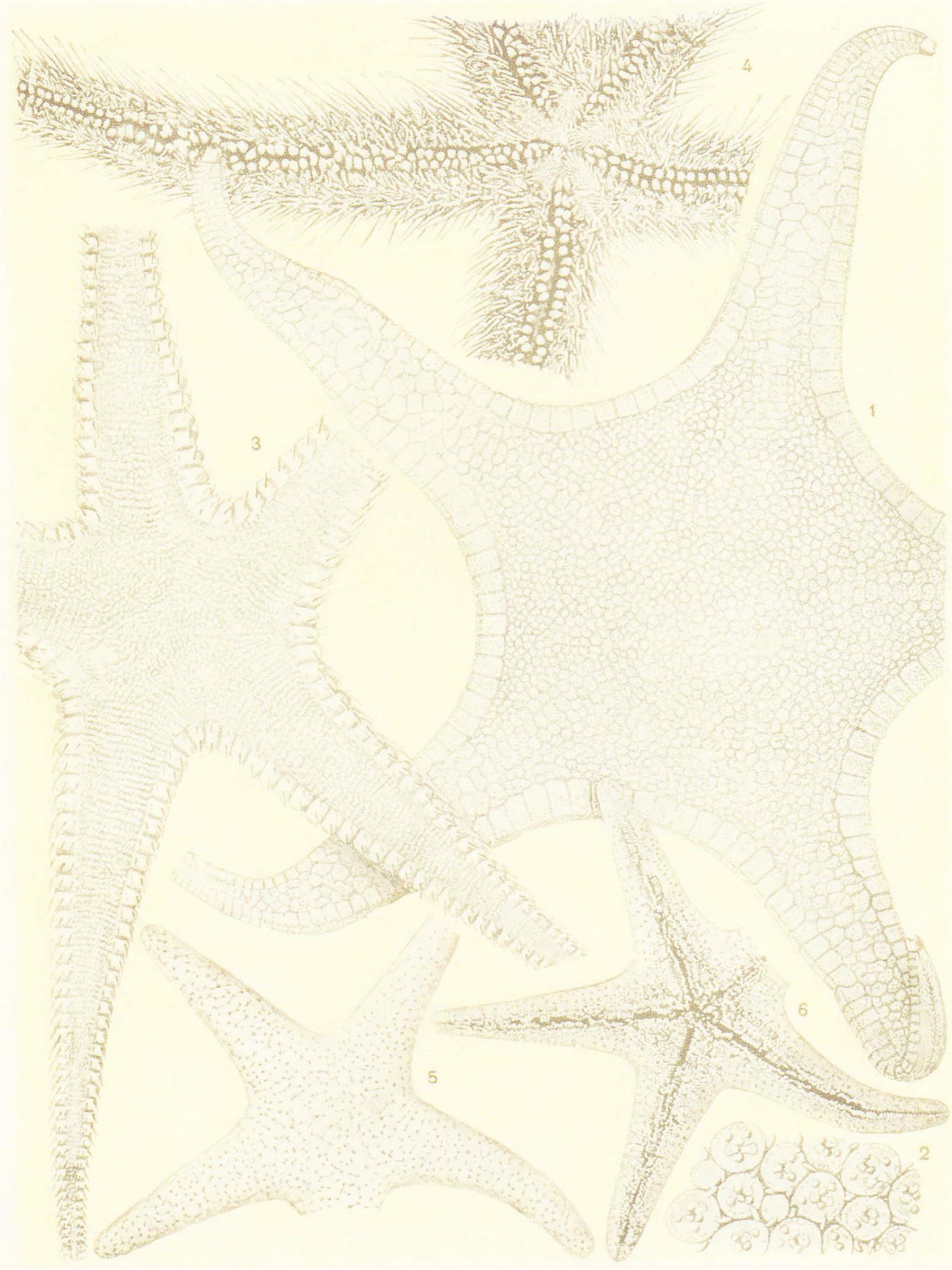

R. Koelaler del 


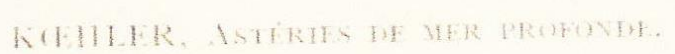

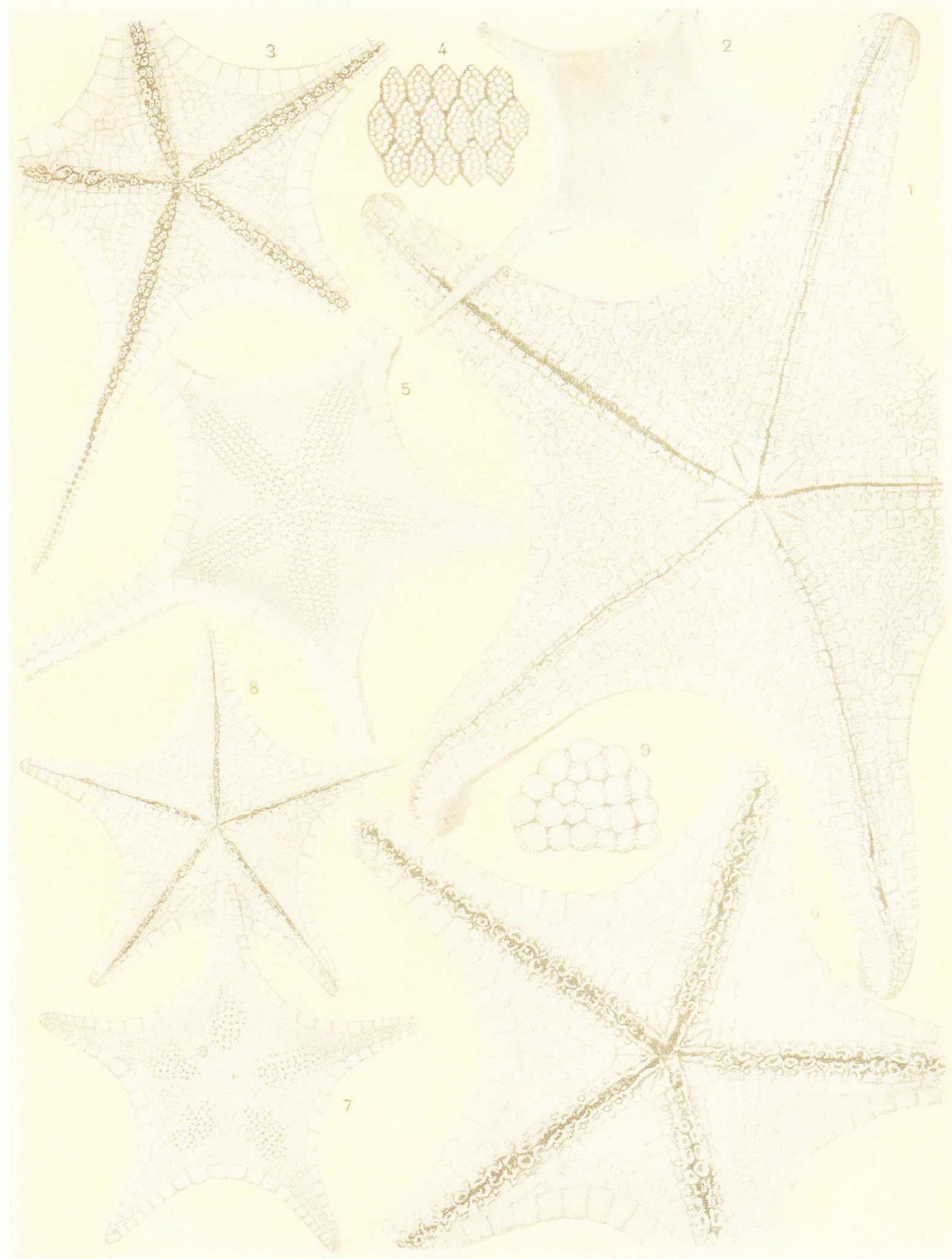




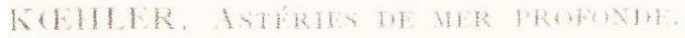

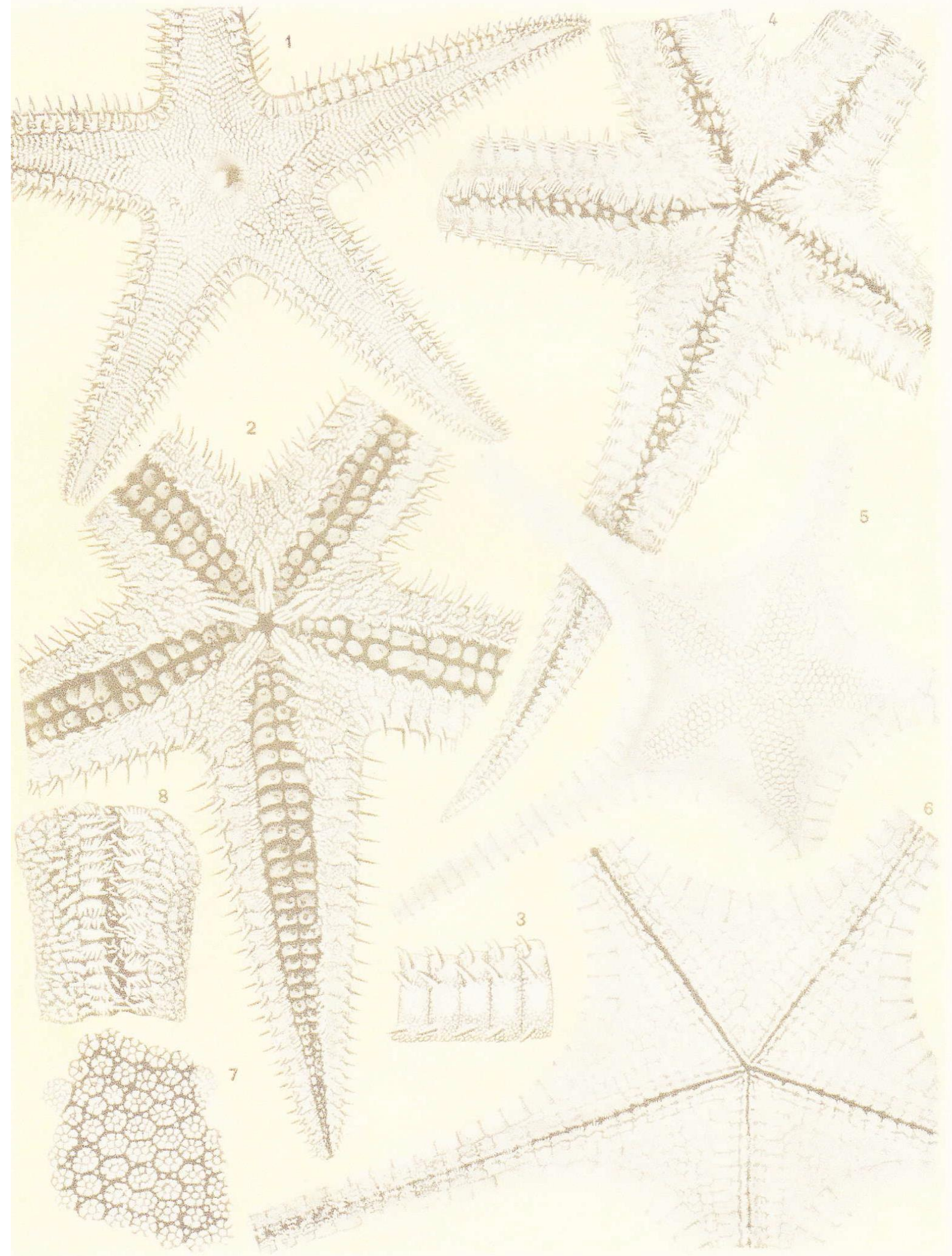




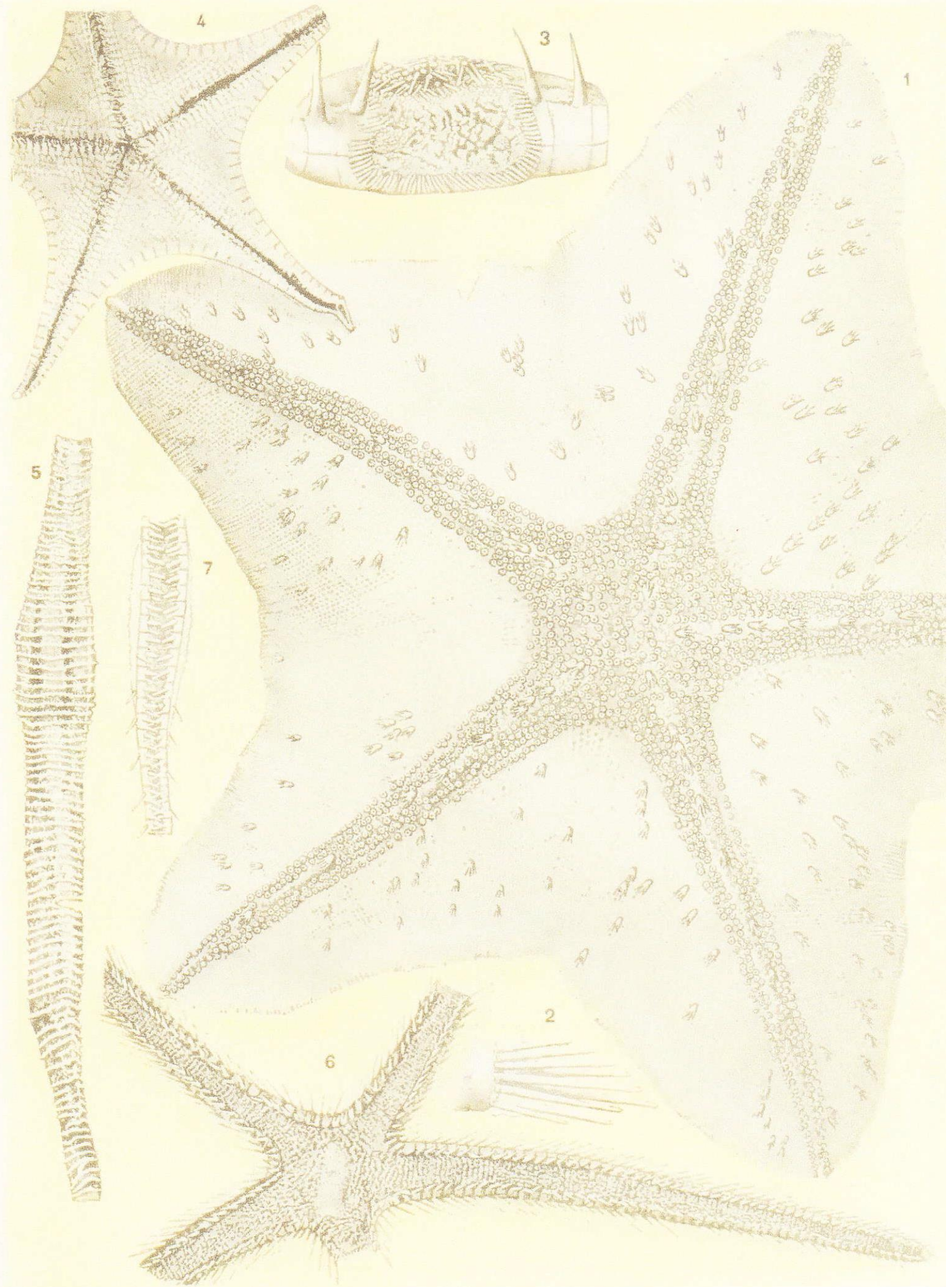




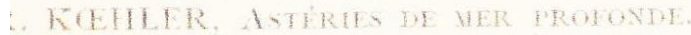

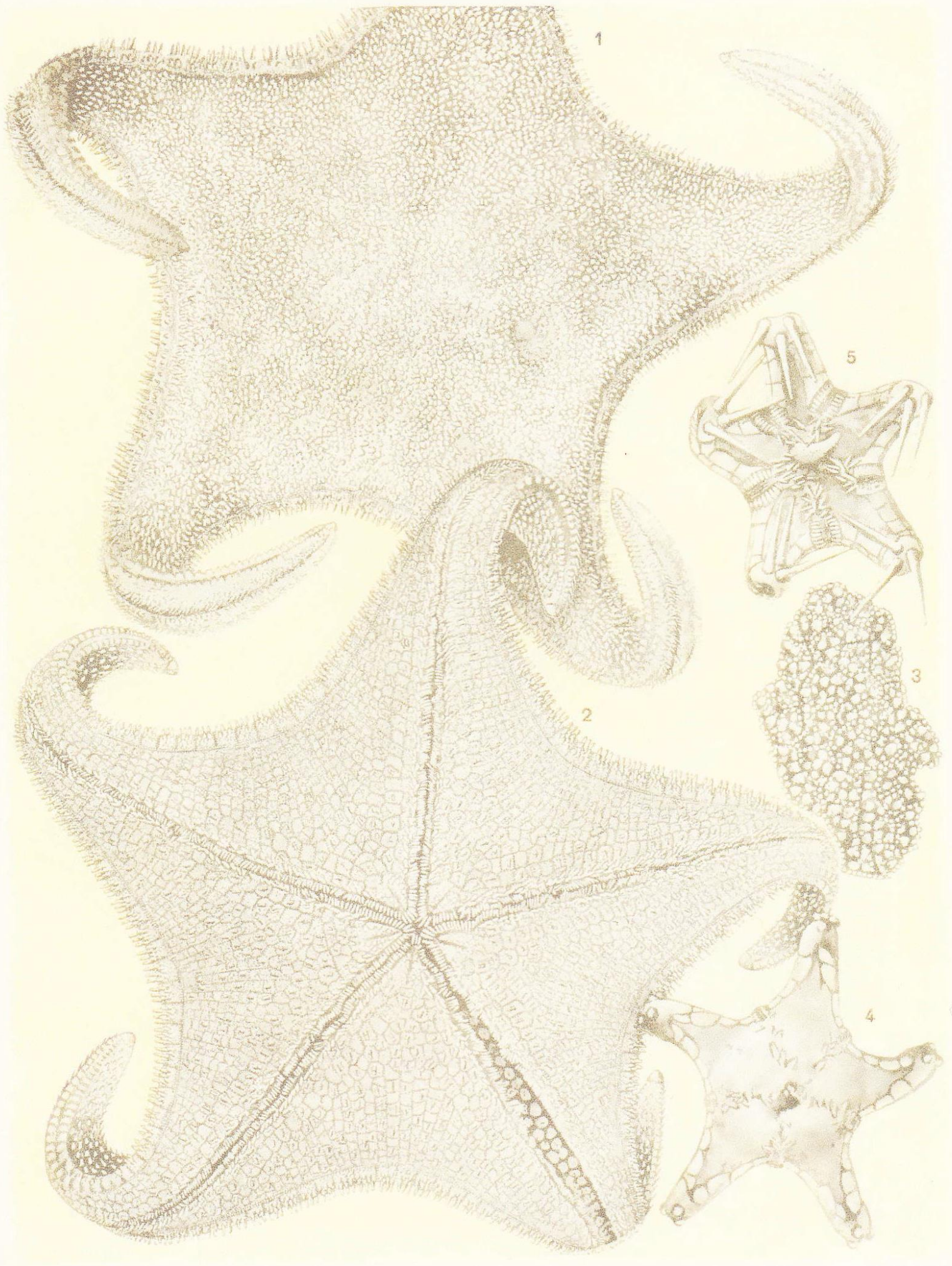

R. Kahler de? 


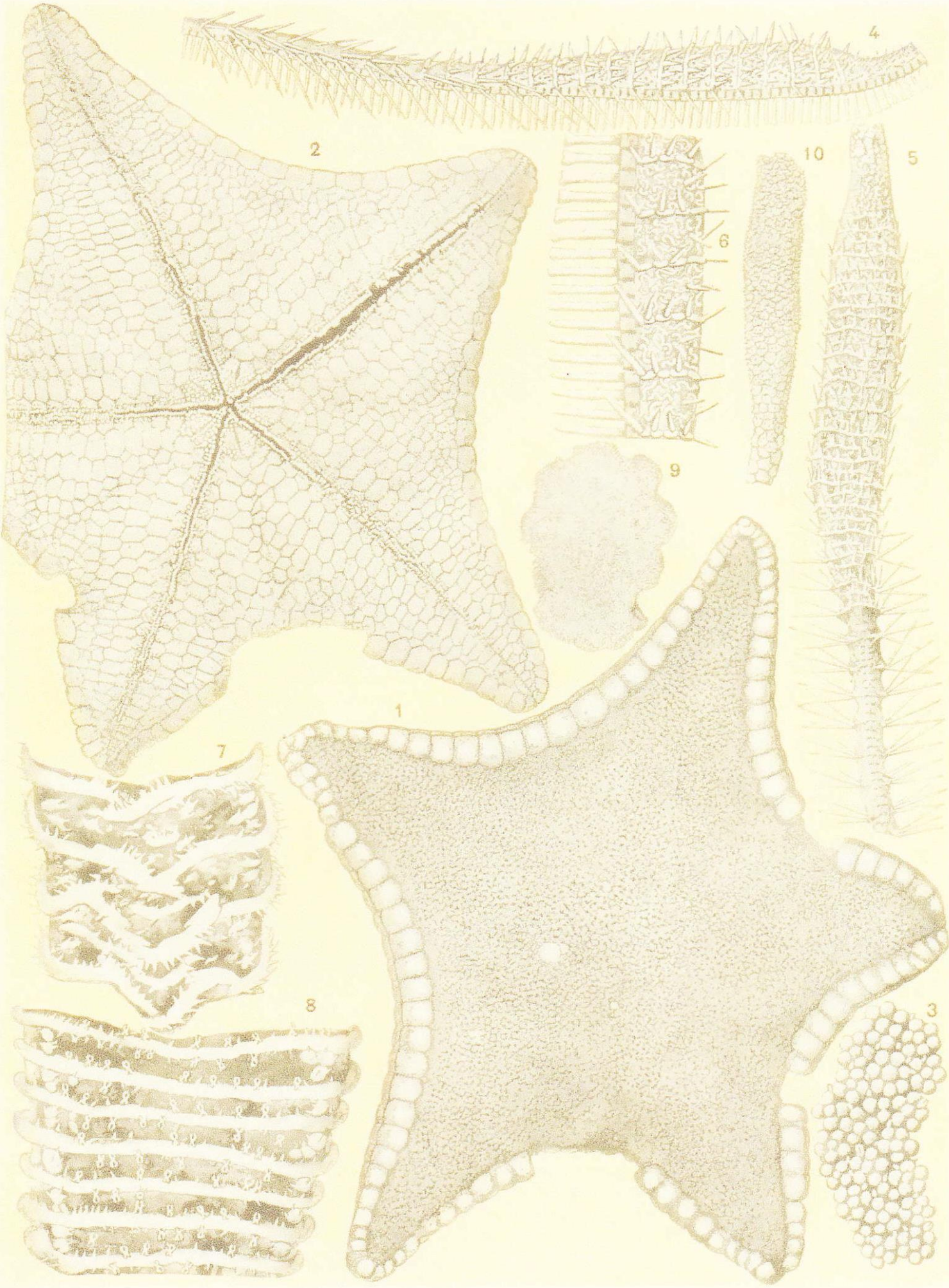

R. Kohler del. 


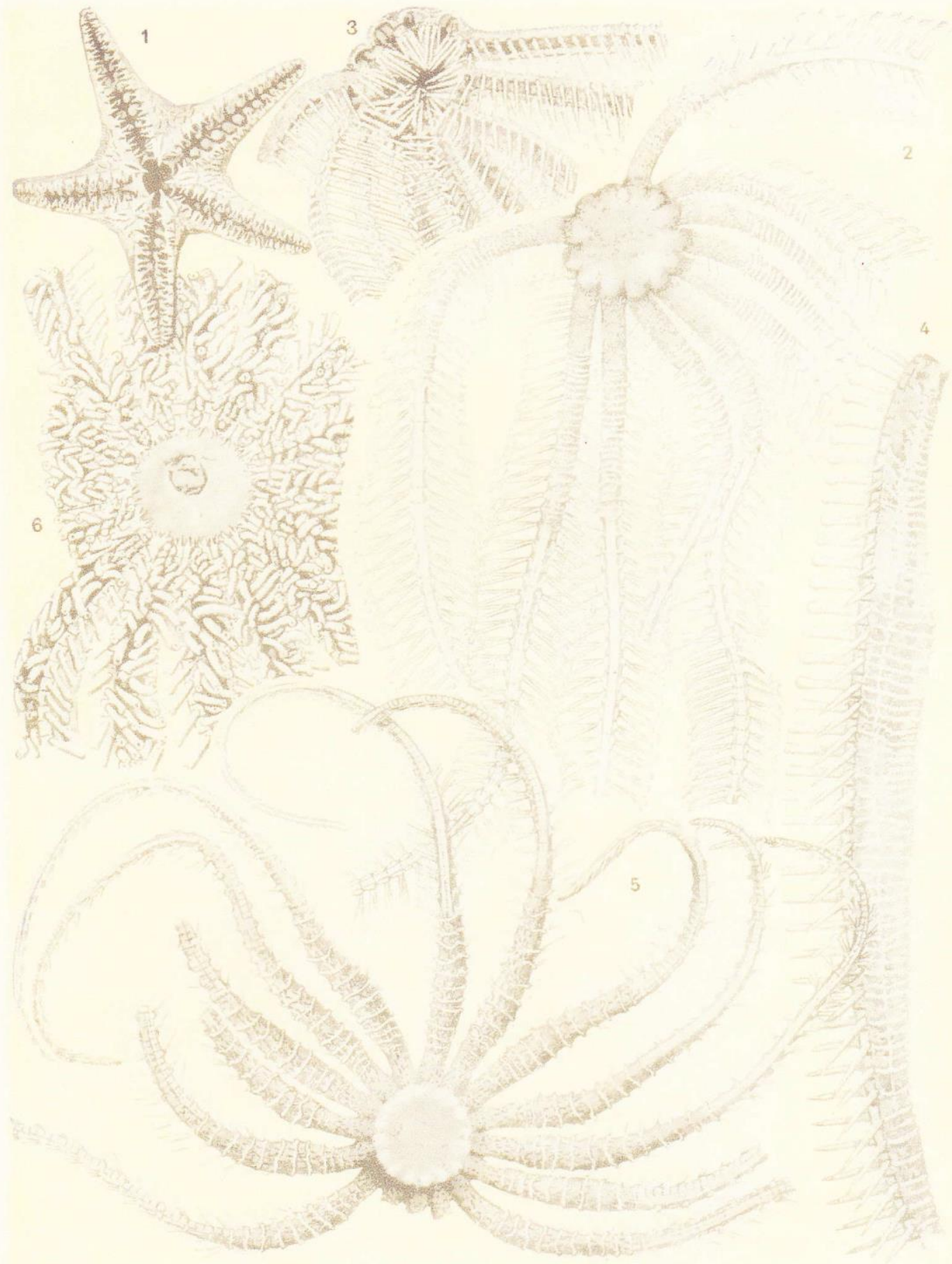

